Ambiente para desenvolvimento de métodos aplicados a problemas de otimização

Márcio da Silva Arantes 
SERVIÇO DE PÓS-GRADUAÇÃO DO ICMC-USP

Data de Depósito: 12/05/2014

Assinatura:

\title{
Ambiente para desenvolvimento de métodos aplicados a problemas de otimização ${ }^{1}$
}

\author{
Márcio da Silva Arantes
}

Orientador: Prof. Dr. Claudio Fabiano Motta Toledo

Dissertação apresentada ao Instituto de Ciências Matemáticas e de Computação - ICMC-USP, como parte dos requisitos para obtenção do título de Mestre em Ciências - Ciências de Computação e Matemática Computacional. VERSÃO REVISADA

USP - São Carlos

Maio de 2014

\footnotetext{
${ }^{1}$ Trabalho Realizado com Auxílio da FAPESP
} 
Ficha catalográfica elaborada pela Biblioteca Prof. Achille Bassi e Seção Técnica de Informática, ICMC/USP, com os dados fornecidos pelo(a) autor(a)

A319a

Arantes, Márcio da Silva

Ambiente para desenvolvimento de métodos

aplicados a problemas de otimização / Márcio da

Silva Arantes; orientador Claudio Fabiano Motta

Toledo. -- São Carlos, 2014.

$118 \mathrm{p}$.

Dissertação (Mestrado - Programa de Pós-Graduação em Ciências de Computação e Matemática

Computacional) -- Instituto de Ciências Matemáticas e de Computação, Universidade de São Paulo, 2014.

1. Framework. 2. Metaheurísticas. 3. Arquitetura Orientada a objetos. 4. Padrões de Projeto. I. Toledo, Claudio Fabiano Motta, orient. II. Título. 
Dedicatória

Dedico este trabalho aos meus pais e a meus avós, pois com muita luta e sacrifícios batalharam e assim conseguiram dar-me melhores oportunidades, as quais não tiveram, sempre amarei vocês! 


\section{Agradecimentos}

Ao meu orientador, prof. Claudio Fabiano Motta Toledo, meus sinceros agradecimentos pelo empenho e dedicação demonstrados, com sua orientação descobri minha vocação para a pesquisa científica.

A todos os professores pelo entusiasmo no qual ministraram as disciplinas cursadas, pois contribuíram diretamente para minha formação.

Ao meu amigo e colega de república, Maurício Acconcia Dias, por sua amizade presente, pelo interesse que teve em meu trabalho e sugestões dadas, onde muitas ideias surgiram de nossas conversas.

Agradeço ao meu irmão e melhor amigo Jesimar da Silva Arantes por estar sempre por perto e compartilhar tudo que aprende comigo.

Aos colegas do Laboratório de Computação Reconfigurável, onde passei a maior parte do tempo durante o desenvolvimento deste trabalho.

Agradeço a FAPESP pelo apoio financeiro concedido, sem o qual não seria possível a realização deste trabalho. 


\section{Resumo}

O presente documento tem por objetivo apresentar o desenvolvimento de uma ferramenta computacional para auxiliar profissionais da área de otimização na implementação de métodos e resolução de problemas. O projeto foi desenvolvido como tema de dissertação no Programa de Mestrado em Ciência da Computação e Matemática Computacional do ICMC/USP. A ferramenta pode ser enquadrada como um ambiente de desenvolvimento

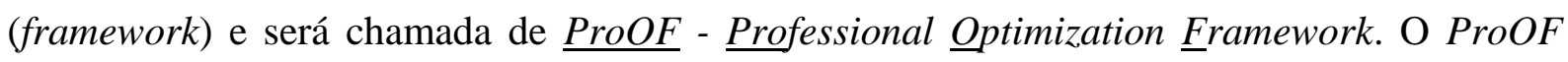
tem como foco principal nortear a implementação computacional de métodos variados para problemas de otimização, utilizando como paradigma a programação orientada a objetos. Esse framework incorpora as principais características encontradas por outras ferramentas propostas na literatura. Além disso, procura facilitar a implementação de métodos e resolução de problemas ao permitir alto reuso de códigos, dar suporte a geração de códigos em diferentes linguagens de programação e gerar uma Graphical User Interface (GUI) automática para parametrização dos métodos inseridos pelo usuário. Alguns trabalhos publicados recentemente utilizaram versões em desenvolvimento do ProOF e serão citados como estudo de caso para atestar a robustez do framework proposto. Por fim, uma comparação será realizada entre o ProOF e outros frameworks existentes na literatura.

Palavras-chave: framework, metaheurísticas, arquitetura orientada a objetos, padrões de projeto. 


\section{Abstract}

This paper aims to present the development of a computational tool to assist professionals in the optimization field in implementation of methods and problem solving. The project was developed as dissertation topic in the Master's Program in Computer Science and Computational Mathematics at ICMC/USP. The tool can be considered as a development environment (framework) and will be called $\underline{\operatorname{ProOF}}$ - Professional Optimization Framework. The ProOF is mainly focused on guiding the implementation of various computational methods for optimization problems using as a paradigm the object-oriented programming. This framework incorporating the principal features found in other tools proposed in the literature. Moreover, seeks to facilitate the implementation of methods and problem resolution by allowing high code reuse, give support to code generation in different programming languages and generate a Graphical User Interface (GUI) automatic for parameter setting of methods implemented by the user. Some recently published studies have used previous versions of the ProOF and they will be cited as a case study to attest the robustness of the proposed framework. Finally, a comparison will be made between the ProOF and other existing frameworks in the literature.

Keywords: framework, metaheuristics, object-oriented architecture, design patterns. 


\section{Sumário}

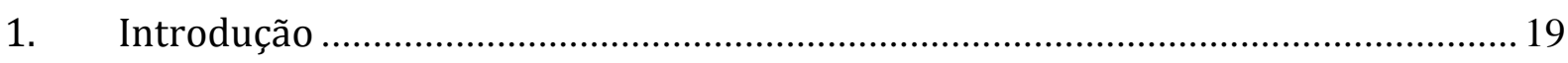

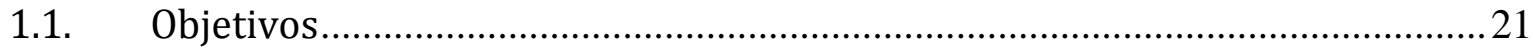

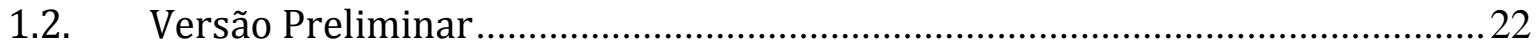

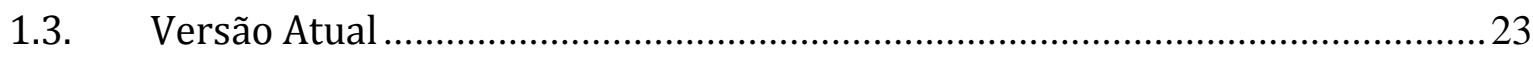

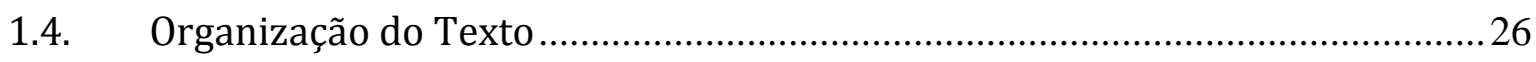

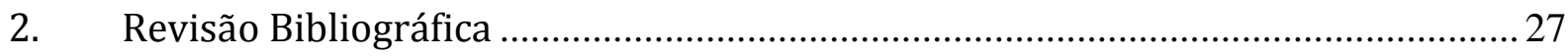

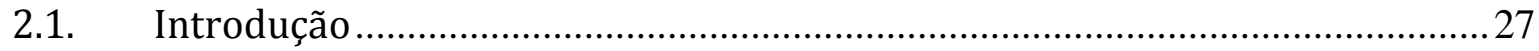

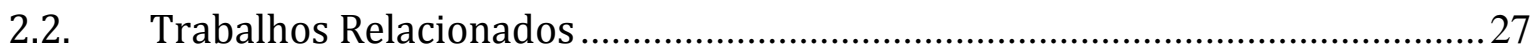

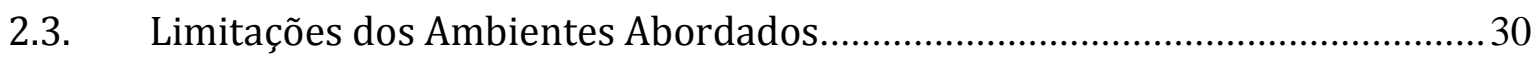

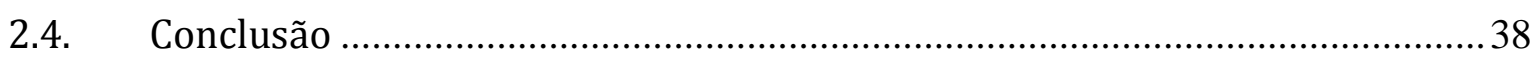

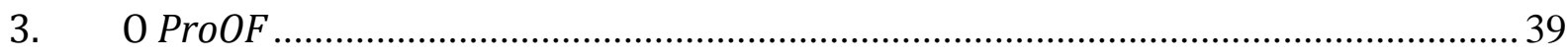

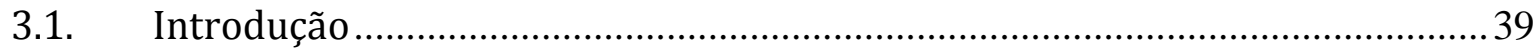

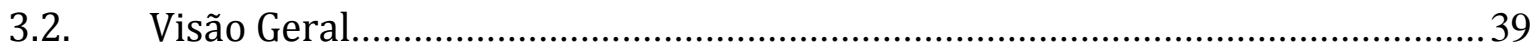

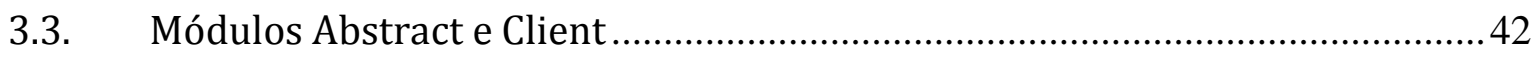

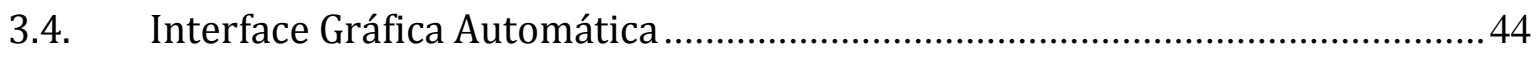

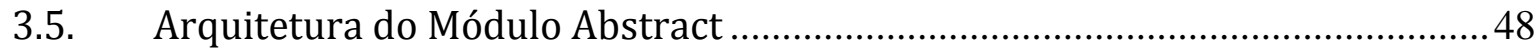

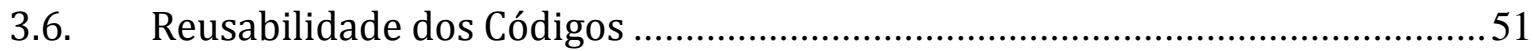

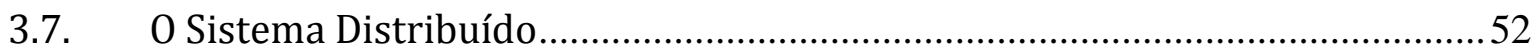

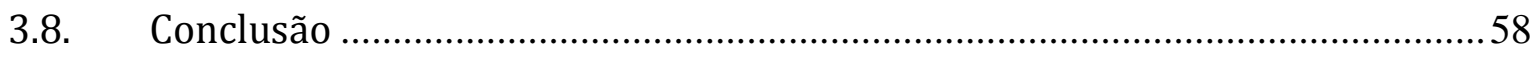

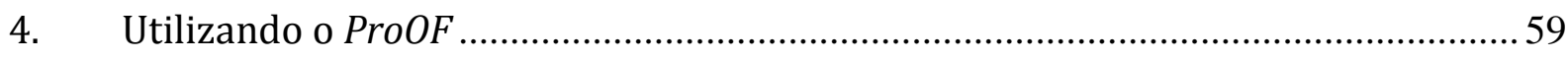

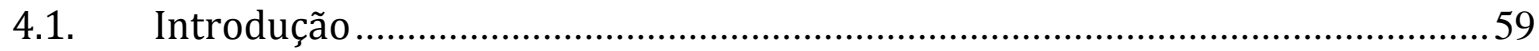

4.2. Download e Instalação do Ambiente ................................................................... 60

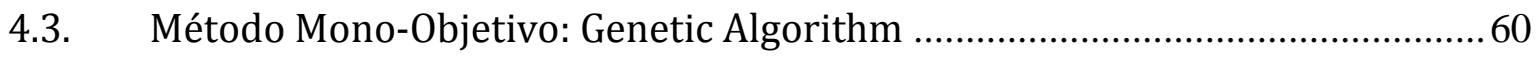

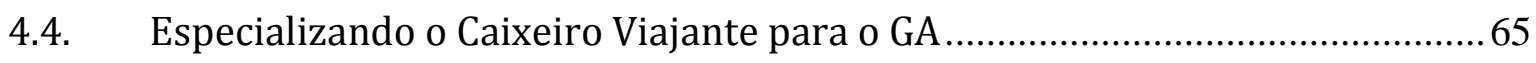

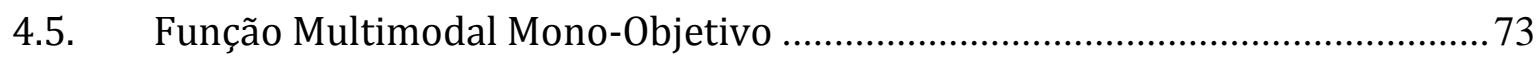

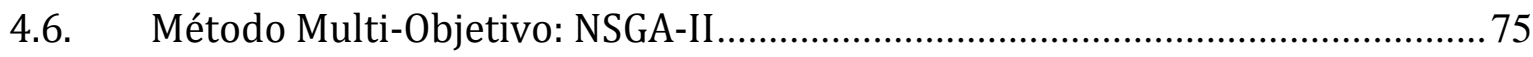

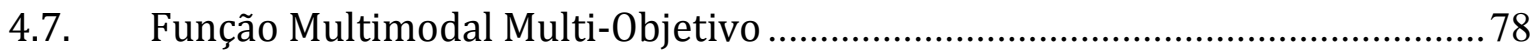

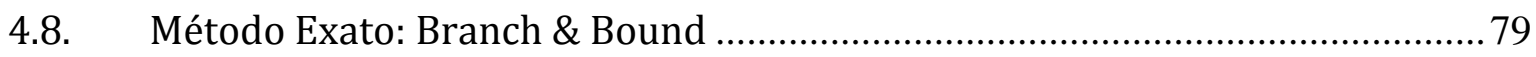


4.9. Especializando o Caixeiro Viajante para o Branch \& Bound ........................... 81

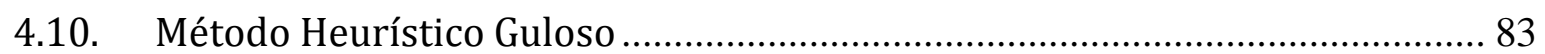

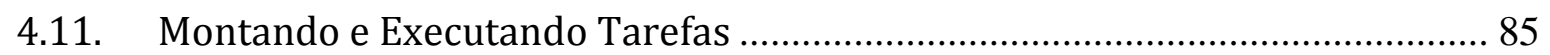

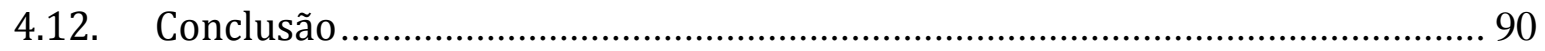

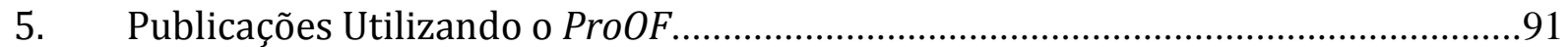

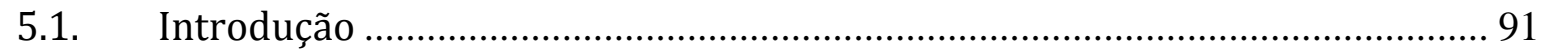

5.2. Algoritmo Genético Multi-Populacional Híbrido ........................................... 91

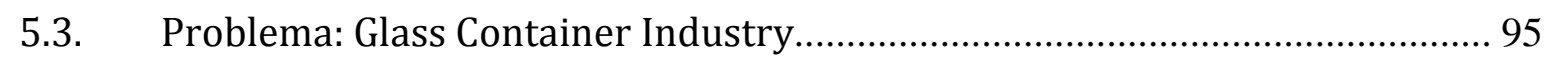

5.4. Problema: Proportional, Integral and Derivative........................................... 98

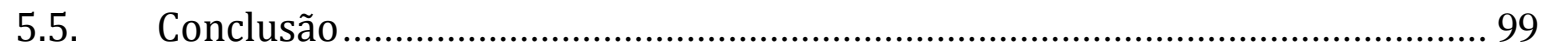

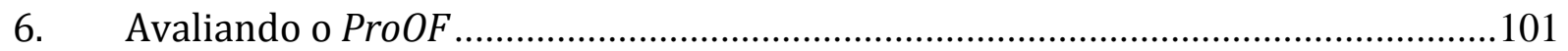

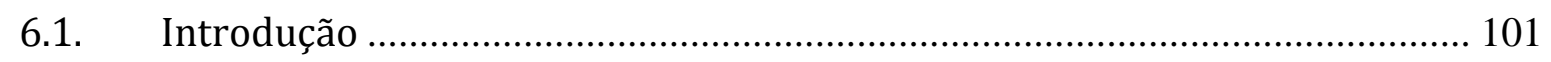

6.2. Comparação com outros Frameworks ........................................................ 101

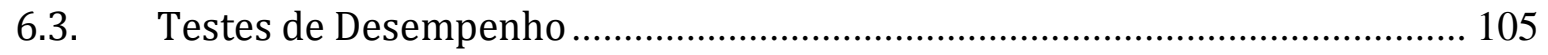

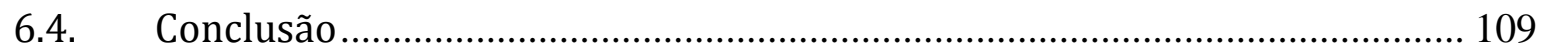

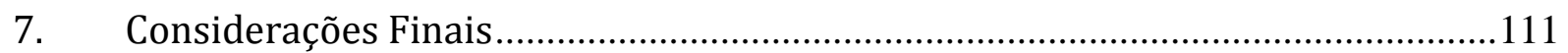

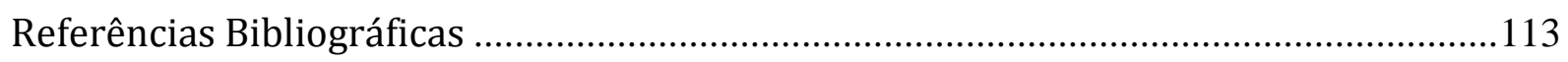




\section{Lista de Figuras}

Figura 1: Áreas de interesse e as características a serem comparadas, adaptado de [59]........ 32

Figura 2: Comparação das características suportadas pelos métodos. ................................... 32

Figura 3: Características para auxiliar na implementação dos problemas................................33

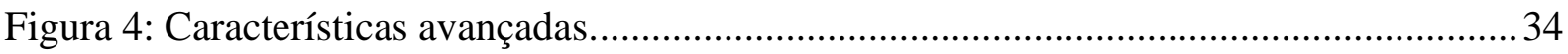

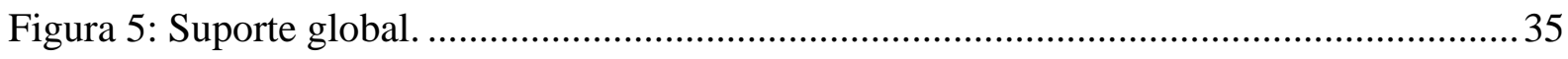

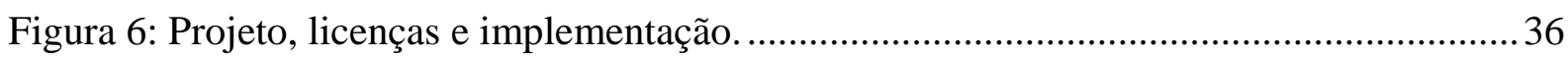

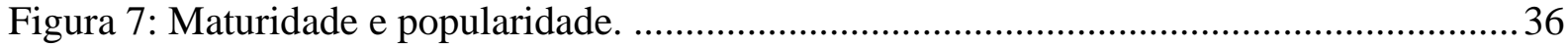

Figura 8: Resumo dos frameworks mais abrangentes e das características mais raras. ............37

Figura 9: Processo geral de interação entre os módulos e o usuário. ...................................... 40

Figura 10: Fluxograma das principais decisões do usuário ao utilizar o ProOF ..................... 41

Figura 11: Arquitetura para adicionar uma nova linguagem de programação. ........................43

Figura 12: Grafo direcionado para interpretação dos parâmetros. ......................................... 45

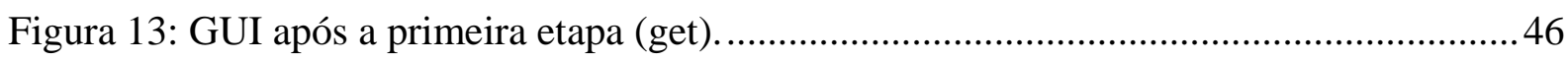

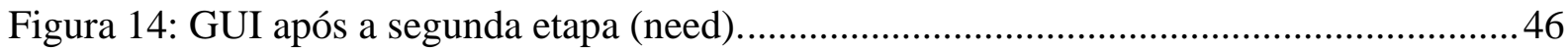

Figura 15: GUI após a terceira etapa (param). ............................................................... 47

Figura 16: Possíveis caminhos nas escolhas do usuário durante a primeira etapa.................. 47

Figura 17: Diagrama de classes UML com a arquitetura do módulo Abstract . ....................... 49

Figura 18: Padrões de Projeto - Factory Method e Singleton (FMS)......................................51

Figura 19: Esquema de compartilhamento de recursos.........................................................52

Figura 20: Diagrama de estados do módulo Client. .................................................................54

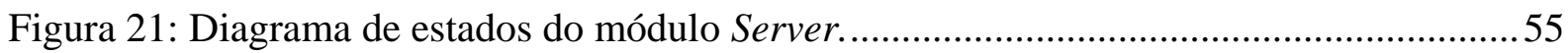

Figura 22: Diagrama de estados do módulo Slave. ...............................................................57

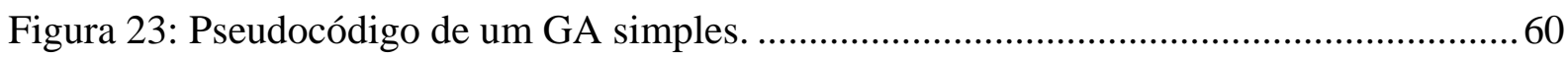

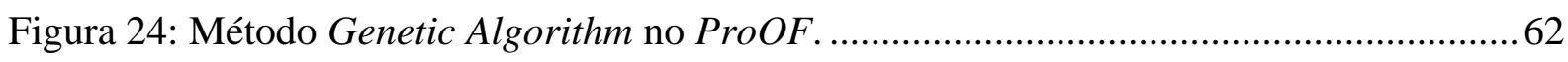

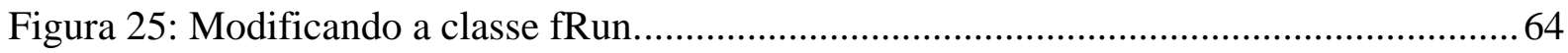

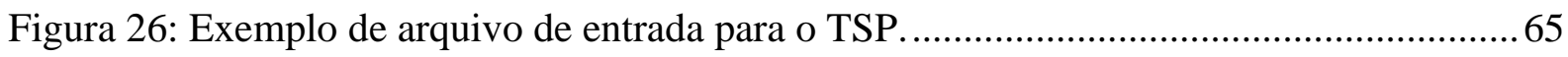

Figura 27: Classe para leitura de arquivo e armazenamento de instâncias do TSP..................66

Figura 28: GUI montada pela solicitação do arquivo para o TSP..........................................66

Figura 29: Exemplo de representação da solução (codificação) e sua rota (decodificação)....67

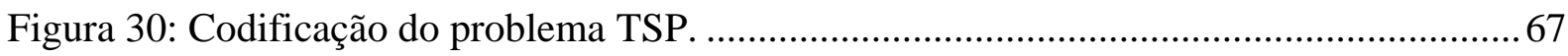

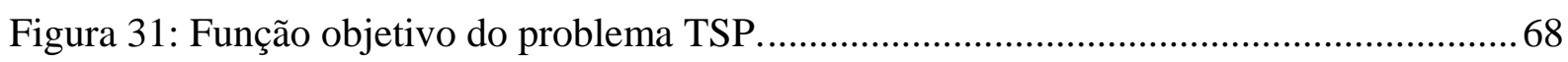

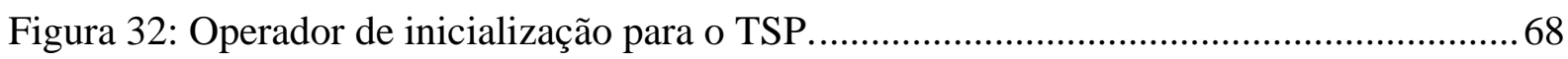

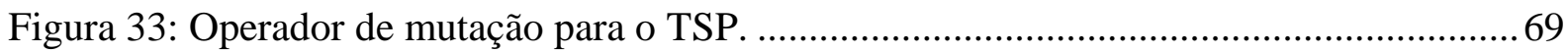




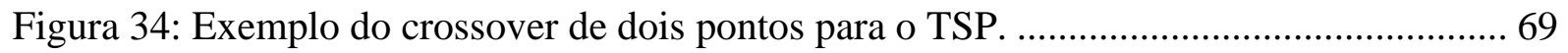

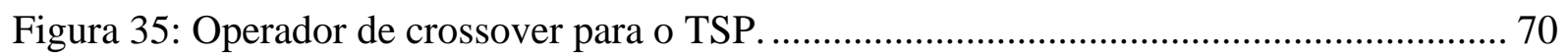

Figura 36: Classe para vinculação dos operadores do TSP. .................................................... 71

Figura 37: Classe para ligar as diferentes partes do problema TSP...................................... 71

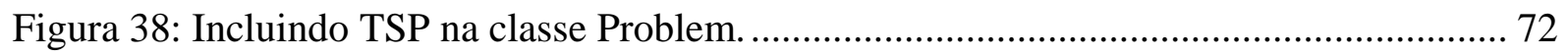

Figura 39: Arquitetura para os problemas reais mono-objetivo. .......................................... 73

Figura 40: Codificação Real implementada no ProOF ......................................................... 74

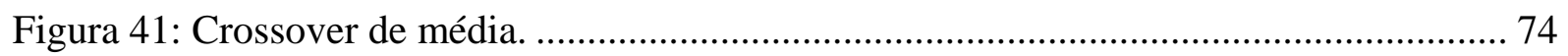

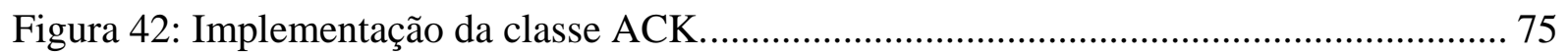

Figura 43: Incluindo ACK na classe fRealSingle.............................................................. 75

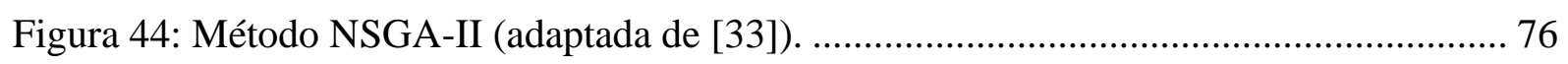

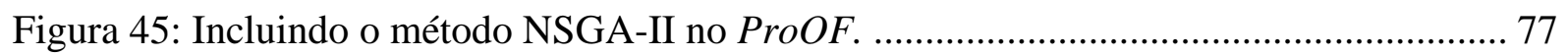

Figura 46: Implementação da função multi-objetivo SCH.................................................. 78

Figura 47: Arquitetura do método Branch \& Bound implementado. ..................................... 79

Figura 48: Implementação do método exato Branch \& Bound no ProOF . .............................. 80

Figura 49: Especializando a classe Branch para o TSP. ......................................................... 81

Figura 50: Implementação do operador Expand para o TSP. ................................................. 82

Figura 51: Implementação do operador LowerBound para o TSP. ........................................ 83

Figura 52: Especializando a classe BranchProblem para ligar as diversas classes do TSP.... 83

Figura 53: Implementação do método heurístico Greedy no ProOF ...................................... 84

Figura 54: GUI para catalogar os códigos do usuário............................................................ 85

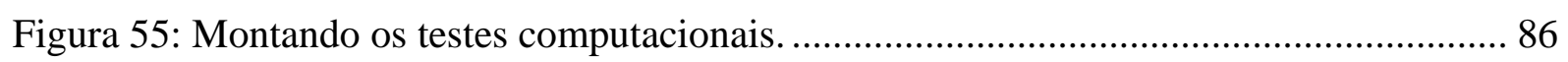

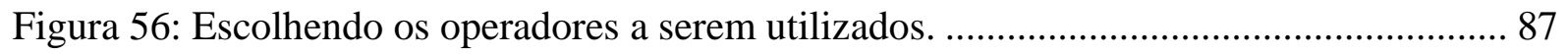

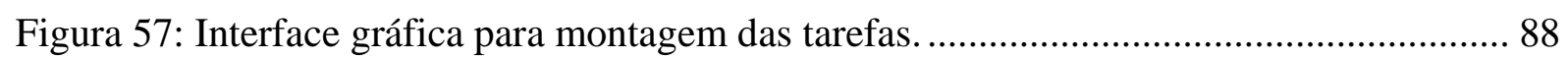

Figura 58: Interface gráfica para gerênciar a execução das tarefas em modo LocalHost........ 89

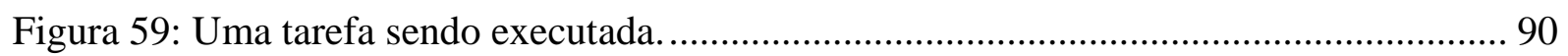

Figura 60: Arquitetura para o algoritmo evolutivo híbrido. ............................................... 92

Figura 61: Pseudocódigo do algoritmo evolutivo híbrido. ................................................... 93

Figura 62: Implementação da busca local Simulated Annealing. ........................................... 94

Figura 63: Dezoito combinações possíveis para uso do MPGA............................................. 95

Figura 64: Arquitetura para o problema Glass Container Industry ...................................... 96

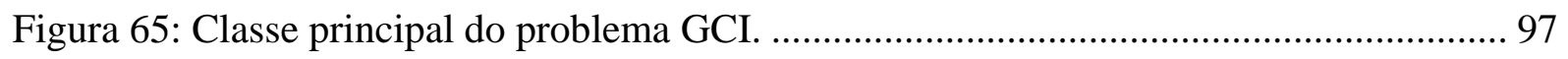

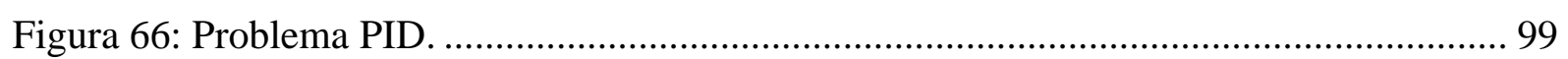

Figura 67: Percentagem de integralização para cada área de interesse................................ 102

Figura 68: Pontuação/média geral de integralização das áreas para cada framework........... 105

Figura 69: Eficiência calculada escalando o tempo e o tamanho do problema. ..................... 108

Figura 70: Eficiência quando é utilizado paralelismo........................................................ 109 


\section{Lista de Abreviaturas}

ACK Ackley Problem

$\mathrm{CH} \quad$ Cavity Heuristic

FMS Factory Method and Singleton

GA Genetic Algorithms

GCI Glass Container Industry

GUI Graphical User Interface

HcGA Hybrid compact Genetic Algorithm

IDE Integrated Development Environment

KP Knapsack Problem

MLCLSP Multi-Level Capacitated Lot Sizing Problem

MPGA Multi-Population Genetic Algorithm

NSGAII Nondominated Sorting Genetic Algorithm II

PID Proportional, Integral and Derivative

ProOF Professional Optimization Framework

SA Simulated Annealing

TSP Travelling Salesman Problem

UML Unified Modeling Language

VRP Vehicle Routing Problem 
xviii 


\section{CAPÍTULO 1}

\section{Introdução}

"O passado serve para evidenciar as nossas falhas e dar-nos indicações para o progresso do futuro."

Henry Ford

A crescente demanda por soluções de problemas reais de otimização tem incentivado o surgimento de ambientes (frameworks) voltados ao desenvolvimento de métodos para resolução de problemas [1] e [2]. Um framework é definido como uma arquitetura básica que guia o usuário nas suas especializações [3]. Também pode ser definido como um projeto reutilizável de todo ou partes de um sistema, representado por um conjunto de classes abstratas e por um mecanismo que rege a interação de suas instâncias [4]. Um framework é como um esqueleto para desenvolver aplicativos [5].

Os frameworks voltados a problemas de otimização podem estar direcionados a determinados tipos de problemas usando métodos específicos, [6] e [7], ou podem permitir a implementação de diversos métodos e problemas [8]. Destaca-se nesses ambientes o uso de linguagens orientadas a objeto que facilitam a reutilização dos códigos disponíveis. As linguagens de programação orientadas a objetos permitem definir abstrações, especializadas posteriormente, que possibilitam um alto nível de reuso de código [9]. Também é relevante o foco desses frameworks no auxílio à implementação de métodos metaheurísticos que, devido ao seu aspecto mais geral, podem ser aplicados na resolução de diversos tipos de problemas.

A partir da revisão bibliográfica apresentada no Capítulo 2, observou-se que diversos frameworks foram projetados para comportar apenas uma linguagen de programação $(\mathrm{C}++$, Java ou C\#) e costumam ser aplicados a classes específicas de problemas (mono ou multiobjetivo). Além disso, as possibilidades de desenvolvimento não abrangem uma generalidade de métodos, ou seja, estão direcionadas muitas vezes a métodos heurísticos específicos. Também não há grande preocupação com princípios de coesão e acoplamento ao guiar o usuário através dos passos necessários para inclusão de métodos e problemas. Isso leva à 
necessidade de um retrabalho considerável quando se deseja compartilhar apenas parte do código com terceiros, ou reaproveitar parte dos métodos e problemas em outras aplicações.

Neste contexto, esta dissertação apresenta o ProOF - Professional Optimization Framework. Trata-se de um ambiente desenvolvido para auxiliar a geração de código para métodos aplicados a problemas de otimização mono e multi-objetivo. O ProOF permite ao usuário tanto a inclusão de métodos quanto problemas e fornece suporte à geração de códigos em mais de uma linguagem de programação. Como ponto de partida, o ambiente oferece suporte para o desenvolvimento de códigos em duas linguagens de programação, Java e C++, fazendo amplo uso do paradigma da programação orientada a objetos.

O ProOF também oferece suporte para o desenvolvimento de métodos exatos, heurísticos, metaheurísticos e híbridos. Um método exato encontrará a solução ótima, se ela existir. Um método heurístico determinará, geralmente de forma rápida, uma solução de boa qualidade. Uma metaheurística é definida como um processo de geração iterativo que guia uma heurística subordinada no espaço de busca para encontrar boas soluções [10].

De acordo com [11] e [12], os métodos heurísticos são conhecidos por retornarem boas soluções para problemas complexos de otimização dentro de um tempo computacional razoável. Todavia, esses métodos não necessariamente comprovam a otimalidade da solução obtida. Uma metaheurística permite solucionar uma ampla variedade de problemas de otimização, sem precisar de uma adaptação relevante ao contexto de cada problema.

Dentro das metaheurísticas, há os métodos de computação evolutiva que são baseados em população de soluções (population-based). Estas técnicas geram e testam soluções, explorando e intensificando a busca no espaço de soluções do problema. Novas soluções são criadas e adicionadas à população pela aplicação de operadores de seleção, recombinação e mutação. Tais métodos têm sido aplicados em vários problemas de otimização em diversas áreas [11], [12] e [13], onde um dos principais métodos são os algoritmos genéticos (Genetic Algorithm - GA). Outras aplicações da computação evolutiva são a programação genética, a estratégia evolutiva e a programação evolutiva [14].

A combinação de diferentes métodos define as chamadas metaheurísticas híbridas. Uma revisão da literatura focada em metaheurísticas híbridas é apresentada em [15]. Além disso, heurísticas e metaheurísticas também podem ser utilizadas em conjunto com técnicas de programação matemática. Uma revisão da literatura para métodos heurísticos baseadas em programação matemática é descrita em [16]. Em muitos dos trabalhos que utilizam 
programação matemática é comum o uso do solver IBM ILOG CPLEX [17]. Este solver já foi utilizado em combinações com vários métodos desenvolvidos no ProOF conforme será indicado na seção 1.3.

Sendo assim, a ferramenta proposta é caracterizada como um ambiente ou framework. Segundo [3], aplicativos são difíceis de projetar, bibliotecas de códigos são mais difíceis e frameworks são os mais difíceis entre esses. O projetista de um framework deve cuidar para que sua arquitetura trabalhe bem para todas as aplicações de um domínio. Quaisquer alterações substanciais futuras na arquitetura reduzem consideravelmente os seus benefícios, visto que a principal contribuição de um framework para o usuário é a arquitetura previamente estabelecida. Portanto, é imperativo projetar um framework extensível e com alta flexibilidade. Nesta direção, as principais contribuições alcançadas neste trabalho e que o diferencia de outras abordagens são:

- Define uma arquitetura abstrata o suficiente que permite a especialização de vários métodos e problemas, unindo as principais características encontradas em outros trabalhos da literatura.

- Guia os usuários na implementação de métodos e resolução de problemas com alto reuso de códigos e bibliotecas.

- Flexibiliza a criação de códigos em diferentes linguagens de programação.

- Gera uma Graphical User Interface (GUI) automática para parametrização dos métodos inseridos pelo usuário.

- Funciona como sistema distribuído, permitindo assim o gerenciamento das diversas execuções em vários computadores.

\subsection{Objetivos}

O presente projeto estabeleceu como meta atingir os seguintes objetivos específicos:

- Adicionar ao ambiente proposto um nível de abstração que permita a implementação de métodos exatos, heurísticos e metaheurísticos aplicados a diferentes tipos de problemas de otimização com o maior reuso possível de código.

- Implementar uma base computacional suficiente para que a ferramenta possa comportar várias linguagens de programação, disponibilizando inicialmente o uso de códigos em pelo menos duas linguagens: Java e $\mathrm{C}++$.

- Implementar a ferramenta como um sistema distribuído, permitindo assim o gerenciamento das diversas execuções em várias máquinas. 
- Implementar a inteface gráfica, módulos para coleta de resultados e outras fucionalidades de propósito geral.

- Utilizar a ferramenta desenvolvendo métodos, como estudo de caso, e resolvendo problemas de aplicação real.

- Criar uma página web e tutorial para divulgação do ProOF.

\subsection{Versão Preliminar}

A ferramenta computacional proposta neste projeto é resultado de um estudo iniciado anteriormente em um projeto de Iniciação Científica (IC). Na época, sob a orientação do prof. Claudio Fabiano Motta Toledo, um grupo formado por alunos de IC utilizavam o framework NP-Opt proposto por Alexandre de Sousa Mendes em sua tese de doutorado [18].

Tanto os recursos quanto as limitações existentes no NP-Opt motivaram o desenvolvimento de um novo framework. A ideia inicial era criar um ambiente que facilitasse a obtenção de parâmetros e análise de resultados através de uma nova interface gráfica. Também era desejada a utilização de outra linguagem de programação, ao invés de apenas desenvolver códigos em Java.

O grupo iniciou então o projeto de dois ambientes independentes, um para implementações em linguagem Java e o outro em $\mathrm{C}++$. Esses dois ambientes preenchiam melhor a necessidade do grupo e foram utilizados em sete trabalhos que permitiram também compreender melhor diferentes métodos de otimização como:

- Algoritmos evolutivos publicados em [19] e [20].

- Busca Tabu publicado em [21]

- Algoritmo evolutivo híbrido publicado em [22] combinado com:

○ Threshold Accepting

- Busca Tabu

- Seleção Clonal publicado em [23]

- Enxame de Partículas publicado em [24]

- Heurística determinística baseada em programação matemática criada especificamente para o trabalho publicado em [25].

Observou-se que tais ambientes também eram falhos ou incompletos uma vez que: não eram capazes de distribuir as tarefas automaticamente, não suportavam problemas multiobjetivo e tinham seu foco na construção de metaheurísticas. As linguagens também eram fixas, ou seja, se fosse preciso projetar código em outra linguagem (diferente de C++ e Java), todo o ambiente deveria ser construído na nova linguagem, incluindo a interface gráfica. 


\subsection{Versão Atual}

A revisão bibliográfica realizada nesta dissertação (ver Capítulo 2) e a experiência adquirida com as versões preliminares mencionadas na seção 1.2 ajudaram a revelar diversas características existentes em outros frameworks que poderiam ser incorporadas ao ambiente proposto.

Logo, o ProOF começou a ser construído partindo de uma completa remodelagem das versões preliminares, definindo um novo ambiente que fosse capaz de expressar tudo que os dois anteriores já conseguiam e suportando novas características disponíveis em outros ambientes da literatura.

Durante as etapas de desenvolvimento do ProOF, sempre foi mantida uma versão funcional da ferramenta para que fosse possível desenvolver novos trabalhos. Isso permitiu a implementação de métodos e resolução de problemas recentemente publicados na literatura, [26]-[30]. A forma como dois destes trabalhos, [26] e [30], foram desenvolvidos no ProOF será apresentada em detalhes no Capítulo 5 desta dissertação. Além disso, a ferramenta apresenta um conjunto de códigos já desenvolvido como estudo de caso:

- Implementação de métodos de otimização com características variadas:

○ Genetic Algorithm (GA): a implementação de um algoritmo genético simples adaptado de [31] já está disponível no ambiente, os passos seguidos para incluir este método são descritos na seção 4.3.

- Simulated Annealing (SA): este método de busca local também se encontra disponível no ambiente e sua implementação foi adaptada de [32].

○ NSGAII: este é um dos algoritmos multi-objetivo mais conhecidos e foi proposto em [33]. Na seção 4.6, será descrito como este método foi incluído no ambiente.

○ Branch \& Bound: será apresentado na seção 4.8 como este método exato foi implementado no ambiente a partir da descrição apresentada em [34].

○ Heurística Gulosa (Greedy): na seção 4.10 é descrito como esta heurística simples foi incorporada ao ProOF, seguindo as ideias definidas em [35].

○ Multi-Population Genetic Algorithm (MPGA): este método foi implementado no ProOF e gerou duas publicações, [26] e [30], os detalhes de como o método foi incluído no ambiente estão na seção 5.2.

○ Hybrid compact Genetic Algorithm (HcGA): trata-se de um algoritmo genético compacto híbrido que resultou em dois trabalhos: [27] e [29]. 
○ Combinações com IBM ILOG CPLEX: vários dos trabalhos publicados utilizaram as facilidades do ProOF em conjunto com a biblioteca solver CPLEX: [27]-[30].

- Um conjunto exemplo de problemas de otimização mono e multi-objetivo:

- Travelling Salesman Problem (TSP): a implementação deste problema de otimização [36] encontra-se no ProOF como um exemplo, onde os detalhes de sua adaptação para métodos de otimização variados são descritos nas seções 4.4 e 4.9.

- Ackley Problem (ACK): trata-se de um problema de otimização de função multimodal [37] mono-objetivo apresentado como exemplo na seção 4.5.

- Glass Container Industry (GCI): trata-se de um problema de aplicação real para uma indústria de produção de garrafas de vidro, este trabalho foi conduzido com o uso do ProOF e foi publicado em [30], os detalhes são apresentados na seção 5.3.

- Proportional, Integral and Derivative (PID): é um problema de ajuste de controle e foi conduzido com o uso do ProOF, os detalhes são apresentados na seção 5.4 e o estudo deste problema gerou uma publicação, [26].

○ Multi-Level Capacitated Lot Sizing Problem (MLCLSP): este problema de otimização foi estudado e implementado com o uso do ProOF e três trabalhos foram publicados [27]-[29].

- Benckmark com funções mono-objetivo: todo o conjunto com as 50 funções mono-objetivo apresentadas em [38] foram implementadas no ProOF para auxiliar na avaliação dos métodos mono-objetivo incluídos no ambiente, visto que são funções com ótimos conhecidos.

○ Benchmark com funções multi-objetivo: as funções multi-objetivo apresentadas em [39] também foram incluídas no ambiente, onde na seção 4.7 será apresentada como uma destas funções foi implementada com o uso do ProOF.

- Diferentes formas de critério de parada para os métodos:

- Tempo: este critério de parada foi implementado como um componente reutilizável no ProOF e a mesma implementação foi utilizada em três trabalhos distintos [27][29].

- Avaliações: este componente é capaz de coletar automaticamente o número de funções avaliadas dentro do ambiente e foi utilizada em [26].

- Número de Gerações: este componente é específico e somente alguns métodos do ambiente são capazes de manipulá-lo, onde foi utilizado combinado com o MPGA em [26]. 
- Tempo com Corte: este critério de parada foi criado especificamente para o trabalho publicado em [30] e ilustra a capacidade do ProOF de aceitar formas variadas de critério de parada.

- As codificações mais comuns já estão disponíveis no ambiente:

- Binária: ainda não foi utilizada em nenhum trabalho publicado, mas está disponível no ambiente para ser utilizada.

○ Real: esta codificação será descrita na seção 4.5 e já foi utilizada em um trabalho publicado [26] também descrito na seção 5.4. Além disto, está disponível para resolver todas as funções dos benchmarks com funções mono e multi-objetivo descritas em [38] e [39], respectivamente.

○ Binária Codificando Real: ainda não foi utilizada em nenhum trabalho publicado, mas também está disponível para resolver as funções Benchmarks, [38] e [39], definidas para a codificação real.

○ Permutações: apesar de não ter sido publicada, esta codificação é descrita na seção 4.4 para resolver o TSP e encontra-se disponível no ProOF, podendo ser reaproveitada para vários outros problemas conforme apresentado na seção 4.4 .

- Os principais operadores para manipular cada uma das codificações implementadas já estão prontos:

○ Inicialização: utilizado para gerar uma ou mais soluções iniciais para os métodos inseridos no ambiente.

○ Crossover: utilizado para geração de novas soluções pelos algoritmos evolutivos dentro do ProOF.

○ Mutação: utilizado para causar uma perturbação nas soluções, utilizado pelos algoritmos evolutivos.

○ Movimento Local: este operador é semelhante à mutação, porém realiza primeiramente uma cópia da solução e faz a perturbação na cópia, gerando uma nova solução. O operador é utilizado pelos métodos de busca local dentro do ambiente. 


\subsection{Organização do Texto}

Este texto está organizado da seguinte forma:

- Capítulo 2: apresenta uma breve revisão de trabalhos relacionados, onde são destacados os principais frameworks existentes voltados à implementação de métodos para problemas de otimização. As principais limitações nos frameworks existentes são destacadas e indicado onde se pretende avançar nesta dissertação.

- Capítulo 3: caracteriza o problema a ser abordado nesta dissertação, onde os principais desafios inerentes à construção do framework proposto serão detalhados, estabelecendo o funcionamento do ProOF e descrevendo como foram alcançadas as contribuições deste trabalho.

- Capítulo 4: ilustra como é a usabilidade do ProOF ao projetar novos códigos para métodos e problemas com características variadas, onde são definidos exemplos simples e comuns para cada caso de teste.

- Capítulo 5: trata dos problemas onde a ferramenta foi aplicada até o momento que resultaram em cinco trabalhos publicados, sendo dois destes trabalhos apresentados neste capítulo.

- Capítulo 6: apresenta os resultados alcançados por esta dissertação, realizando uma comparação da ferramenta proposta com os principais frameworks encontrados na literatura. Também define a perda de desempenho com o uso do ProOF em comparação com a implementação de código diretamente na linguagem de programação, sem o uso do ambiente.

- Capítulo 7: termina com as considerações finais sobre o trabalho, onde é sumarizado o que foi discutido neste texto, sua contribuição e trabalhos futuros. 


\section{CAPÍTULO 2}

\section{Revisão Bibliográfica}

"No meio da confusão, encontre a
simplicidade. A partir da
discórdia, encontre a harmonia.
No meio da dificuldade reside a
oportunidade."

Albert Einstein

\subsection{Introdução}

Uma breve revisão bibliográfica de trabalhos relacionados à construção de frameworks de otimização será descrita neste capítulo. Nos últimos anos, surgiram diversas ferramentas computacionais para auxiliar profissionais da área de otimização, onde a maioria delas foi projetada para contextos específicos. Há um considerável uso do paradigma de programação orientada a objetos no desenvolvimento destes frameworks e a implementação de metaheurísticas como abordagem na solução de problemas. Na seção 3.2, uma revisão considerando os frameworks mais relacionados ao ProOF é apresentada, onde os aspectos gerais propostos em cada framework são descritos. A seção 3.3 destaca as limitações encontradas nas propostas existentes e buscando definir quais aspectos serão abordados no ProOF. As conclusões deste capítulo seguem na seção 3.4.

\subsection{Trabalhos Relacionados}

Neste projeto será considerado o uso de métodos exatos, heurísticos e metaheurísticos na resolução de problemas de otimização. Diversos problemas práticos têm como característica inerente a otimização multi-objetivo, ou seja, a necessidade de otimizar duas ou mais funções ou objetivos conflitantes. A ferramenta jMetal ${ }^{1}$ [40] é apresentada em [39] e [40] como um framework de otimização multi-objetivo programado em linguagem Java. O foco principal da ferramenta está na inclusão de métodos e problemas de otimização multi-objetivo, dispondo para isto de um modelo a ser seguindo durante o processo de inclusão. O jMetal foi

\footnotetext{
${ }^{1}$ http://jmetal.sourceforge.net/
} 
desenvolvido inicialmente em Java, porém uma versão em $\mathrm{C}++$ foi projetada posteriormente e comporta atualmente cerca de $70 \%$ dos códigos já projetados na versão Java. Essa versão foi publicada em [41] e a ferramenta disponibiliza também outra versão em C\#.

O jMetal disponibiliza algoritmos bem conhecidos para problemas multi-objetivos como o NSGAII, SPEA2, PAES, AbYSS, MOEAD, IBEA, MOCell e SMPSO. Também possui implementado um conjunto de indicadores de qualidade que consideram duas propriedades: convergência e diversidade da solução em relação à fronteira Pareto ótima. Os principais indicadores de qualidade propostos na literatura e disponíveis no jMetal são: Epsilon, Generational Distance, Inverted Generational Distance, Hyper Volume, Spread e Generalized Spread. Também há uma interface gráfica para configuração dos testes a serem executados que possibilita a visualização, para problemas com dois objetivos, da fronteira Pareto encontrada pelo algoritmo em relação a uma fronteira Pareto ótima conhecida.

O framework ParadisEO ${ }^{2}$ [42], desenvolvido em C++, é dedicado ao projeto de metaheurísticas para otimização de problemas de natureza contínua, discreta e combinatória. Um modelo geral para a implementação de algoritmos evolutivos que otimizem problemas multi-objetivos dentro deste ambiente é proposto em [8]. Um algoritmo evolutivo híbrido para o problema de redes de celular multi-objetivo foi proposto em [43], onde este método e problema foram incluídos utilizando paralelismo com distribuição em grid e hibridização com buscas locais. Dois trabalhos, [44] e [45], utilizaram o ParadisEO com um algoritmo evolutivo que também explorou a computação paralela em grid em problema de mineração de dados. Abordou-se também o problema de redes de rádio utilizando o mesmo algoritmo desenvolvido neste framework em [45]. Uma estrutura com todos os métodos de busca local implementados no ParadisEO é apresentada em [46], descrevendo como funciona cada busca local e como foram adaptadas ao ParadisEO.

MOEAT (Multiobjective Evolutionary Algorithms Tool), apresentado em [2], é uma ferramenta programada na linguagem C\# que tem foco na utilização de algoritmos evolutivos para a resolução de problemas multi-objetivo. Assim como o jMetal, o MOEAT possui vários algoritmos conhecidos para otimização multi-objetivo. O framework possui uma interface gráfica robusta e um editor próprio que simplifica a inclusão de novas funções e restrições para problemas multi-objetivo. Sua interface gráfica possibilita também configurar os testes

\footnotetext{
${ }^{2}$ http://paradiseo.gforge.inria.fr/
} 
de forma simples e rápida, além da visualização da fronteira Pareto para problemas com dois objetivos.

O framework oMetah ${ }^{3}$ [47] foi desenvolvido em linguagem $\mathrm{C}++$ e soluciona problemas mono-objetivo contínuos através do uso de metaheurísticas. Possui métodos previamente implementados, onde os principais são: colônia de formigas, algoritmo genético e Simulated Annealing. O framework oferece vários testes estatísticos para realizar uma rigorosa avaliação de desempenho.

O Open Beagle ${ }^{4}$ [48] foi implementado em C++ e seu foco também está na criação de algoritmos evolutivos. Este framework consegue tratar problemas mono e multi-objetivo [49]. O EasyLocal $++^{5}$ [50] e [51] é um framework orientado a objetos, desenvolvido em $\mathrm{C}++$, específico para a criação de metaheurísticas de busca local. O EasyLocal++ contém os métodos Hill Climbing, Simulated Annealing e Tabu Search permitindo também a criação de métodos baseados em busca local de forma combinada para a solução de problemas monoobjetivo. Este framework é utilizado em [6] para resolver o problema Course Timetabling. A arquitetura e utilização do EasyLocal++ são detalhados em [7], através de um estudo de caso focado no problema de coloração de grafos.

O METSlib ${ }^{6}$ [52] é um framework programado em C++ que permite desenvolver metaheurísticas de busca local para problemas de otimização mono-objetivo. O framework possui implementados os métodos baseados em busca local: Random Restart, Simulated Annealing e Tabu Search. Em sua documentação é apresentado como utilizar este framework através de um estudo de caso com o problema de designação quadrática.

$\mathrm{O} \mathrm{FOM}^{7}$ [53] foi programado em Java e seu foco está na construção de hyper-heurísticas. Hyper-heurísticas são métodos que buscam a construção de outras heurísticas para melhor resolver um problema particular. Este framework trabalha com problemas de otimização mono-objetivo e disponibiliza metaheurísticas como: colônia de formigas, algoritmos evolutivos e métodos baseados em busca local (GRASP, VNS, Hill Climibing, Simulated Annealing, Tabu Search). As principais características e a arquitetura deste framework são descritas em [54].

\footnotetext{
${ }^{3}$ http://developer.berlios.de/projects/ometah/

${ }^{4}$ http://code.google.com/p/beagle/

5 http://www.diegm.uniud.it/satt/projects/EasyLocal/doc/index.html

${ }^{6}$ https://projects.coin-or.org/metslib

7 http://www.isa.us.es/fom/modules/portalWFInterface/init.php
} 
Um framework de otimização para construção de métodos exatos voltados para problemas mono e multi-objetivo foi proposto em [55]. Os autores não atribuíram um nome a ferramenta, mas aqui ela será chamada pelas siglas do título do trabalho, GeFEOA (Gridenabled Framework for Exact Optimization Algorithms). O ambiente guia a implementação de métodos distribuídos em grid utilizado uma arquitetura mestre-escravo para paralelização. O ambiente disponibiliza a implementação do algoritmo Branch \& Bound.

O NP-Opt é um framework de otimização proposto por Alexandre de Sousa Mendes em sua tese de doutorado [18]. Os resultados iniciais obtidos e apresentados neste projeto de mestrado partiram de estudos realizados a partir do NP-Opt. A ferramenta utiliza orientação a objetos e é programada na linguagem Java. De acordo com [18], o ambiente está centrado no uso de algoritmos genéticos e algoritmos meméticos. O framework foi desenvolvido para tratar problemas mono-objetivo como: Sequenciamento em Máquina Simples e Máquinas Paralelas, Flowshop, Gate Matrix Layout e Ordenamento de Genes. O NP-Opt é composto por quatro blocos: Interface com o Usuário, Métodos e Problemas, Processamento Distribuído e Interface de Saída e Resultados.

A estrutura do NP-Opt é descrita em [9], bem como os passos para a inclusão de novos problemas de otimização. A estrutura e funcionamento de um algoritmo memético paralelo implementado no NP-Opt é detalhada em [56], onde o método foi aplicado ao problema de sequenciamento em máquinas simples. Os recursos do NP-Opt foram utilizados em [57] e [58] para o desenvolvimento de um algoritmo memético e um algoritmo genético, respectivamente, aplicado ao problema integrado de dimensionamento de lotes e programação da produção.

\subsection{Limitações dos Ambientes Abordados}

Definir as limitações em um framework de otimização e realizar uma comparação entre este tipo de ambiente pode ser uma tarefa difícil. Para auxiliar nesta comparação a partir de uma base coerente, serão utilizados os mesmos critérios definidos e publicados recentemente em [59], onde são detalhadas as principais características que um framework de otimização deve ter para projetar metaheurísticas. As características mais comuns levantadas foram: técnicas metaheurísticas suportadas, mecanismos de codificação de solução, manuseio de restrição, operadores suportados, hibridização, computação paralela e distribuída, uso de práticas de engenharia de software, documentação e interface do usuário. Para alcançar as características, os autores em [59] propuseram 10 perguntas a serem respondidas e que foram 
organizadas em seis áreas distintas (Figura 1). As mesmas perguntas foram adaptadas para esta dissertação e são descritas abaixo.

P1. Quais métodos são suportados?

P2. Que mecanismos são fornecidos, a fim de auxiliar a implementação de problemas?

P3. Suporta a combinação e hibridização dos métodos?

P4. Fornece suporte para encontrar os melhores parâmetros para os métodos?

P5. Tira vantagens da paralelização e computação distribuída?

P6. Quais funcionalidades são fornecidas a fim de apoiar todo o processo de implementação, resolução e avaliação?

P7. Quais os custos e formas de licenciamento do ambiente?

P8. Que plataformas (sistemas operacionais, linguagens de programação) são suportadas?

P9. O ambiente utiliza práticas de engenharia de software, a fim de melhorar a qualidade do código, facilidade de manutenção, flexibilidade e desempenho?

P10. Qual o grau de maturidade e popularidade do ambiente (importância dos problemas resolvidos, documentação, tutorial de uso, $n^{o}$ de publicações)?

Avaliar uma ferramenta de software implica compreensão e balanceamento de interesses conflitantes em relação à nova tecnologia. Seguindo a mesma abordagem proposta em [59], os critérios comparativos abrangem seis áreas de interesse. Para estas áreas foram definidas um total de 29 características específicas a serem avaliadas, conforme ilustrado na Figura 1, onde é descrito o conjunto de características para o estudo e cada característica está associada a apenas uma das perguntas levantadas. Para cada característica também é indicado um símbolo que será referenciado nas comparações entre os frameworks.

Adiante será realizada a comparação dos frameworks apresentados na seção anterior tentando definir quais os melhores em cada área e verificando também quais características estão faltando em cada um.

A área C1 (Métodos) é relacionada a responder a pergunta P1 e pretende verificar quais técnicas de resolução dos problemas são suportadas pelos ambientes. Neste contexto, considerou-se o uso de metaheurísticas baseadas em população de soluções (BP), metaheurísticas de busca local (BL), construção de heurísticas específicas (Heur), o uso de programação matemática (Mat) e métodos exatos (Exat). A comparação destas características para os ambientes considerados é ilustrada na Figura 2. 


\begin{tabular}{|c|c|c|c|}
\hline Áreas & Características & Símbolos & Perguntas \\
\hline \multirow{5}{*}{ C1. Métodos } & C1.1. Buscas locais & BL & P1. \\
\hline & C1.2. Baseados em população & BP & - \\
\hline & C1.3. Heurísticas específicas & Heur. & - \\
\hline & C1.4. Programação matemática & Mat. & - \\
\hline & C1.5. Métodos exatos & Exat. & - \\
\hline \multirow{5}{*}{ C2. Problema } & C2.1. Codificações & Codif. & $\mathrm{P} 2$. \\
\hline & C2.2. Operadores & Oper. & - \\
\hline & C2.3. Função objetivo & Obj. & - \\
\hline & C2.4. Restrições & Rest. & - \\
\hline & C2.5. Facilidades para problemas específicos & Fac. & - \\
\hline \multirow{4}{*}{$\begin{array}{c}\text { C3. Caraterísticas } \\
\text { avançadas }\end{array}$} & C3.1. Hibridização & Hibri. & P3. \\
\hline & C3.2. Hyper-heurísticas & Hyper. & P4. \\
\hline & C3.3. Computação paralela & Paral. & P5. \\
\hline & C3.4. Computação distribuída & Dist. & - \\
\hline \multirow{5}{*}{ C4. Suporte global } & C4.1. Critérios de parada & Crit. & P6. \\
\hline & C4.2. Execução em batch & Batch & - \\
\hline & C4.3. Analise estatística & Est. & - \\
\hline & C4.4. GUI e saídas gráficas & GUI & - \\
\hline & C4.5. Interoperabilidade & Inter. & 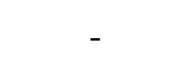 \\
\hline \multirow{5}{*}{$\begin{array}{l}\text { C5. Projeto, licenças e } \\
\text { implementação }\end{array}$} & C5.1. Licenciamento & Lic. & P7. \\
\hline & C5.2. Linguagem de implementação & Ling. & P8. \\
\hline & C5.3. Sistemas operacionais & Sist. & - \\
\hline & C5.4. Práticas de engenharia de software & Eng. & P9. \\
\hline & C5.5. Tamanho (classes, pacotes e módulos) & Tam. & - \\
\hline \multirow{5}{*}{$\begin{array}{l}\text { C6. Maturidade e } \\
\text { popularidade }\end{array}$} & C6.1. Relevância dos problemas resolvidos & Rel. & P10. \\
\hline & C6.2. Documentação & Doc. & - \\
\hline & C6.3. Tutorial & Tut. & - \\
\hline & C6.4. Página web & Pág. & - \\
\hline & C6.5. Publicações geradas & Publ. & . \\
\hline
\end{tabular}

Figura 1: Áreas de interesse e as características a serem comparadas, adaptado de [59].

\begin{tabular}{|l|c|c|c|c|c|c|}
\hline Frameworks & $\mathrm{BL}$ & $\mathrm{BP}$ & Heur. & Mat. & Exat. & $\mathrm{N}^{\mathrm{o}}$ \\
\hline ParadisEO & $\mathrm{x}$ & $\mathrm{x}$ & & & & 2 \\
\hline jMetal & & $\mathrm{x}$ & & & & 1 \\
\hline MOEAT & & $\mathrm{x}$ & & & & 1 \\
\hline NP-Opt & $\mathrm{x}$ & $\mathrm{x}$ & & & & 2 \\
\hline Open Beagle & & $\mathrm{x}$ & & & & 1 \\
\hline oMetah & $\mathrm{x}$ & $\mathrm{x}$ & & & & 2 \\
\hline METSlib & $\mathrm{x}$ & & & & & 1 \\
\hline EasyLocal++ & $\mathrm{x}$ & & & & & 1 \\
\hline FOM & $\mathrm{x}$ & $\mathrm{x}$ & $\mathrm{x}$ & & & 3 \\
\hline GeFEOA & & & & & $\mathrm{x}$ & 1 \\
\hline
\end{tabular}

Figura 2: Comparação das características suportadas pelos métodos. 
Observa-se que nenhum dos frameworks mencionados apresenta funcionalidades que auxiliem a implementação de métodos baseados em técnicas de programação matemática (Mat), este tipo de abordagem é comum em solvers como o CPLEX [17] e nenhum dos ambientes destacou o uso combinado com o solver CPLEX. A construção de heurísticas específicas (Heur) para resolver um problema foi encontrada apenas no FOM e a implementação de métodos exatos (Exat) apenas em GeFEOA. Por fim, apenas quatro ambientes trabalham com ambas as características: buscas locais (BL) e baseadas em população (BP). A última coluna da Figura 2, ilustra a contagem do total de características para cada ambiente, sendo os melhores classificados na área de métodos: FOM, ParadisEO, NP-Opt e Metah (nomes destacados em negrito).

Para responder a pergunta P2 foi definida a área C2 (Problemas) que busca verificar quais características relativas aos problemas são encontradas nos ambientes avaliados. Alguns ambientes foram projetados para trabalhar com características marcadas como livres (x) ou fixas (_), conforme ilustrado na Figura 3. Sendo assim, apenas três ambientes promovem mecanismos para guiar os usuários na implementação de novas codificações (Codif) ao projetar um problema, os demais definem apenas o uso de codificações padrões já previamente implementadas. O mesmo ocorreu na comparação dos tipos de função objetivos (Obj), onde somente os mesmos três ambientes suportam a modelagem de problemas mono e multi-objetivos. Todos os ambientes permitiram definir livremente restrições (Rest) para espaço de busca das suas codificações.

\begin{tabular}{|l|c|c|c|c|c|c|}
\hline Frameworks & Codif. & Oper. & Obj. & Rest. & Fac. & $\mathrm{N}^{\mathrm{o}}$ \\
\hline ParadisEO & $\mathrm{x}$ & & $\mathrm{x}$ & $\mathrm{x}$ & & 3 \\
\hline jMetal & $\mathrm{x}$ & & $\mathrm{x}$ & $\mathrm{x}$ & & 3 \\
\hline MOEAT & & & & $\mathrm{x}$ & & 1 \\
\hline NP-Opt & & & & $\mathrm{x}$ & & 1 \\
\hline Open Beagle & $\mathrm{x}$ & & $\mathrm{x}$ & $\mathrm{x}$ & & 3 \\
\hline oMetah & & & & $\mathrm{x}$ & & 1 \\
\hline METSlib & & & & $\mathrm{x}$ & & 1 \\
\hline EasyLocal++ & & & & $\mathrm{x}$ & & 1 \\
\hline FOM & & & & $\mathrm{x}$ & & 1 \\
\hline GeFEOA & & & $\mathrm{x}$ & $\mathrm{x}$ & & 2 \\
\hline
\end{tabular}

Figura 3: Características para auxiliar na implementação dos problemas.

Nenhum ambiente, entretanto, destacou a possibilidade de criar novos tipos de operadores, permitindo apenas a especialização dos operadores já previamente definidos para as suas 
codificações. Entende-se aqui por criar novos operadores a definição de novos conceitos que escapam às classificações bem conhecidas como crossover, mutação e movimento local. Da mesma forma, nenhum framework promoveu mecanismos para facilitar (Fac) a implementação de problemas específicos. Considera-se como mecanismos que facilitam a implementação de problemas específicos: uma forma rápida de incluir problemas gerando maior reuso de código ou que reduz o número de passos para incluir um problema específico em relação a um problema mais geral, auxiliando a implementação. Por fim, os melhores frameworks classificados na área de problemas são ParadisEO, jMetal e Open Beagle.

A área C3 (Características Avançadas) busca responder as perguntas P3, P4 e P5, informando quais frameworks trabalham com hibridização (Hibri), hyper-heurísticas (Hyper), computação paralela (Paral) e distribuída (Dist). Considera-se aqui um ambiente como sendo paralelo quando sua execução pode ocorrer simultaneamente em diferentes núcleos de uma mesma máquina. Por outro lado, assume-se como ambiente distribuído aquele cuja execução pode ocorrer simultaneamente em várias máquinas com as mesmas ou diferentes arquiteturas.

\begin{tabular}{|l|c|c|c|c|c|}
\hline Frameworks & Hibri. & Hyper. & Paral. & Dist. & $\mathrm{N}^{\mathbf{0}}$ \\
\hline ParadisEO & $\mathrm{x}$ & & $\mathrm{x}$ & $\mathrm{x}$ & 3 \\
\hline jMetal & $\mathrm{x}$ & & $\mathrm{x}$ & & 2 \\
\hline MOEAT & & & & & 0 \\
\hline NP-Opt & $\mathrm{x}$ & & $\mathrm{x}$ & $\mathrm{x}$ & 3 \\
\hline Open Beagle & & & $\mathrm{x}$ & $\mathrm{x}$ & 2 \\
\hline oMetah & & & & & 0 \\
\hline METSlib & & & & & 0 \\
\hline EasyLocal++ & $\mathrm{x}$ & & & & 1 \\
\hline FOM & $\mathrm{x}$ & $\mathrm{x}$ & & & 2 \\
\hline GeFEOA & & & $\mathrm{x}$ & $\mathrm{x}$ & 2 \\
\hline
\end{tabular}

Figura 4: Características avançadas.

Na Figura 4 observa-se que, apenas um ambiente, o FOM, desenvolve hyper-heurísticas, sendo também capaz de projetar métodos híbridos. Dos 10 frameworks, cinco trabalham com hibridização, cinco com paralelismo e quatro são distribuídos. O ParadiEO e o NP-Opt se mostraram melhores na área de características avançadas conseguindo completar três das quatro características avaliadas.

Na busca por responder a pergunta P6, fica definida a área C4 (Suporte global) que verifica quais características são encontradas nos frameworks avaliados que auxiliam no processo de implementação, resolução e avaliação. Na Figura 5, observa-se que apenas três ambientes 
deixam livres para o usuário definir como será o critério de parada (Crit), os demais trabalham com critérios fixos já na construção de seus métodos. A maioria já disponibiliza mecanismos para configurar e executar um conjunto grande de testes em lote (Batch). Cinco ambientes disponibilizam meios para fazer a análise estatística ou auxiliam na comparação os resultados (Est), outros cinco possuem interface gráfica (GUI).

A característica de interoperabilidade (Inter) é alcançada, se o framework consegue trocar informações com outros sistemas de software como, por exemplo, exportar os resultados como tabelas LaTeX, arquivos XML, gráficos em PNG e resultados para serem lidos em planilhas eletrônicas. O jMetal trabalha com tabelas LaTeX de resultados, o Open Beagle com saídas de log em XML, o oMetah com relatórios LaTeX, HTML e gráficos PNG. Ao fim os melhores foram jMetal, oMetah e FOM.

\begin{tabular}{|l|c|c|c|c|c|c|}
\hline Frameworks & Crit. & Batch & Est. & GUI & Inter. & $\mathrm{N}^{\mathrm{o}}$ \\
\hline ParadisEO & $\mathrm{x}$ & & $\mathrm{x}$ & & & 2 \\
\hline jMetal & & $\mathrm{x}$ & $\mathrm{x}$ & $\mathrm{x}$ & $\mathrm{x}$ & 4 \\
\hline MOEAT & & $\mathrm{x}$ & $\mathrm{x}$ & $\mathrm{x}$ & & 3 \\
\hline NP-Opt & & $\mathrm{x}$ & & $\mathrm{x}$ & & 2 \\
\hline Open Beagle & & & & & $\mathrm{x}$ & 1 \\
\hline oMetah & & $\mathrm{x}$ & $\mathrm{x}$ & $\mathrm{x}$ & $\mathrm{x}$ & 4 \\
\hline METSlib & $\mathrm{x}$ & & & & & 1 \\
\hline EasyLocal++ & & $\mathrm{x}$ & & & & 1 \\
\hline FOM & $\mathrm{x}$ & $\mathrm{x}$ & $\mathrm{x}$ & $\mathrm{x}$ & & 4 \\
\hline GeFEOA & & & & & & 0 \\
\hline
\end{tabular}

Figura 5: Suporte global.

A Figura 6 apresenta as características C5 (Projeto, licenças e implementação) que se relaciona com as perguntas P7, P8 e P9. Observa-se em C5 qual a forma de licenciamento (Lic) do ambiente: livre/acadêmica (x) ou proprietária (_). Se é portável para vários sistemas operacionais (Sist) ou permite a implementação em mais de uma linguagem de programação (Ling). Se o ambiente promove o uso de boas práticas de engenharia de software (Eng). Por fim, é informado qual o número de classes que possui o framework avaliado. Os valores desconhecidos foram marcados com ( ), isto ocorreu quando o ambiente não disponibiliza acesso à sua documentação ou ao seu código on-line.

Todos os ambientes declararam o acesso livre/acadêmico para uso, exceto 3 que não foram deixados disponíveis para download e nada foi declarado na página web, documentação ou publicações. Apenas o jMetal permitiu seu uso em mais que uma linguagem de programação. 
O jMetal foi programado inicialmente em Java com uma versão em C++ e em C\# projetada posteriormente, porém se tratam de projetos separados e independentes.

\begin{tabular}{|l|c|c|c|c|c|c|}
\hline Frameworks & Lic. & Ling. & Sist. & Eng. & Tam. & $\mathrm{N}^{\mathbf{0}}$ \\
\hline ParadisEO & $\mathrm{x}$ & & $\mathrm{x}$ & & $\underline{579}$ & 3 \\
\hline jMetal & $\mathrm{x}$ & $\mathrm{x}$ & $\mathrm{x}$ & & 334 & 3 \\
\hline MOEAT & & & & & $\sim$ & 0 \\
\hline NP-Opt & $\mathrm{x}$ & & $\mathrm{x}$ & & 94 & 2 \\
\hline Open Beagle & $\mathrm{x}$ & & $\mathrm{x}$ & $\mathrm{x}$ & 277 & 3 \\
\hline oMetah & $\mathrm{x}$ & & $\mathrm{x}$ & & $\sim$ & 2 \\
\hline METSlib & $\mathrm{x}$ & & $\mathrm{x}$ & & 44 & 2 \\
\hline EasyLocal++ & & & $\mathrm{x}$ & & 78 & 1 \\
\hline FOM & $\mathrm{x}$ & & $\mathrm{x}$ & & 510 & 2 \\
\hline GeFEOA & & & & & $\sim$ & 0 \\
\hline
\end{tabular}

Figura 6: Projeto, licenças e implementação.

Apenas o Open Beagle definiu o uso de boas práticas de engenharia de software, utilizando o padrão de projeto Abstract Factory definido em [3]. O ParadisEO foi o ambiente que possuiu o maior número de classes. Logo, os melhores na área de Projeto, licenças e implementação foram: ParadisEO, jMetal e Open Beagle.

Por fim, para responder a pergunta P10 sobre qual seria o grau de maturidade e popularidade dos ambientes, foi definida a área C6 (Maturidade e popularidade, Figura 7) que atenta para a relevância (Rel) de suas aplicações, se possui documentação (Doc), tutorial (Tut) e página web para divulgação (Pág). Também foi avaliado em quantas publicações declaradas foi utilizado cada ambiente.

\begin{tabular}{|l|c|c|c|c|c|c|}
\hline Frameworks & Rel. & Doc. & Tut. & Pág. & Publ. & $\mathrm{N}^{\mathbf{0}}$ \\
\hline ParadisEO & $\mathrm{x}$ & $\mathrm{x}$ & $\mathrm{x}$ & $\mathrm{x}$ & $\underline{11}$ & 5 \\
\hline jMetal & $\mathrm{x}$ & $\mathrm{x}$ & $\mathrm{x}$ & $\mathrm{x}$ & 3 & 4 \\
\hline MOEAT & $\mathrm{x}$ & & & & 2 & 1 \\
\hline NP-Opt & $\mathrm{x}$ & $\mathrm{x}$ & $\mathrm{x}$ & & 5 & 3 \\
\hline Open Beagle & $\mathrm{x}$ & $\mathrm{x}$ & $\mathrm{x}$ & $\mathrm{x}$ & 1 & 4 \\
\hline oMetah & & & & $\mathrm{x}$ & 0 & 1 \\
\hline METSlib & & $\mathrm{x}$ & $\mathrm{x}$ & $\mathrm{x}$ & 0 & 3 \\
\hline EasyLocal++ & $\mathrm{x}$ & $\mathrm{x}$ & & $\mathrm{x}$ & 2 & 3 \\
\hline FOM & & $\mathrm{x}$ & & $\mathrm{x}$ & 1 & 2 \\
\hline GeFEOA & & & & & 1 & 0 \\
\hline
\end{tabular}

Figura 7: Maturidade e popularidade. 
Os ambientes melhor classificados foram ParadisEO, jMetal e Open Beagle. Tais ambientes foram utilizados e aplicados ao estudo de problemas e métodos de relevância (Rel), além de serem aplicados apenas em simples casos de teste. Também apresentaram documentação, tutorial e página web para divulgação. Os demais possuem sempre alguma destas características faltando. O ParadisEO é o que possui maior número de publicações.

A Figura 8 apresenta um resumo, constando para cada área quais os frameworks mais abrangentes, qual a porcentagem (\%) que eles conseguiram abranger de todos os itens daquela área. Pode-se perceber que todas as áreas permanecem incompletas, exceto a C6. As mais incompletas são Métodos e Problemas, pois os frameworks propostos não conseguem lidar com métodos e problemas muito variados. Para cada característica, foi definida também qual percentagem do total de 10 ambientes que conseguiram atender aquela característica. $\mathrm{Na}$ última coluna, são ordenadas até o $4^{\circ}$ nível quais as características mais raras: Mat, Oper e Fac $\rightarrow$ Heur, Exat, Hyper, Ling e Eng $\rightarrow$ Codif, Crit e Inter $\rightarrow$ Obj e Dist.

\begin{tabular}{|c|c|c|c|c|c|}
\hline \multicolumn{3}{|c|}{ Áreas } & \multicolumn{3}{|c|}{ Características } \\
\hline nome & $\%$ & mais abrangentes & símbolo & $\%$ & raras \\
\hline C1. Métodos & $\begin{array}{c}60 \\
40 \\
- \\
-\end{array}$ & $\begin{array}{c}\text { FOM } \\
\text { ParadisEO } \\
\text { NP-Opt } \\
\text { Metah }\end{array}$ & $\begin{array}{c}\text { BL } \\
\text { BP } \\
\text { Heur. } \\
\text { Mat. } \\
\text { Exat. }\end{array}$ & $\begin{array}{c}60 \\
70 \\
10 \\
0 \\
10\end{array}$ & $\begin{array}{l}2^{o} \\
1^{o} \\
2^{o}\end{array}$ \\
\hline C2. Problemas & $\begin{array}{c}60 \\
- \\
-\end{array}$ & $\begin{array}{c}\text { ParadisEO } \\
\text { jMetal } \\
\text { Open Beagle }\end{array}$ & $\begin{array}{c}\text { Codif. } \\
\text { Oper. } \\
\text { Obj. } \\
\text { Rest. } \\
\text { Fac. }\end{array}$ & $\begin{array}{c}30 \\
0 \\
40 \\
100 \\
0\end{array}$ & $\begin{array}{l}3^{\mathrm{o}} \\
1^{\mathrm{o}} \\
4^{\mathrm{o}} \\
1^{\mathrm{o}}\end{array}$ \\
\hline C3. Características avançadas & $\begin{array}{l}75 \\
-\end{array}$ & $\begin{array}{c}\text { ParadiEO } \\
\text { NP-Opt }\end{array}$ & $\begin{array}{c}\text { Hibri. } \\
\text { Hyper. } \\
\text { Paral. } \\
\text { Dist. }\end{array}$ & $\begin{array}{l}50 \\
10 \\
50 \\
40\end{array}$ & $\begin{array}{l}2^{\circ} \\
4^{o}\end{array}$ \\
\hline C4. Suporte global & $\begin{array}{c}80 \\
- \\
-\end{array}$ & $\begin{array}{c}\text { jMetal } \\
\text { oMetah } \\
\text { FOM }\end{array}$ & $\begin{array}{c}\text { Crit. } \\
\text { Batch } \\
\text { Est. } \\
\text { GUI } \\
\text { Inter. }\end{array}$ & $\begin{array}{l}30 \\
60 \\
50 \\
50 \\
30\end{array}$ & $3^{\circ}$ \\
\hline $\begin{array}{l}\text { C5. Projeto, licenças e } \\
\text { implementação }\end{array}$ & $\begin{array}{c}75 \\
- \\
50\end{array}$ & $\begin{array}{c}\text { jMetal } \\
\text { Open Beagle } \\
\text { ParadisEO }\end{array}$ & $\begin{array}{c}\text { Lic. } \\
\text { Ling. } \\
\text { Sist. } \\
\text { Eng. } \\
\text { Tam. }\end{array}$ & $\begin{array}{l}70 \\
10 \\
80 \\
10\end{array}$ & $\begin{array}{l}2^{\circ} \\
2^{\circ}\end{array}$ \\
\hline C6. Maturidade e popularidade & 100 & $\begin{array}{c}\text { ParadisEO } \\
\text { jMetal } \\
\text { Open Beagle }\end{array}$ & $\begin{array}{l}\text { Rel. } \\
\text { Doc. } \\
\text { Tut. } \\
\text { Pág. } \\
\text { Publ. }\end{array}$ & $\begin{array}{c}60 \\
70 \\
50 \\
70 \\
-\end{array}$ & \\
\hline
\end{tabular}

Figura 8: Resumo dos frameworks mais abrangentes e das características mais raras. 


\subsection{Conclusão}

Neste capítulo, foi apresentado e avaliado um conjunto com os principais frameworks de otimização disponíveis na literatura que mais se aproximam da proposta nesta dissertação. Uma adaptação dos mesmos critérios levantados em [59] foi descrita para comparar as características dos ambientes, onde no total de 29 características foram avaliadas e divididas nas seis áreas propostas em [59]. Esta avaliação mostrou que nenhum ambiente foi capaz de trabalhar com metaheurísticas, heurísticas específicas e métodos exatos em conjunto. Isso representa uma divisão na área C1 (Métodos), onde para projetar métodos de certos domínios de seria preciso utilizar um ambiente específico. Também apenas quatro frameworks definiam o projeto de ambos os tipos de metaheurísticas: buscas locais e baseadas em população.

Ao avaliar o domínio dos problemas que os ambientes eram capazes de resolver (área C2 Problemas), apenas três ambientes guiavam o usuário ao especializar suas próprias codificações e resolver problemas mono e multi-objetivos. Entretanto, nenhum ambiente guiava o usuário na implementação de novas classes de operadores, permitindo apenas as especializações dos operadores padrão: crossover, mutação e busca local. Também não definiam nenhuma forma de passos mais simples para implementar problemas específicos.

Nenhum ambiente avaliado conseguiu combinar todas as características avançadas mencionadas (área C3). Neste contexto, esta proposta deixará para trabalhos futuros a integração de todas estas características. Sendo que será trabalhado apenas o projeto de métodos híbridos, o uso de paralelismo e de distribuição de tarefas. Deixando hyperheurísticas como trabalho futuro. Somente três ambientes auxiliavam o usuário na definição de critérios de parada específicos. Aproximadamente metade dos frameworks gerenciavam a execução de um conjunto de testes, promoviam análise estatística dos resultados ou possuíam uma interface gráfica de uso. Havia também alguns poucos que interagiam com outros softwares, (área C4). Na área C5, apenas um framework permite projetar em duas linguagens de programação e apenas outro utilizava padrões de projeto no seu desenvolvimento. Quanto à maturidade e popularidade (área C6), apenas três frameworks conseguiram integrar todas as características desta área, possuindo documentação, tutorial, página web e sendo aplicados em problemas relevantes.

Conforme será apresentado nos capítulos subsequentes, neste projeto foram integradas todas as características das áreas C1 (métodos), C2 (problemas), C4 (suporte global), C5 (Projeto, licenças e implementação) e C6 (maturidade e popularidade). 


\section{CAPÍTULO 3}

\section{O ProOF}

"Não encontre defeitos, encontre soluções. Qualquer um sabe queixar-se."

Henry Ford

\subsection{Introdução}

O problema proposto neste projeto de mestrado é o desenvolvimento de um framework de otimização. Os desafios encontrados na construção deste framework serão detalhados neste capítulo. O ProOF é composto por quatro módulos principais: Server, Client, Slave, Abstract. A seção 3.2 apresenta uma visão geral destes quatro módulos, explicando como o usuário poderá interagir com a ferramenta proposta. A seção 3.3 descreve os detalhes no funcionamento dos módulos Client e Abstract e como estes permitem a criação de códigos em diferentes linguagens de programação. Na seção 3.4 é apresentado como o ProOF é capaz de gerar uma GUI automática para parametrização dos métodos inseridos pelo usuário. Na seção 3.5 é definida para o ProOF uma arquitetura abstrata o suficiente que permite a especialização de vários métodos e problemas, unindo as principais características encontradas em outros trabalhos conforme indicados no Capítulo 2. A seção 3.6 define como questões relacionadas à coesão e acoplamento de código são tratadas, visando guiar os usuários na implementação de métodos e resolução de problemas com alto reuso de códigos, fazendo assim o uso de boas práticas de engenharia de software. A seção 3.7 apresenta detalhes dos módulos Server e Slave que definem o ProOF como um sistema distribuído. Portanto, as seções 3.3, 3.4, 3.5, 3.6 e 3.7 buscam justificar cada uma das contribuições deste trabalho indicadas no Capítulo 1 desta dissertação. A conclusão deste capítulo segue na seção 3.8.

\subsection{Visão Geral}

O ProOF é um ambiente de programação que pretende facilitar o desenvolvimento de códigos para métodos e problemas de otimização. O objetivo é definir um conjunto de passos básicos que facilitem a implementação e reutilização dos códigos desenvolvidos. 
O ProOF também se encarregará de integrar um novo código desenvolvido com outros já implementados, compilar o código do usuário, fornecer uma interface básica de entrada de dados, fornecer um arquivo de saída com os principais resultados obtidos, entre outras funcionalidades. A interação do usuário com o ambiente poderá ocorrer algumas vezes tanto para a implementação de novos códigos quanto para utilização de funcionalidades existentes. A Figura 9 ilustra o processo geral de interação do usuário com o ambiente. Essa interação considera as relações estabelecidas entre os quatro módulos presentes no ProOF (Server, Client, Slave, Abstract) e o usuário (User) com seu projeto (Project).

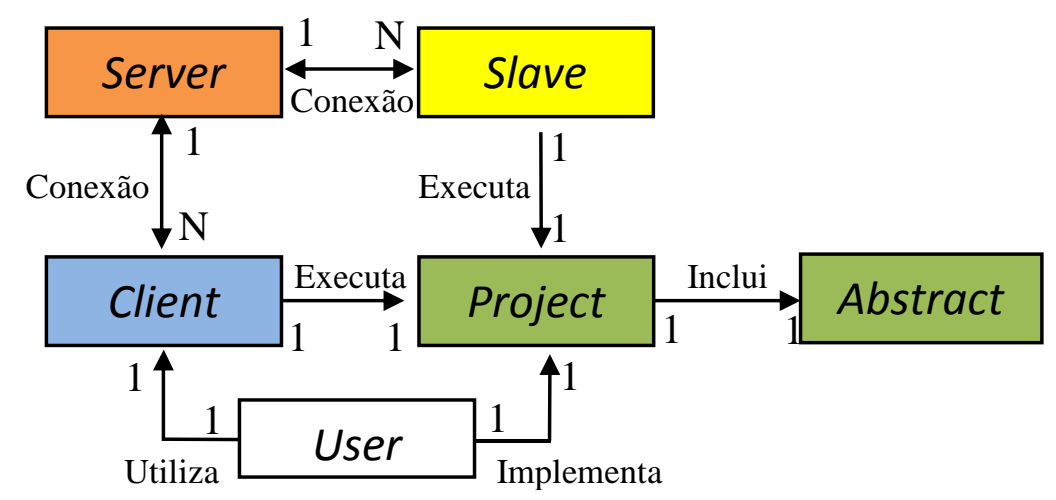

Figura 9: Processo geral de interação entre os módulos e o usuário.

Na Figura 10 está um fluxograma com os principais passos que o usuário deve seguir para utilizar o ProOF. Inicialmente, o usuário decide qual será a linguagem de programação utilizada. Em seguida, o usuário deverá implementar o seu código (Project) de acordo com passos previamente definidos pelo módulo Abstract. Tais passos permitem ao módulo Client se comunicar corretamente com os códigos desenvolvidos pelo usuário. Ao final da fase de implementação do código pelo usuário, o módulo Client registra a versão do código desenvolvido, realiza sua compilação e interpreta seus parâmetros. Após interpretar os parâmetros, o Client consegue gerar de forma automática uma GUI para obter valores para parâmetros de entrada do código do usuário.

Terminada a implementação, o usuário (User) definirá os testes computacionais utilizando o módulo Client. Esse módulo poderá executar diretamente o projeto (Project) ou repassar os testes para módulos Server e Slave via conexões em rede, ilustradas na Figura 10 pelas opções Localhost e Serverhost, respectivamente. Os módulos Server e Slave permitem que o ProOF seja um sistema distribuído. Trata-se de uma funcionalidade útil aos usuários que possuem diversos computadores à sua disposição. O módulo Server recebe tarefas de módulos Client e gerencia a distribuição das tarefas entre computadores que passam a executar o módulo Slave. 
Ao final, o módulo Server recupera os resultados oriundos dos diversos computadores e repassa para o módulo Client.

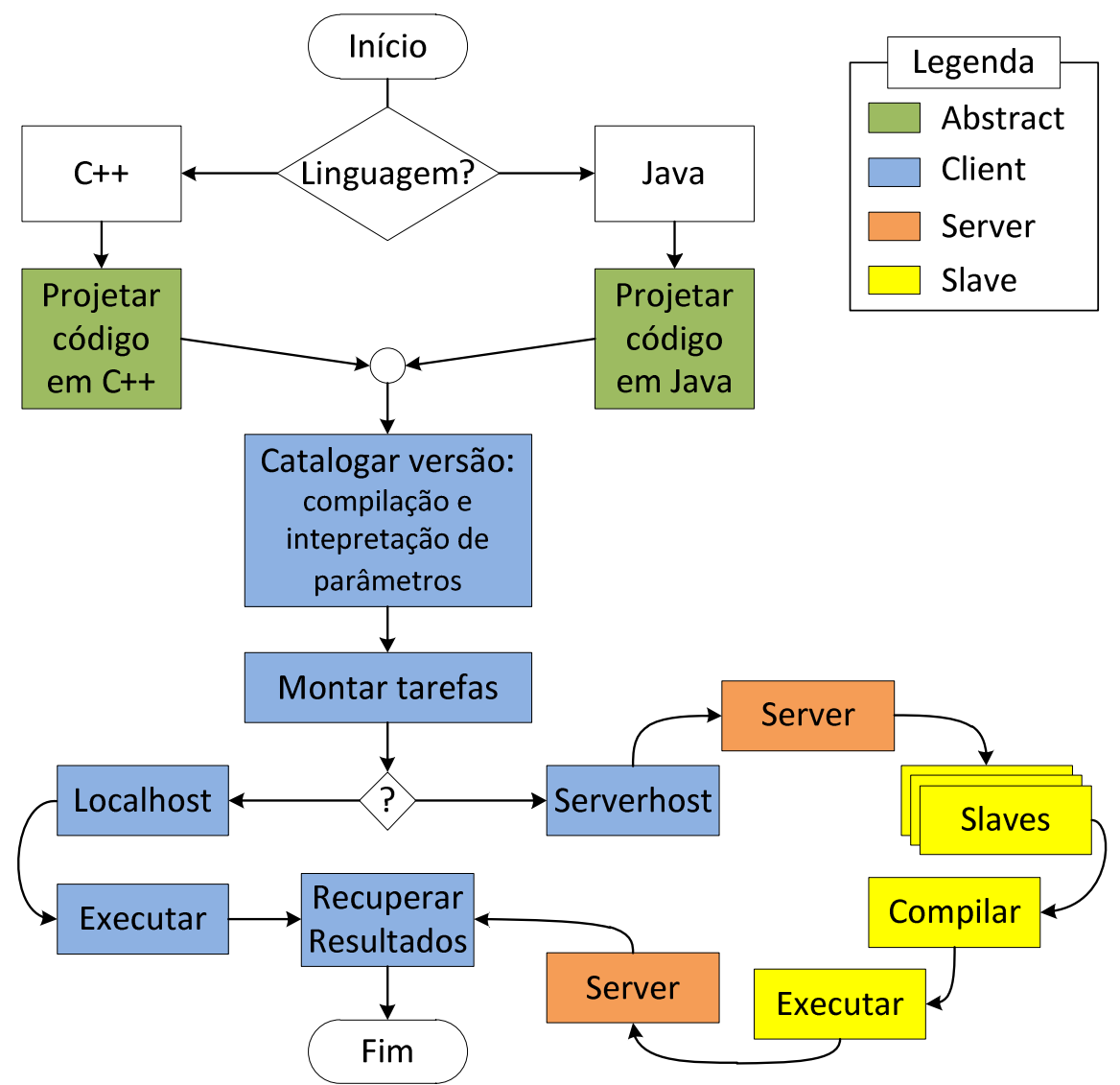

Figura 10: Fluxograma das principais decisões do usuário ao utilizar o ProOF.

O módulo Abstract será o único módulo em que o usuário deverá se guiar para realizar suas implementações. Este é composto por vários módulos distintos, onde cada um contém códigos implementados nas linguagens de programação suportadas pelo ProOF. Atualmente, o ProOF oferece suporte às linguagens de programação Java e $\mathrm{C}++$. Tais módulos são responsáveis por formatar os dados de entrada e saída do código desenvolvido pelo usuário de forma que possam ser interpretados pelo módulo Client. Logo, o módulo Abstract, independentemente da linguagem de programação utilizada, vai se comunicar da mesma maneira com o Client desenvolvido em Java. Outras linguagens poderão ser incorporadas ao ProOF bastando para isso implementar um novo módulo Abstract. O objetivo do módulo Abstract é estabelecer protocolos de comunicação com os demais módulos do ProOF que viabilizem a inclusão de códigos em outra linguagem de programação.

O Client permitirá que o usuário realize os testes computacionais de seu código, ajustando diferentes valores para os parâmetros de entrada e montando conjuntos distintos de configurações (tarefas) para execução do seu código. Logo, o módulo Client integra um 
código recentemente desenvolvido pelo usuário com outros já disponíveis. A GUI gerada nesse módulo exibirá todos os métodos e problemas que os usuários do ProOF tenham desenvolvidos até então, permitindo a montagem e execução de diverso tipos de métodos para diversos tipos de problema. Ao final das execuções, os resultados obtidos são recuperados pelo módulo Client e salvos.

Os módulos Server e Slave foram desenvolvidos com o objetivo de tornar o ProOF um sistema distribuído e serão detalhados na seção 3.7. Esses dois módulos permitem ao ProOF gerenciar a execução de várias tarefas em diversos computadores simultaneamente.

\subsection{Módulos Abstract e Client}

Quanto aos aspectos computacionais, o ProOF deverá suportar a geração de códigos em várias linguagens de programação, a começar por Java e C++ (Abstract), sendo também um sistema com interface gráfica, capaz de recuperar e armazenar os resultados automaticamente (Client). A Figura 11 ilustra a comunicação dos módulos Client e Abstract com o código do usuário. O módulo Client é formado por diversas classes em linguagem Java que já estão previamente implementadas no ProOF. Essas classes contêm métodos responsáveis por executar as seguintes tarefas:

- Copiar o projeto (Project) desenvolvido pelo usuário para dentro do framework. Tratase de um controlador simples de versão onde, a cada alteração realizada pelo usuário, uma cópia da versão mais recente é adicionada ao ambiente. Assim, o ProOF permite controlar o conjunto de versões de um mesmo método ou de um mesmo problema implementado pelo usuário.

- Compilar o código (Project) implementado pelo usuário. O ambiente oferece métodos capazes de realizar a compilação de acordo com a linguagem em que o usuário desenvolveu seu código.

- Interpretar os parâmetros de entrada e a saída do código desenvolvido pelo usuário. O ProOF consegue fornecer funcionalidades como uma interface básica para que o usuário realize a entrada de dados e a geração de um arquivo de saída contendo os principais resultados a serem avaliados.

- Executar o código do usuário independente da linguagem utilizada. Após executar o processo de compilação, o ambiente também oferece métodos capazes de realizar a execução do código. 
O Client irá se comunicar com os códigos desenvolvidos pelo usuário que estão escritos em determinada linguagem de programação. Essa comunicação é estabelecida através de uma interface definida por códigos pertencentes ao módulo Abstract. Há um módulo Abstract para cada linguagem de programação suportada pelo ProOF, ou seja, um módulo Abstract deve ser projetado para cada nova linguagem integrada ao ProOF. O objetivo do módulo Abstract é formatar adequadamente os parâmetros do código do usuário (Project) de tal forma que o módulo Client possa interagir com o mesmo.

O ambiente proposto suporta qualquer linguagem de programação que tenha um compilador ou interpretador e que permita a execução de seus serviços por chamadas ao sistema operacional. Os detalhes avançados de como projetar um módulo Abstract para uma nova linguagem não serão abordados neste texto. Essas informações podem ser obtidas em tutorial específico disponível na página web (http://lcrserver.icmc.usp.br/projects/release/wiki) do ProOF.

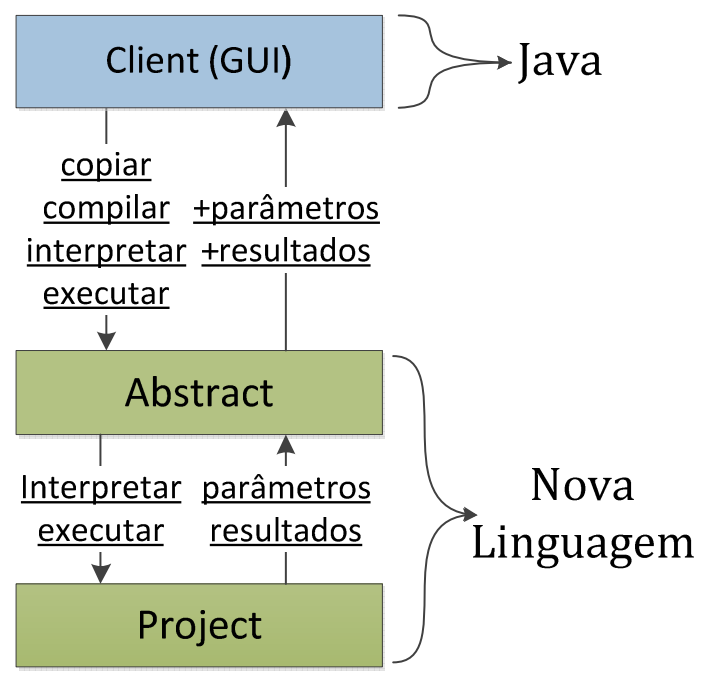

Figura 11: Arquitetura para adicionar uma nova linguagem de programação.

Na Figura 11, o código do usuário (Project) informa para o módulo Abstract os parâmetros necessários para sua execução e os valores dos resultados obtidos. Após o usuário definir em código os parâmetros de entrada e a saída de resultados, há métodos no módulo Abstract que realizarão a formatação desses parâmetros e resultados ilustrados pelo sinal + na Figura 11. Após sua formatação, os parâmetros poderão então ser manipulados pelo módulo Client. Essa formatação garante que as classes do módulo Client consigam executar suas funcionalidades independentemente da linguagem de programação utilizada pelo usuário. 
Além disso, uma vez mapeados esses parâmetros, os métodos do módulo Client conseguem criar uma interface automática para execução do código desenvolvido pelo usuário como detalhado na seção 3.4 .

\subsection{Interface Gráfica Automática}

Uma das principais funcionalidades do ProOF é a criação automática de uma Graphical User Interface (GUI) através das classes definidas em Client. Essa interface permitirá ao usuário montar tarefas que consistem na definição de parâmetros relativos a problemas e métodos implementados. A GUI será gerada da mesma forma, não importando qual seja a linguagem de programação usada para projetar o código do usuário. Isso foi viabilizado pela formatação dos parâmetros do código do usuário realizada pelas classes do módulo Abstract.

Uma dificuldade encontrada para gerar de forma automática uma GUI é a existência de dependência entre alguns parâmetros. A Figura 12 ilustra como tal dificuldade foi resolvida. Uma estrutura de dependências representada usando grafo foi proposta. Este grafo é definido por dois tipos de vértices, approach (cinza claro) e factory (cinza escuro), e três tipos de arestas: get, add e need.

Um vértice do tipo factory representa um construtor de classes diretamente relacionadas ao método ou problema implementado pelo usuário. Esse vértice ilustra o uso do padrão de projeto Factory Method [3] pelo ProOF que será detalhado na seção 3.6. Um vértice do tipo approach representa uma classe específica do método ou problema implementado que é criada por um vértice do tipo factory.

As arestas estabelecem as dependências existentes no código do usuário. Arestas get indicam uma solicitação que depende de um vértice factory para ser criada. Por exemplo, os valores (1) e (2) na Figura 12 indicam que o vértice approach GA solicita aos vértices do tipo factory (fProblem e fStop) que criem um problema (ACK ou TSP) e um critério de parada (Time ou Eval), respectivamente. O vértice Time é um componente capaz de reconhecer quando parar a execução por tempo e Eval representa parada por número de funções avaliadas, onde CountEval é um contador de funções avaliadas.

Arestas add indicam que o vértice de origem adiciona o vértice de chegada. Isso significa que a funcionalidade do vértice de chegada se torna disponível para outras abordagens (approachs) dentro do ProOF. Vértices do tipo factory sempre tornam disponíveis vértices do tipo approach. Um vértice do tipo approach pode adicionar outro vértice do tipo approach ou 
solicitar a um vértice factory que o faça. Os valores (3) e (4) sobre as arestas da Figura 12 ilustram isso. $\mathrm{O}$ valor (3) representa o vértice do tipo approach ACK solicitando a adição de outro vértice do tipo approach chamado CountEval. O valor (4) indica o mesmo vértice ACK agora solicitando ao vértice factory ACK-Cross que torne disponível todos os operadores de crossover existentes para o problema ACK.
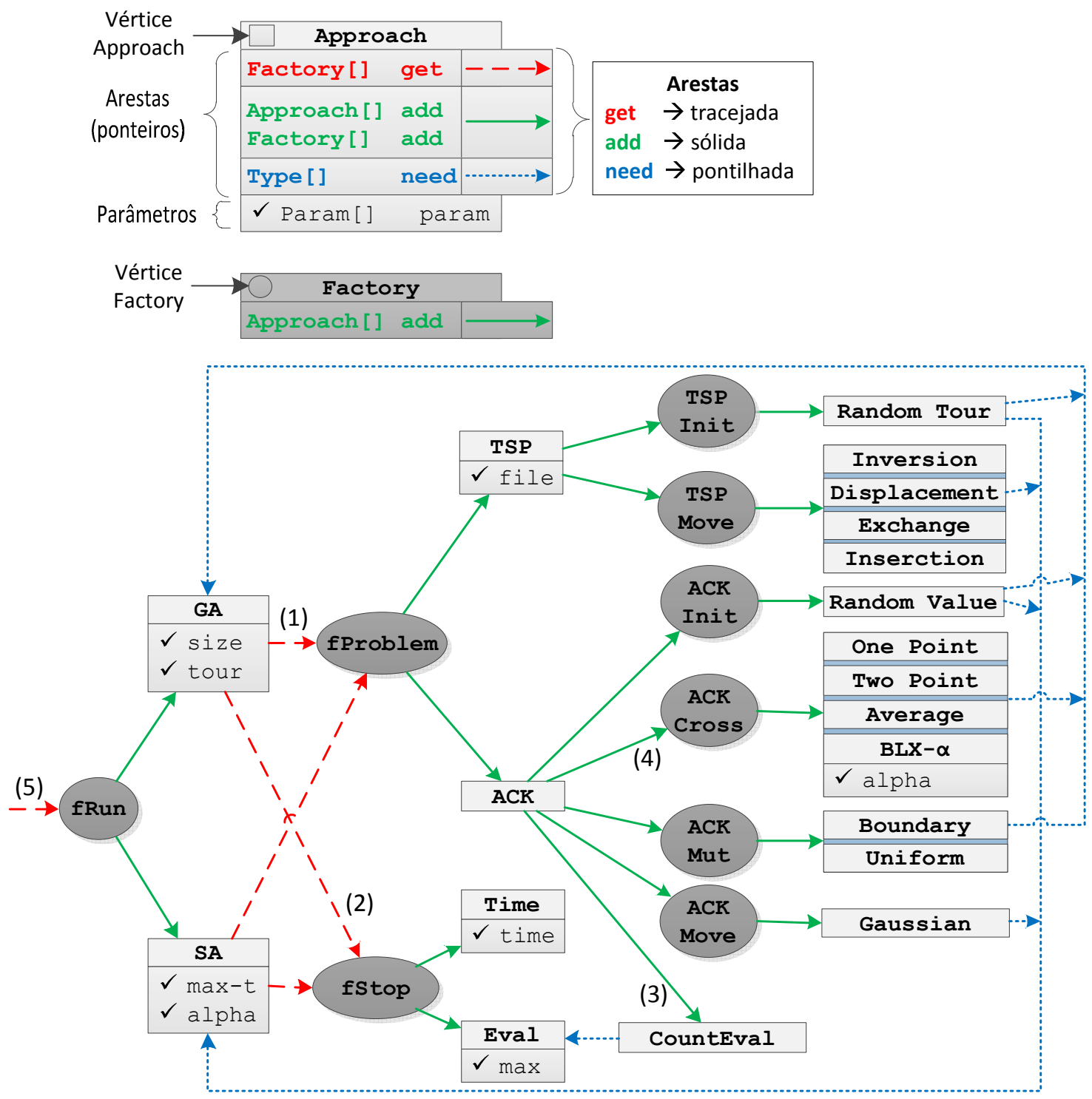

Figura 12: Grafo direcionado para interpretação dos parâmetros.

Arestas do tipo need representam dependências que passarão a existir em consequência das decisões tomadas pelo usuário nas etapas anteriores. Por exemplo, na Figura 12, o vértice approach GA necessitará agora de operadores de inicialização, crossover e mutação depois que um dos problemas ACK ou TSP foi escolhido pelo usuário.

Agora vamos ilustrar como o ProOF utiliza a estrutura de grafo descrita para gerar um GUI automaticamente. As arestas do tipo get serão inicialmente processadas. Na Figura 12, o 
grafo inicia este processamento pela aresta com valor (5) incidente ao vértice factory fRun. A partir deste processamento, o ProOF disponibilizará ao usuário a caixa de seleção Run como ilustrado na Figura 13. Os dois métodos GA e SA, disponibilizados pela factory fRun (arestas do tipo $a d d$ ), podem ser ajustados na caixa Run. O usuário deve definir um entre os dois métodos possíveis. Supondo que GA seja escolhido, as arestas do tipo get ligando GA aos dois vértices do tipo factory ( $\mathrm{EProblem} \mathrm{e} \mathrm{fStop)} \mathrm{são} \mathrm{então} \mathrm{processadas.} \mathrm{O} \mathrm{usuário} \mathrm{passa} \mathrm{a} \mathrm{ter}$ caixas de seleção Problem e Stop geradas como ilustrado na Figura 13. Assim, um dos problemas disponíveis (TSP ou ACK) e um dos critérios de parada (Time ou Eval) deverão ser escolhidos agora. Suponha que foram selecionados ACK e Time, respectivamente. Como os vértices ACK e Time não possuem outras arestas do tipo get, a primeira etapa do processamento para gerar a GUI termina como ilustrado na Figura 13.

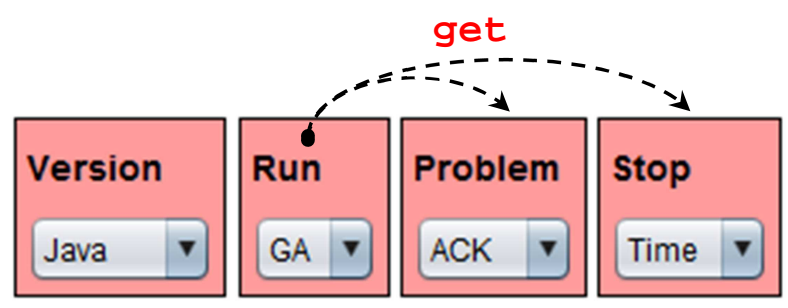

Figura 13: GUI após a primeira etapa (get).

$\mathrm{Na}$ segunda etapa, as arestas do tipo need passam a ser processadas. No exemplo, Figura 12, apenas arestas do tipo need incidem sobre o vértice GA escolhido. As arestas do tipo need incidentes no vértice SA não são processadas já que o método não foi selecionado. Neste momento, o usuário deverá escolher um dos operadores de crossover (One Point, Two Point, Average ou BLX- $\alpha$ ) e uma das mutações (Uniform ou Boundary) implementadas pelo usuário. Observe que o operador de inicialização (Random Value) é definido automaticamente uma vez que é a única opção de operador implementado.

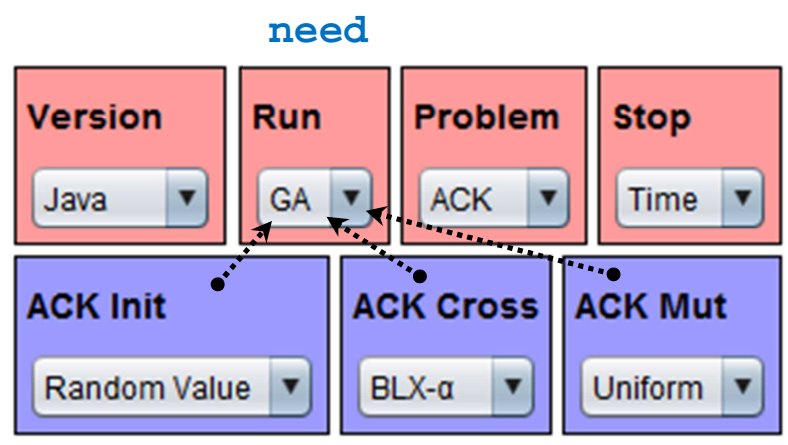

Figura 14: GUI após a segunda etapa (need).

Não há opção de escolha para o operador Gaussian visto que a aresta need saindo de Gaussian incide apenas em SA. Também não há possibilidade de escolha do operador de 
inicialização Random Tour para o problema TSP, pois, apesar de existir uma aresta need incidindo em GA, o fluxo de escolhas do usuário não ativou o vértice TSP. Logo, as escolhas são ativadas apenas para os vértices que estejam a jusante daqueles escolhidos pelo usuário na primeira etapa. Isso encerra a segunda etapa do processamento, gerando uma GUI conforme apresentada na Figura 14.

Numa terceira etapa, o procedimento vai processar os parâmetros individuais definidos em todos os vértices escolhidos ou ativados nas etapas anteriores. No exemplo, foram escolhidos os vértices GA, ACK, Time, BLX- $\alpha$, Uniform e Random Value, onde o vértice CountEval também foi ativado como consequência da ativação de ACK (conforme indicado pelo valor (3) na Figura 12). Logo, aparecerá na GUI os parâmetros size, tour, time e alpha para o usuário atribuir valores. A Figura 15 ilustra como ficará a GUI ao final desta etapa.

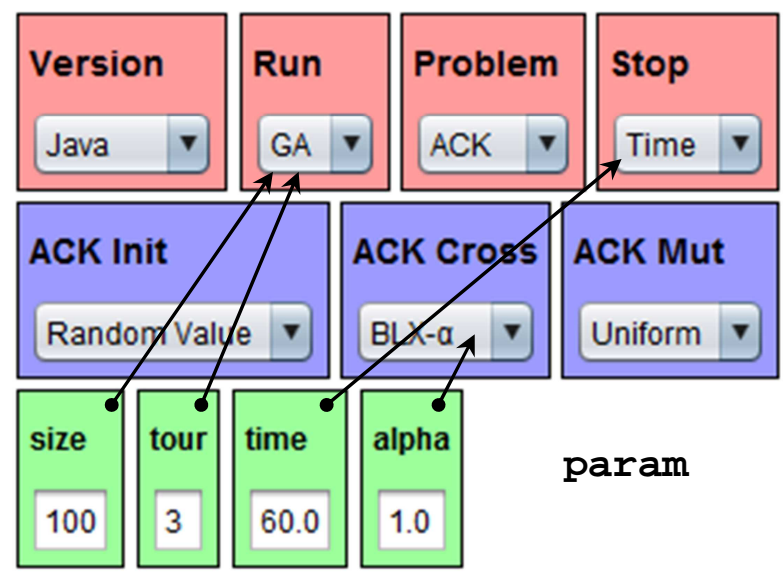

Figura 15: GUI após a terceira etapa (param).

O grafo de dependências também deixa claro o que não poderá ser selecionado pelo usuário. Partindo do exemplo da Figura 12, observa-se que o problema TSP não é um problema viável para ser resolvido pelo GA por não possuir os operadores de crossover e mutação desenvolvidos pelo usuário. Além disso, se o problema TSP for selecionado, então o critério de parada Eval não pode ser escolhido já que o problema ACK é o único que utiliza CountEval solicitado pelo critério de parada Eval. As combinações de métodos, problemas e critérios de parada válidos na Figura 12 estão sumarizadas na Figura 16. Há um total de cinco combinações, considerando a primeira etapa, onde a linha contínua na Figura 16 representa as escolhas ilustradas na GUI da Figura 13.

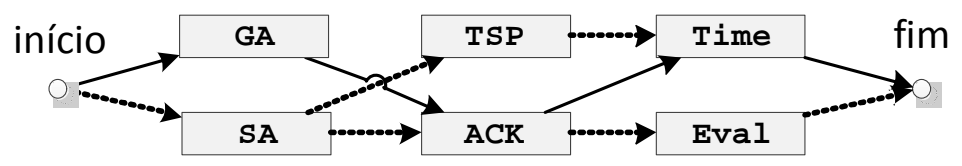

Figura 16: Possíveis caminhos nas escolhas do usuário durante a primeira etapa. 
Uma vantagem da representação em grafo é a modelagem das dependências de forma independente da linguagem de programação. Logo, o ProOF pode montar uma GUI para códigos projetados em qualquer linguagem desde que uma estrutura de dependências baseada neste grafo seja definida. Todavia, o grafo pode apresentar um crescimento considerável na sua complexidade dependendo da quantidade de relações existentes. O usuário pode adicionar códigos com o passar do tempo de forma que o grafo inicial precisará ser atualizado e manter o grafo atualizado manualmente pode se tornar complicado para o usuário. Por isso, o módulo Abstract é formado por classes que devem ser estabelecidas para cada linguagem de programação incorporada ao ProOF. Este módulo será responsável por criar e gerenciar este grafo de acordo com a especificidade de cada linguagem como será explicado na seção 3.5 a seguir.

\subsection{Arquitetura do Módulo Abstract}

O problema principal para construir o módulo Abstract está em incorporar ao uso do ProOF um nível de abstração que conduza com facilidade seus usuários durante o desenvolvimento de novos códigos. Tais códigos podem ser métodos exatos, heurísticos, metaheurísticos ou híbridos. Também deve ser possível a utilização dos métodos implementados no ProOF na solução de diferentes problemas de otimização.

Como dito anteriormente, há um módulo Abstract, responsável por estabelecer a interface com o módulo Client, para cada linguagem de programação incorporada ao ProOF. Atualmente, dois módulos Abstract estão implementados nas linguagens C++ e Java. Nesses casos, a mesma arquitetura orientada a objetos foi adotada para ambas as linguagens com o intuito de facilitar a inclusão de novos componentes e a reutilização daqueles existentes. Esta seção descreve em linhas gerais essa arquitetura. Também é apresentado como o usuário interage com essa arquitetura durante o desenvolvimento dos seus códigos.

O diagrama de classes UML (Unified Modeling Language) [60] para estes dois módulos Abstract é apresentado na Figura 17. A base desta arquitetura está nas classes Factory e Approach introduzidas como vértices no grafo de dependência na seção 3.4. Essas duas classes dão origem a um conjunto de classes filhas.

A classe Factory é uma abstração que será herdada pelas classes fProblem, fRun e fStop (Cinza escuro, Figura 17). De acordo com os conceitos apresentados na seção 3.4, as classes Factory representam um construtor de classes diretamente relacionadas ao método ou problema implementado pelo usuário. Essas classes instanciam classes Approach que 
serão classes específicas das abordagens implementadas. Classes Approach têm como filhas diretas Stop, Problem, operator e Run que por sua vez derivam outras classes filhas do tipo Approach. Por exemplo, se um usuário quer inserir um novo método como um GA, ele deverá criar uma classe pertencente à hierarquia da classe Metaheuristic, filha de Run, e modificar a classe do tipo factory fRun para instanciar a classe GA.

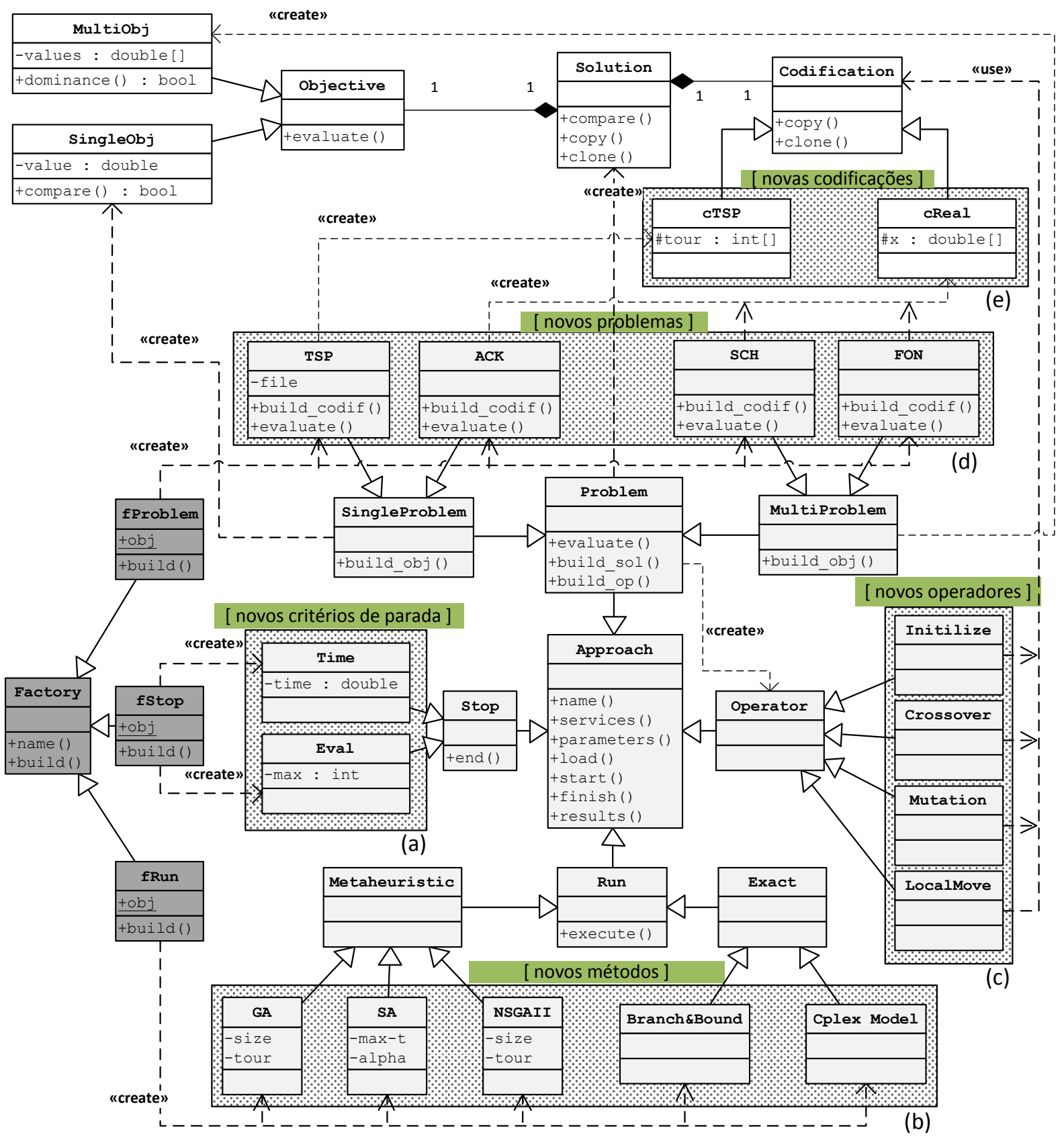

Figura 17: Diagrama de classes UML com a arquitetura do módulo Abstract.

Todas as classes filhas de Approach têm uma função membro services utilizada para estabelecer as ligações existentes com outras classes do tipo Approach e Factory. Isso 
significa que nesta função são realizadas as chamadas do tipo get, need e add conforme interpretação dos parâmetros descrita na seção 3.4 (Figura 12).

As demais funções membro de Approach são chamadas durante a etapa de execução do código na mesma ordem em que estão descritas. A função membro load é utilizada para carregar recursos demandados pelas classes do tipo Approach. Por exemplo, na Figura 12, temos a approach TSP que precisa carregar o arquivo file de determinada instância solicitada. A função start é chamada antes da execução de um método e a função finish é chamada ao final desta execução. Por exemplo, a função start pode iniciar contadores e algumas rotinas antes da execução de um método. A função finish pode ser usada para executar rotinas de pós-processamento deste método. Por fim a função results é utilizada para coletar os resultados obtidos.

As áreas (a)-(e) no diagrama da Figura 17 representam os pontos onde o usuário vai interagir ao projetar novos códigos. Ao projetar um problema deverá ser definida sua função objetivo (classe Objective), a representação da solução para este problema (classe Codification) e os operadores para esta representação (classe operator).

Vários problemas possuem a mesma representação permitindo o reaproveitamento de uma codificação existente. Por exemplo, os problemas $\mathrm{ACK}, \mathrm{SCH}$ e $\mathrm{FON}$ na Figura 17 utilizam o mesmo tipo de representação real definida em cReal assim como todos os operadores definidos para esta representação (Initialize, Crossover, Mutation e Local Move). Logo, um problema com uma nova representação para sua solução (problema TSP) demanda uma nova codificação, levando também a definição de novos operadores para manipular tal representação. Na Figura 17, os operadores utilizam (<<use>>) uma codificação onde o problema é responsável por criar $(<<$ create $>>)$ objetos para esta codificação e seus operadores.

Ao projetar um novo método, o usuário deverá especializar a função execute herdada da classe Run. Alguns métodos já disponibilizados no ProOF estão na Figura 17: GA, SA, NSGAII, Branch\&Bound e Cplex Model. Se um usuário desejasse incluir uma rotina que implementa e soluciona um modelo matemático usando o IBM ILOG CPLEX Optimization Studio [17], o código seria incluído como um método (Cplex Model). Este componente mapeia os parâmetros mais comuns ao solver CPLEX para um formato conhecido pelo ProOF. Isso permite disponibilizar automaticamente uma GUI intuitiva para parametrização do solver CPLEX no ProOF. 


\subsection{Reusabilidade dos Códigos}

Uma alta coesão e baixo acoplamento são fundamentais para criar códigos facilmente separáveis e independentes. A coesão representa o quão fortemente as classes no mesmo componente estão associadas e o acoplamento representa quão fortemente um componente interage com os outros. Tais métricas mensuram características de qualidade tais como reusabilidade e manutenibilidade [61]. Os projetistas precisam maximizar a coesão e minimizar o acoplamento. Esta tarefa se torna mais difícil à medida que um software evolui e aumenta a sua complexidade interna [62].

Essa alta coesão e baixo acoplamento estarão presentes no ProOF já que este framework irá tratar independentemente métodos e problemas. Trata-se de uma importante característica e um diferencial em relação a outros frameworks. Para isso, serão utilizados padrões de projeto para organizar separadamente os códigos de cada método e problema. Nesta seção, apresentaremos como os padrões de projeto Factory Method e Singleton foram utilizados para se atingir tal objetivo.

De acordo com [3], o padrão Factory Method define uma interface para criar objetos, deixando para as classes que implementam a interface decidir qual classe será instanciada. Isso permite a uma classe adiar a instanciação de subclasses. O uso deste padrão de projeto no ProOF é ilustrado na Figura 18. O padrão Singleton garante a existência de apenas uma instância de uma classe do tipo Factory, mantendo um ponto global de acesso ao seu objeto (obj). A classe do tipo Factory é chamada $(\langle<\mathrm{call}>>)$ por uma classe other para criar objetos concretos derivados do tipo Approach. O polimorfismo nas linguagens orientadas a objetos permite que a classe Other utilize $(\langle<$ use $>>)$ a abordagem abstrata para seu funcionamento interno.

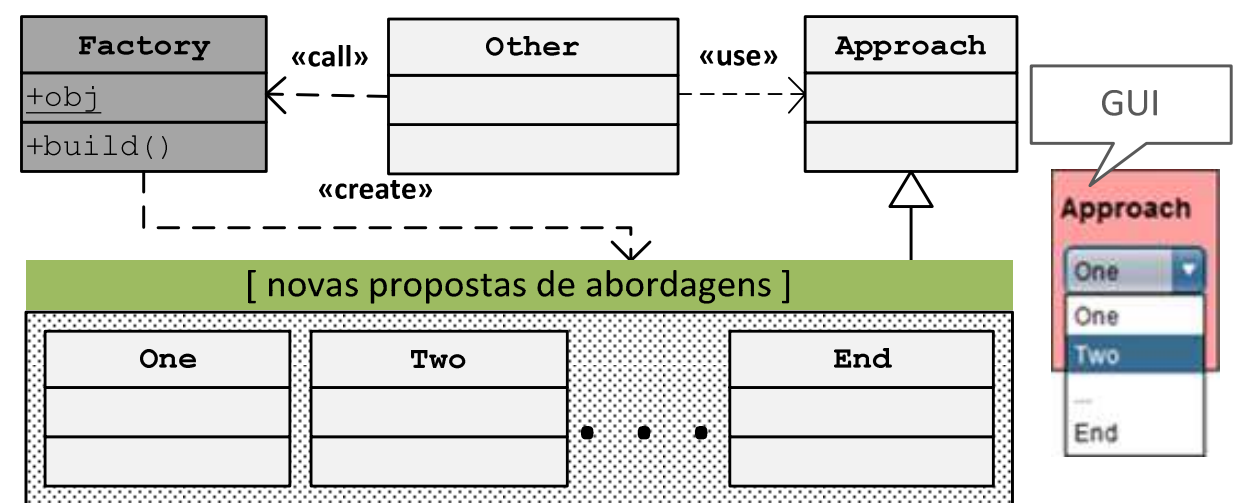

Figura 18: Padrões de Projeto - Factory Method e Singleton (FMS). 
A caixa de seleção à direita na Figura 18 mostra também que este padrão já define na GUI do ProOF uma forma do usuário escolher qual abordagem irá executar, sendo esta escolha a classe concreta utilizada para funcionamento interno da classe other.

A estrutura definida na Figura 18 será aqui chamada de FMS (Factory Method and Singleton), sendo implementada da mesma forma nas linguagens $\mathrm{C}++$ e Java. Todas as classes derivadas de Factory na Figura 17 da seção 3.5 implementam os padrões de projeto Factory Method e Singleton (estrutura FMS). As classes fProblem, fStop, fRun possuem um único objeto estático (obj) definindo o padrão Singleton e são responsáveis por criar (função build) novos objetos derivados de Problem, Stop, e Run, respectivamente, definindo assim o padrão Factory Method.

Nos Capítulos 4 e 5 será mostrado como novas estruturas FMS podem ser incorporadas ao ProOF, além de como o uso do padrão Factory Method foi aplicado proporcionando a ferramenta maior flexibilidade e manutenibilidade, facilitando a extensão dos códigos bem como seu reuso.

\subsection{Sistema Distribuído}

Outra característica importante do ProOF envolve as funcionalidades relativas ao módulo Server. O módulo Server é configurado em um servidor conectado à internet, permitindo o envio e a execução de tarefas em qualquer local que esteja compartilhando com o usuário seus recursos, via conexão de rede. A Figura 19 ilustra o processo de compartilhamento de recursos. Assim, as aplicações que compõem o ProOF devem ser portáveis, tendo seu uso focado para sistemas com base em Windows e Linux., permitindo assim que o sistema todo funcione em computadores heterogêneos com arquiteturas e sistemas operacionais diferentes.

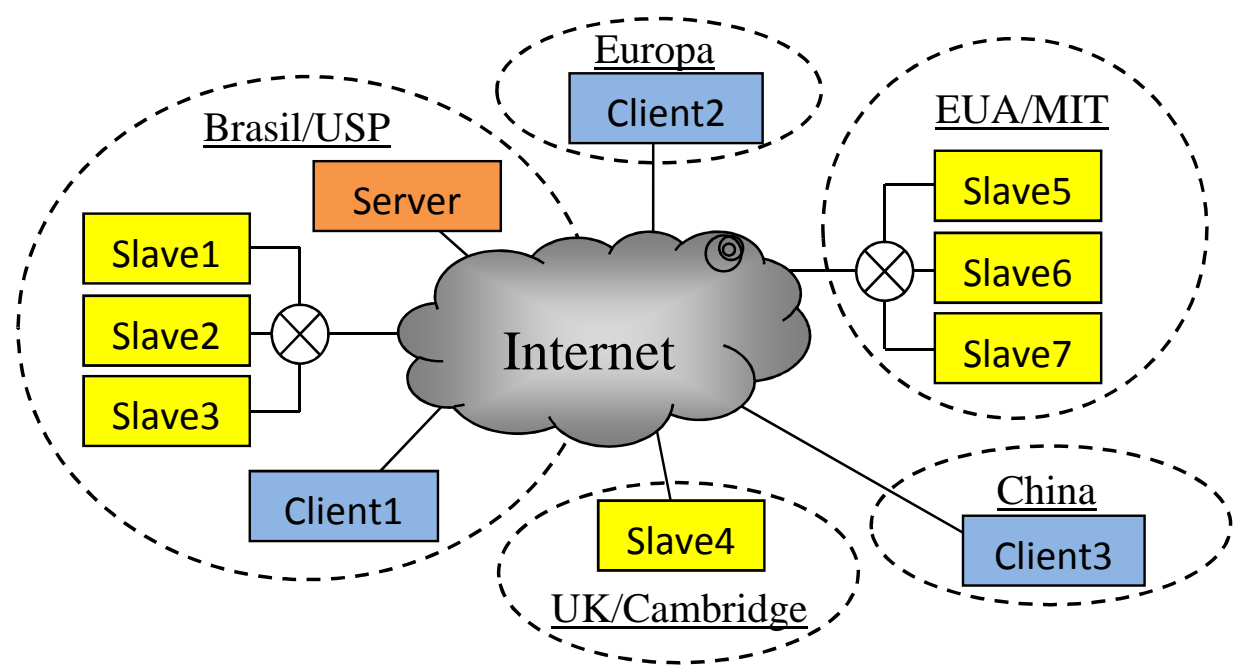

Figura 19: Esquema de compartilhamento de recursos. 
Portanto, os detalhes sobre o funcionamento do ProOF como um sistema distribuído e como é o compartilhamento dos recursos computacionais são apresentados nesta seção. $\mathrm{Na}$ seção 3.2 foi descrita uma visão geral sobre o funcionamento do ProOF, onde na Figura 10 o usuário, após montar um conjunto de tarefas para execução, podia escolher executar seu código em modo LocalHost ou ServerHost. A opção ServerHost é utilizada no ProOF para distribuir o código do usuário e as tarefas montadas para um conjunto de computadores.

Os módulos Client, Server e Slave utilizam conexão de rede para se comunicarem. A Figura 20 descreve a forma como o módulo Client estabelece esta comunicação com o módulo Server através de um diagrama de estados. Logo, após iniciar a execução do módulo Client (ponto escuro) a execução é dividida (barra vertical) em duas threads. A primeira fica responsável por receber e encaminhar as tarefas (task) do usuário que chegam via ServerHost. A segunda irá estabelecer a conexão e Login com o módulo Server e tratará das trocas de informações com o servidor. Para isto, este thread mantém na memória três listas de tarefas. Uma lista guarda as tarefas que estão esperando para ser enviada ao servidor (W waiting), enquanto outra lista temporária (T) armazena as tarefas que já foram enviadas pra o servidor, mas ainda não foi retornada uma confirmação de que a tarefa foi aceita por um módulo Slave. Por último, há uma lista para as tarefas que já estão escalonadas em um módulo Slave e estão marcadas para execução (E). Qualquer tarefa sempre vai passar pelas três listas na ordem descrita, terminando na última lista. Isto foi definido para permitir um tratamento robusto da distribuição das tarefas, evitando as falhas comuns como: compilador não está instalado para a linguagem do código, o código possui erros de compilação, o código do usuário não é compatível com a arquitetura do computador Slave, ocorre perda de conexão com o servidor.

Além disso, a execução continua distribuída mesmo com a perda da conexão de rede. Assim quando a lista de execução (E) estiver completa com todas as tarefas, W e T estarão vazias e o Client pode fechar a conexão de rede. Isso ocorre já que todas as tarefas foram enviadas para o servidor e o servidor também já escalonou para os seus escravos. Caso a conexão de internet seja perdida entre o servidor e os clientes, ou entre o servidor e os escravos, as execuções continuam até o término. Assim se o usuário (Client) havia determinado um grande número de testes que, por exemplo levando vários dias para terminar, este envia as tarefas ao servidor e depois de confirmar o envio, o computador com o Client pode ser desligado. Isso permite voltar a fazer uma conexão mais adiante para recuperar os resultados quando as tarefas já tiverem sido executadas. 


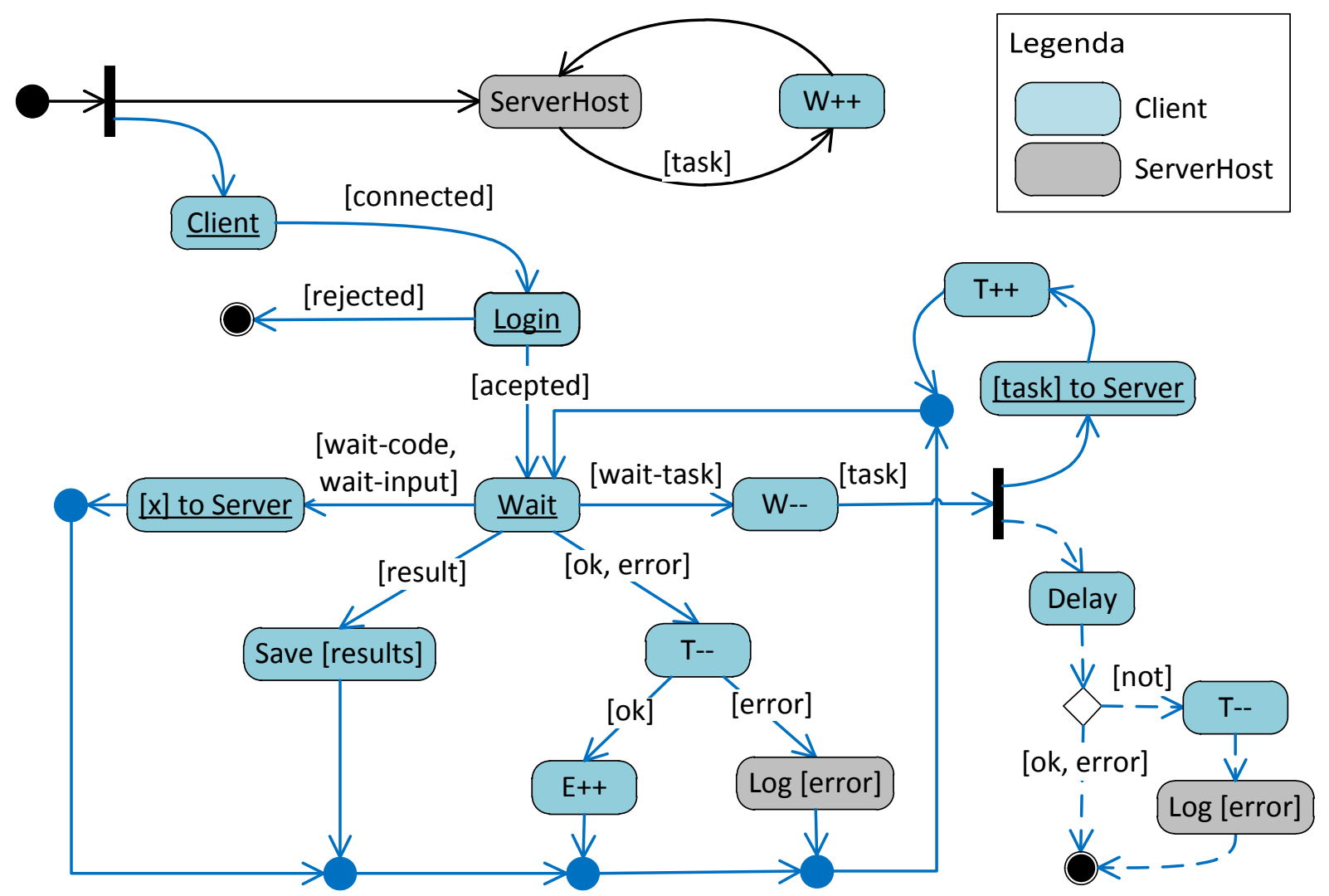

Figura 20: Diagrama de estados do módulo Client.

Analisando a Figura 20, vemos que a segunda thread fica esperando (Wait) uma resposta do servidor após efetuar o Login. O servidor vai informar que está esperando por novas tarefas [wait-task]. Neste momento, o Client remove a tarefa da lista de espera (W--), envia para o servidor, adiciona na lista temporária $(\mathrm{T}++)$ e volta ao estado (Wait). Se um [ok] for recebido, a tarefa vai para a lista de execução indicando que a situação está normal. Caso ocorra algum problema [error], a tarefa será descartada e registrada em um Log de erro. Se nenhum retorno do servidor ocorrer, após um tempo de espera (Delay), será considerado que houve um erro e a tarefa também será descartada e um Log de erro é informado ao usuário. $\mathrm{O}$ usuário deverá verificar e corrigir o erro fazendo uma nova tentativa de envio das tarefas com erro, onde a causa dos erros será indicada no Log. Caso o servidor ainda não tenha a versão do código do usuário para execução daquela tarefa, este fará uma solicitação [wait-code] e o Client enviará o código para o servidor automaticamente. Se uma tarefa utiliza um arquivo de entrada como instância, este também será envidado para o servidor [wait-input], pois para executar aquela determinada tarefa será preciso deste arquivo de entrada. Ao final da execução, o servidor enviará os resultados [result] ao Client que os salvará.

A Figura 21 apresenta o diagrama de estados do módulo Server. O módulo Server gerência a conexão com vários Clients e vários Slaves ao mesmo tempo, possibilitando o 
compartilhamento dos recursos computacionais por todos os Clients. Para este projeto foi definido uma política simples de usabilidade deste sistema, onde as tarefas serão escalonadas como uma fila (a primeira a chegar é a primeira a ser atribuída a um Slave). Melhoras nesta política de escalonamento são deixadas como trabalho futuro.
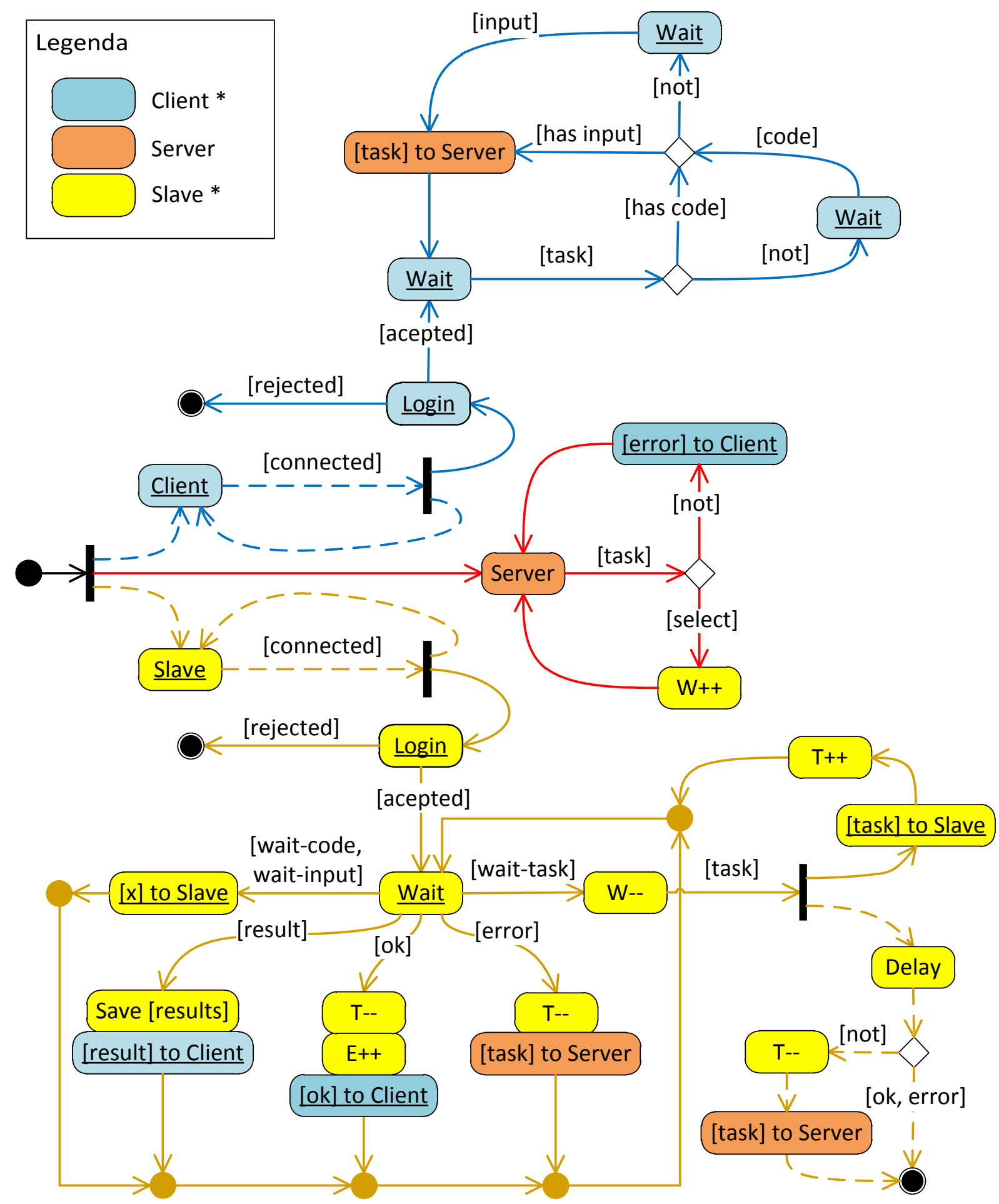

Figura 21: Diagrama de estados do módulo Server.

Ainda na Figura 21, a execução é dividida em três threads ao iniciar o diagrama, uma (Server) vai tratar como será o escalonamento das tarefas e as outras duas (client e 
Slave) vão gerenciar as conexões com vários módulos Clients e Slaves, respectivamente. Quando um módulo Client se conecta ao servidor é criada uma nova thread para gerenciar esta comunicação e realizado um Login. Há um thread no servidor para cada módulo Client e Slave conectado. Após o Login a thread esta esperando (Wait) por tarefas envidas pelo módulo Client e, após o envio de uma tarefa para esta thread, é verificado se já existe aquela versão do código no servidor e, caso não exista, este é solicitado ao Client e a thread entrará em mais um estado de espera (Wait). Após chegar o código, é verificado de forma semelhante se a instância está disponível. Quando todos os requisitos para execução daquela tarefa estão no servido, esta é enviada para ser escalonada na thread Server.

A thread Server vai selecionar e adicionar a tarefa na lista de espera $(\mathrm{W}++)$ de um dos escravos. Caso nenhum escravo possa ser selecionado, um erro será reportado ao Client que enviou aquela tarefa. Os motivos mais comuns para isto ocorrer são: não existe nenhum escravo conectado ao servidor naquele momento, nenhum escravo possui os requisitos de recursos computacionais para a execução daquela tarefa (CPU, RAM, HD, no de núcleos), existem erros de compilação no código do usuário em que a tarefa seria executada.

Continuando na Figura 21, cada thread que gerência a conexão com um módulo Slave é semelhante ao definido anteriormente para a aplicação Client (Figura 20). Inicialmente esta thread estará em espera (Wait), onde a tarefa é removida da lista de espera (W--), após ser informada que o Slave está a espera de novas tarefas [wait-task], enviada para o Slave e adicionada na lista temporária $(\mathrm{T}++)$, votando ao estado de espera. Se o Slave retornar um [ok], a tarefa vai para a lista de execução e um [ok] é retornado ao Client que enviou aquela tarefa. Se ocorrer um erro ou o servidor ficar sem resposta do Slave, a tarefa é envida de volta para ser escalonada (Server) em outro Slave. Se a tarefa já passou por todos os Slaves e nenhum a aceitou, um [error] é enviado ao Client. Caso o Slave não tenha disponível a versão do código ou a entrada para a execução da tarefa, este fará uma solicitação [wait-code] ou [wait-input], respectivamente, e o código ou a entrada será enviado imediatamente para aquele Slave, visto que o código ou a entrada já está disponível no servidor. Para uma tarefa chegar a esta etapa, ela já passou pelo escalonador e, antes de chegar ali, o servidor já solicitou ao Client que lhe seja enviado o código e a entrada. Por fim, quando os resultados chegarem, eles serão enviados ao Client.

A Figura 22 ilustra os estados que podem assumir o módulo Slave, considerando sua comunicação com o módulo Server. Após o início da execução, o módulo Slave é dividido em 
duas threads, Slave e Run, aonde a primeira vai se conectar ao servidor e terminando por esperar (Wait) o envido de tarefas pelo servidor. De uma forma muito semelhante à comunicação do servidor com o Client, aqui também a thread Slave vai verificar se o código e a entrada já estão disponíveis. Caso o código não esteja disponível, será solicitado ao servidor que o envie e, após esta etapa, o código é compilado para a arquitetura do computador em que o Slave está. Nesta etapa, erros de compilação podem ocorrer, se por qualquer motivo o código mostrar-se inválido para este Slave. Assim, um erro é reportado para o servidor e a tarefa é ignorada pelo Slave que voltará a esperar por mais tarefas. Entretanto, se o código estiver validado e a entrada estiver disponível, então a tarefa será envida para execução na outra thread (Run).

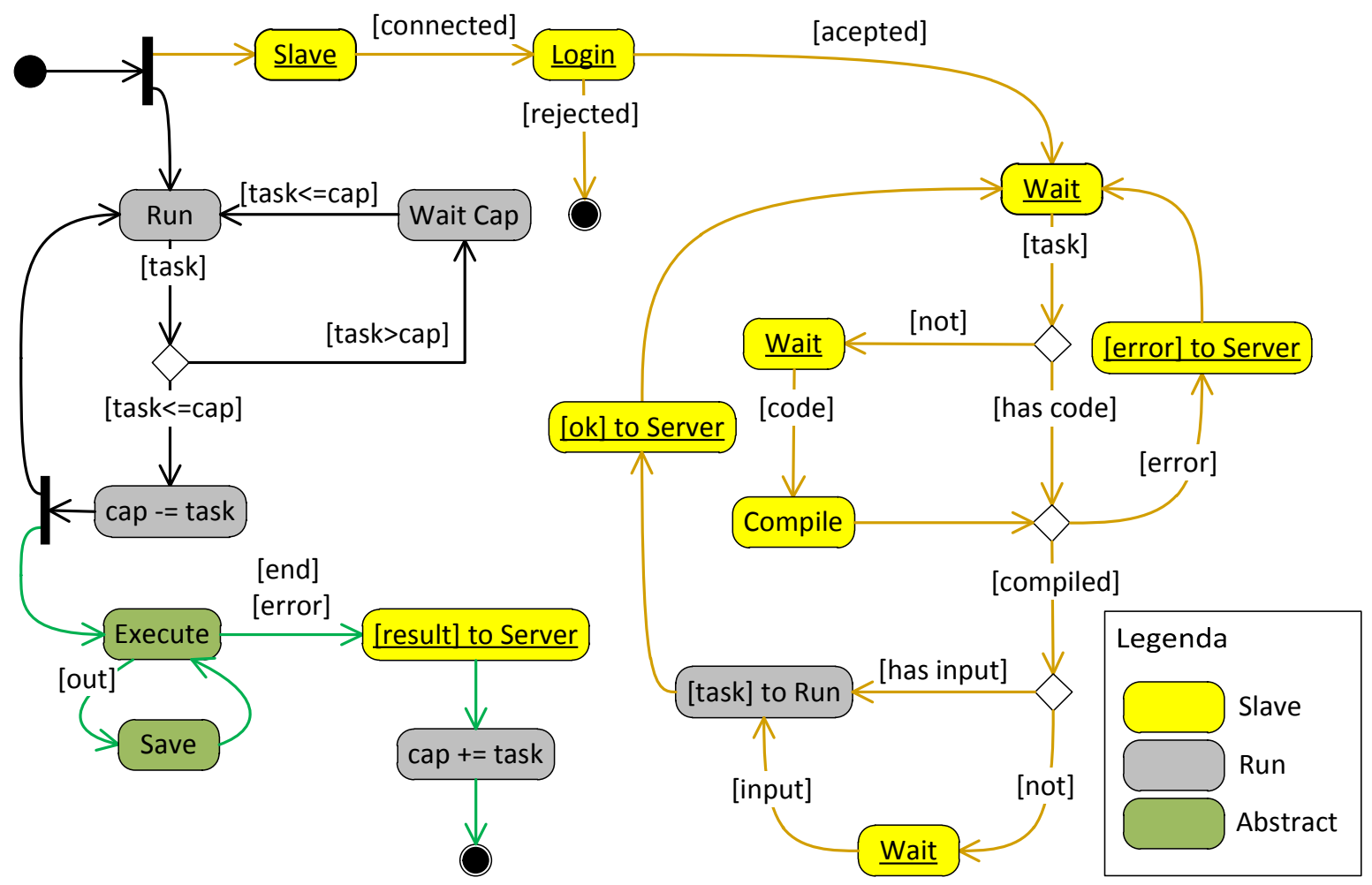

Figura 22: Diagrama de estados do módulo Slave.

A thread Run sempre estará executando independentemente de haver conexão com o servidor ou não, assim, caso a conexão seja perdida, esta continuará a executar as tarefas que lhe foram atribuídas. Uma vez que atualmente muitos computadores possuem várias unidades de processamento (núcleos), esta arquitetura também se beneficiará do processamento paralelo. Assim, para cada tarefa é associado alguns recursos ou capacidade (cap) que esta consumirá do computador como: quantos núcleos aquela tarefa vai utilizar e memória consumida. Como uma precondição, todas as tarefas enviadas do servidor a um Slave já utilizam uma capacidade menor ou igual a disponível naquele Slave, e o Slave inicia sua 
execução com toda sua capacidade (cap) disponível para uso. Sendo assim, quando chegar a primeira tarefa, a capacidade será reduzida (cap - = task) e será definida uma thread para executar (Execute) a tarefa do usuário. Quando a thread Run voltar a solicitar a próxima tarefa e, se esta consumir menos que a capacidade remanescente, mais threads serão criadas para executar esta tarefa em paralelo com as outras já em execução. Caso não tenha capacidade, a Run vai esperar pela disponibilidade de capacidade. Quando a execução (Execute) de uma tarefa terminar, os resultados serão enviados para o servidor e a capacidade será restaurada (cap $+=$ task).

\subsection{Conclusão}

Neste capítulo foram apresentados os quatro módulos que compõem o ProOF e os principais desafios enfrentados para a sua construção, explicando como o usuário poderá interagir com a ferramenta e descrevendo em detalhes como o ambiente permite a criação de códigos em diferentes linguagens de programação. Também foi apresentado como o ProOF é capaz de gerar uma GUI automática para parametrização dos métodos inseridos pelo usuário, além de definir uma arquitetura abstrata que vai permitir a especialização de métodos e problemas de otimização variados. Uma estrutura chamada FMS foi definida para o ProOF que será utilizada para guiar os usuários na implementação de métodos e resolução de problemas com alto reuso de código. Por fim, os módulos Server e Slave definem o ProOF como um sistema distribuído capaz de receber tarefas de vários usuários em conjunto e distribuir estas para um conjunto de computadores. O próximo capítulo apresentará como a arquitetura abstrata, a estrutura FMS e a parametrização automática serão utilizadas para especialização de vários métodos e problemas como estudo de caso. 


\section{CAPÍTULO 4}

\section{Utilizando o ProOF}

"A tecnologia mais necessária para evolução do nosso mundo, se chama: simplicidade."

Di Medeiros

\subsection{Introdução}

Neste capítulo serão apresentados os passos necessários para incluir no ProOF métodos e problemas com características variadas. Todos os métodos e problemas aqui descritos já estão implementados na ferramenta. Atualmente o ProOF fornece suporte a duas linguagens de programação, $\mathrm{C}++$ e Java, e os passos descritos são os mesmos em ambas as linguagens. Os passos para a implementação dos métodos e problemas ilustrados neste capítulo foram definidos com o uso de pseudocódigos, entretanto a implementação diretamente em linguagem de programação pode ser encontrada no tutorial da ferramenta ou visualizando diretamente os códigos disponíveis no site do ProOF [63].

A seção 4.2 descreve como ter acesso a ProOF e realizar sua instalação. Na seção 4.3, é apresentado como incluir um genetic algorithm (GA) no ambiente e na seção 4.4 são definidos os passos necessários para incluir o problema TSP e para especializá-lo para o GA. A seção 4.5 propõe uma estrutura FMS para facilitar os passos quando se deseja incluir problemas usando apenas variáveis reais. Isso é ilustrado utilizando a função ACK. Para demonstrar que o ProOF pode trabalhar com problemas multi-objetivo, o algoritmo NSGA-II e uma função multi-objetivo são implementados nas seções 4.6 e 4.7 , respectivamente. $\mathrm{Na}$ seção 4.8 é apresentada uma extensão da abstração proposta no capítulo anterior, onde tal extensão vai ser utilizada para incluir no ProOF o método exato Branch \& Bound. Na seção 4.9 é ilustrado como especializar o TSP para ser resolvido pelo Branch \&Bound e na seção 4.10 é proposta uma simples heurística gulosa para resolver o problema TSP. A seção 4.11 descreve a utilização do ProOF com sua interface gráfica para montar e executar um conjunto de tarefas. Na seção 4.12, encontram-se as conclusões deste capítulo. 


\subsection{Download e Instalação do Ambiente}

Antes de iniciar a implementação dos passos para incluir métodos e problemas no ProOF, o usuário precisará baixar e instalar o ambiente em seu computador. A última versão do ProOF está disponível em http://lcrserver.icmc.usp.br/projects/release/wiki/. Na página web estão os detalhes dos requisitos de sistema para instalação e também disponíveis tutoriais específicos para programar no ProOF usando as linguagem C++ e Java Uma vez que tanto o ambiente quanto o site do ProOF poderão sofrer atualizações futuras, este texto não definirá os detalhes de como realizar o download e instalação do ambiente. Logo as instruções de download e instalação do ambiente devem obtidas diretamente do site. Abaixo seguem apenas as informações relevantes para tornar este texto autocontido.

No geral é preciso baixar o módulo Client que está projetado em Java e o módulo Abstract para a linguagem em que o usuário deseja projetar novos códigos, C++ ou Java. Futuramente novas linguagens poderão estar disponíveis. Em seguida o usuário deverá criar seu próprio projeto de desenvolvimento utilizando uma IDE (Integrated Development Environment) de sua preferência e importar os códigos do módulo Abstract para seu projeto de forma similar a importação de uma biblioteca de códigos qualquer. Por fim estará apto a iniciar a implementação dos métodos e problemas.

\subsection{Método Mono-Objetivo: Genetic Algorithm}

Nesta seção, serão descritos os passos necessários para inclusão no ambiente de um GA (Genetic Algorithm). Este método foi adaptado de [31] e está disponível no ambiente, onde a implementação representa o mesmo GA ilustrado nas Figura 12-Figura 17 do Capítulo 3. Suponha que este GA será utilizado para resolver algum problema ainda não especificado. A Figura 23 ilustra o pseudocódigo do método que será implementado, onde claramente não está imposta nenhuma definição específica do problema a ser resolvido.

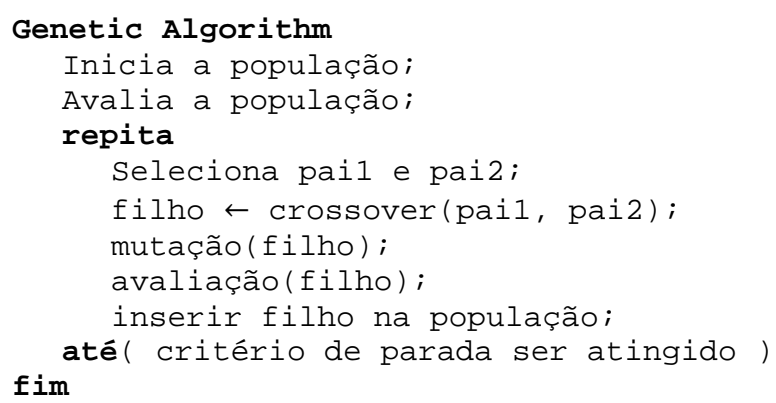

Figura 23: Pseudocódigo de um GA simples. 
O primeiro passo para o usuário inserir um novo método do tipo metaheurística no ProOF é criar uma nova classe que será especializada a partir da classe MetaHeuristic. Em seguida, dentro da nova classe haverá mais quatro passos: especializar as funções membro name, services, parameters e execute. A Figura 24 indica como fica a estrutura do método GA inserido no ambiente. Na linha 10, está a execução do segundo passo, onde o nome definido será o mesmo que ficará apresentado na interface gráfica (GUI) conforme ilustrado na Figura 13 do Capítulo 3.

O terceiro passo será a vinculação de um problema, um critério de parada e dos operadores que o método irá utilizar. Para isto, o usuário declara no escopo da classe criada que haverá um problema, um critério de parada e operadores com os quais seu método irá trabalhar, como descrito nas linhas 2 - 6 na Figura 24. A especialização da função membro services permitirá fazer os pedidos para o ProOF que envolvem escolhas do usuário na GUI (linhas 12 - 18 na Figura 24). A função get é utilizada para selecionar um problema do conjunto de problemas disponíveis em fProblem, linha 13. Como a função get recebe diretamente uma referência ao objeto que contém todos os problemas já adicionados ao ambiente (Problems.obj), o ProOF consegue saber entre quais problemas escolher. De forma semelhante, a função get é utilizada para selecionar um critério de parada (stop) de um conjunto de critérios de parada adicionados anteriormente ao ambiente (Stops.obj), linha 14. Sempre deverá ser informado para a função get um objeto do tipo Factory para que o ProOF consiga saber entre quais opções escolher.

A função need neste exemplo é utilizada para selecionar um dos operadores. Esta função trabalha de forma implícita, pois não é informado para ela onde está a Factory que contém os operadores de inicialização, crossover e mutação. Isto ocorre porque cada operador poderá ser implementado de forma diferente para cada problema tratado. Uma representação da solução (codificação) é estabelecida para cada tipo de problema a ser solucionado. Os operadores manipulam as codificações dos problemas. Logo, só é possível escolher os operadores após a escolha de um problema. Utilizando uma estrutura de grafo, conforme apresentado anteriormente na Figura 12, o ProOF conhece a relação entre operadores e problemas. Isso permite tratar de todos estes detalhes automaticamente e retornar ao método os operadores corretos para o problema a ser solucionado. Ainda no terceiro passo, Figura 24 , foi requisitado operadores de inicialização, crossover e mutação, por isso, utilizou-se a função need e foi declarado objetos para armazenar a inicialização (init), o crossover (cross) e a mutação (mut) no escopo da classe, linhas $4-6$. 
Ao utilizar estas funções (get e need) seguindo o exemplo anterior, o usuário conseguirá que a interface gráfica do ProOF disponibilize uma caixa de seleção. Nesta caixa de seleção, será escolhido primeiro um dos problemas referenciados e, em seguida, uma segunda caixa de seleção permitirá ao usuário escolher qual critério de parada utilizar. Por último, caixas de seleção permitirão escolher operadores de inicialização, crossover e mutação. As Figura 13 e Figura 14, no Capítulo 3, ilustraram isto.

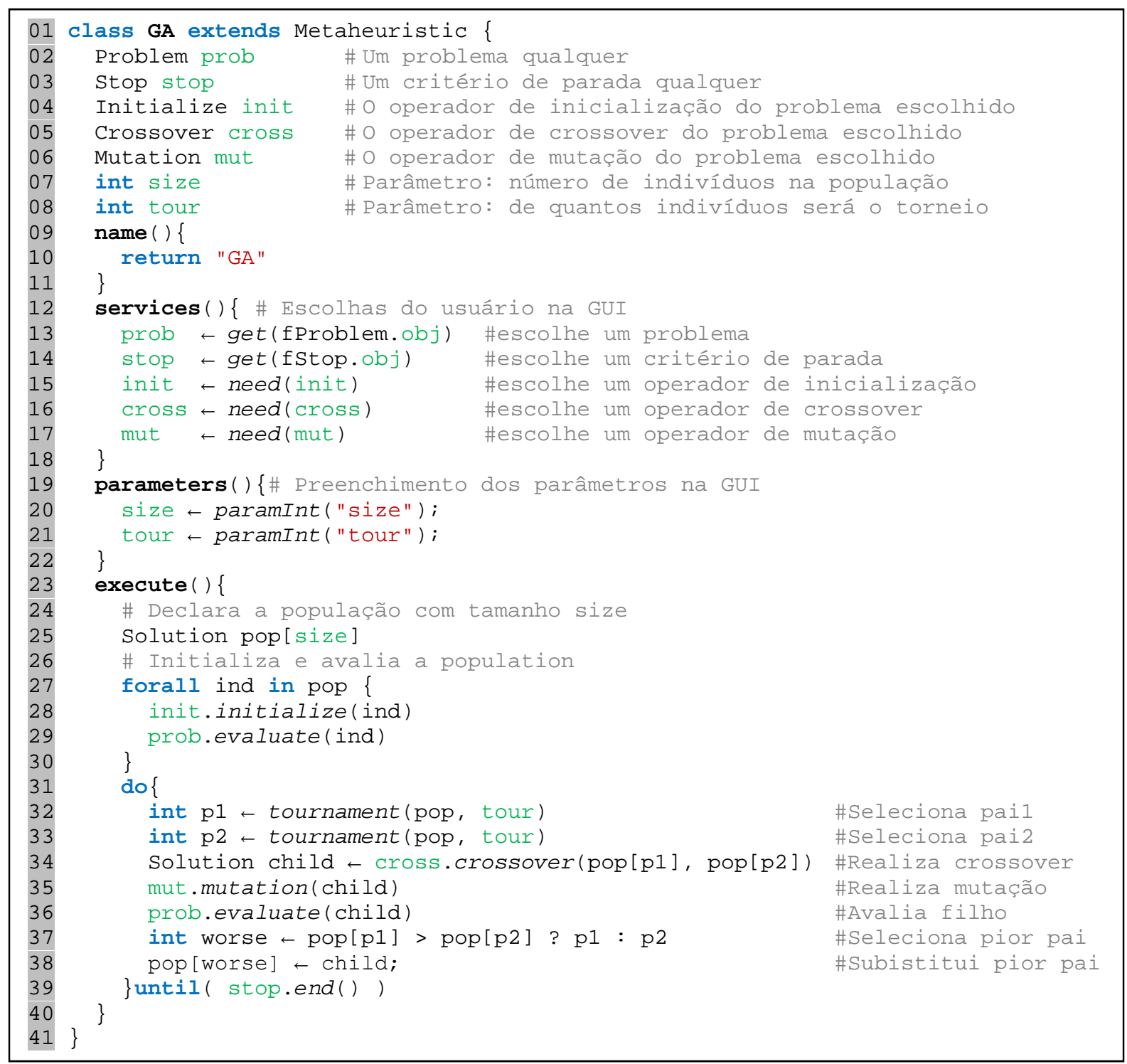

Figura 24: Método Genetic Algorithm no ProOF.

Para o quarto passo será definido os parâmetros do método. Sendo assim, suponha que o usuário decidiu que seu método utilizaria seleção por torneio. Ele decidiu também que haverá dois parâmetros de entrada para configurar seu método: tamanho da população (size) e tamanho da seleção (tour). Esses parâmetros podem ser definidos na interface gráfica automaticamente gerada pelo ProOF. Logo, o quarto passo será como o usuário utilizará o ambiente para a definição destes parâmetros. O usuário deverá declarar os dois parâmetros no 
escopo da sua classe, linhas 7 - 8. E em seguida, sobrescrever a função membro parameters herdada de MetaHeuristic. A Figura 24, linhas 19 - 22, mostra como ficou a função membro parameters com o uso do quarto passo.

Dentro da função membro parameters foram utilizadas funções já disponibilizadas pelo ProOF para obtenção dos parâmetros de entrada. O nome passado como argumento para a função (paramInt) será o nome utilizado na caixa de preenchimento disponível na GUI do ProOF, a Figura 15 no Capítulo 3 ilustra isto. O retorno desta função será o valor escolhido na interface gráfica. Outros valores que o usuário pode solicitar ao ProOF são: Long, Float e String, podendo também solicitar arquivos e expressões regulares.

O quinto passo será a implementação propriamente dita do método dentro do ambiente. $\mathrm{O}$ usuário poderá ou não utilizar as funcionalidades já incluídas no ambiente como seleção por torneio e roleta. O usuário poderá também utilizar qualquer biblioteca ou qualquer código desenvolvido por ele anteriormente para auxiliar na implementação do seu método.

Prosseguindo com o quinto passo, o usuário deve especializar a função membro execute e dentro dela projetar o código do seu método, linhas 23 - 40 na Figura 24. No início da execução, linha 25, é alocada na memória uma população de soluções de tamanho size. Todos os indivíduos são inicializados e avaliados nas linhas 27 - 30. Então, a evolução do algoritmo começa com a seleção de dois pais (linhas 32 e 33), em seguida é criado um filho utilizando crossover (linha 34) e aplicado mutação sobre ele (linha 35). A linha 36 avalia o filho gerado.

A minimização da função objetivo foi adotada para este GA, onde o filho é inserido no lugar do pior pai (linhas 37 e 38) após a comparação entre p1 e p2 ser realizada. O ProOF disponibiliza um conjunto de operações para comparação do valor de duas soluções como: maior que, maior ou igual a, igual a, menor ou igual a, menor que. Por fim, a linha 39 verifica se o critério de parada foi atingido.

Após a implementação do método, o sexto e último passo a ser seguido consiste em adicionar o novo método ao conjunto de métodos do ambiente. Para isto, deve-se modificar a classe do tipo Factory (fRun), acrescentando uma instância da classe GA (linha 9 da Figura 25). A fim de ilustrar melhor, este exemplo considera que já existe outro método no ambiente, na linha 8 o Simulated Annealing (SA) adaptado de [32] já está disponível no ambiente. O algoritmo genético será então o segundo método incluído no ambiente. 


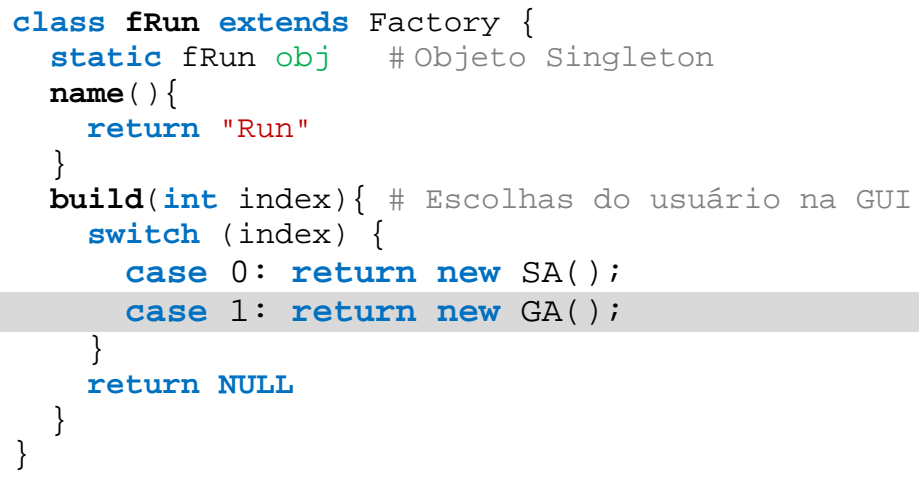

Figura 25: Modificando a classe fRun.

Um aspecto importante na inclusão de um método, como o GA criado, é a capacidade de ser reutilizável. Observe que em momento algum o GA foi vinculado ou conhece o problema a ser solucionado. Assim, a mesma implementação de um método será capaz de resolver vários problemas. Essa característica ficará mais clara a seguir quando forem incluídos novos problemas nas seções 4.4 e 4.5 .

Devido ao reaproveitamento do componente Stop (critério de parada presente nas linhas 3, 14 e 39 da Figura 24), o ProOF deixará disponível três critérios de parada já implementados para serem utilizados: tempo de execução, número de avaliações e tempo com corte. Estes três critérios de parada foram utilizados em três trabalhos publicados: [29], [26] e [30], respectivamente. Caso não seja reaproveitado um critério de parada já definido no ProOF, o usuário poderá controlar a parada do seu método no próprio código.

Resumindo, a inclusão de um método do tipo metaheurística requer a execução dos seguintes passos:

$1^{\circ}$ Passo: criar uma nova classe especializada a partir da classe MetaHeuristic.

$\mathbf{2}^{\circ}$ Passo: definir um nome para o método especializando a função membro name.

$3^{0}$ Passo: especializar a função membro services herdada de MetaHeuristic e nela realizar a vinculação do problema e dos operadores para o método.

$4^{\mathbf{o}}$ Passo: definir os parâmetros do método especializando a função membro parameters herdada de MetaHeuristic.

$5^{\circ}$ Passo: implementar o código do método dentro da função membro execute herdada de MetaHeuristic.

$6^{\circ}$ Passo: modificar a classe do tipo Factory ( $f$ Run) para adicionar o novo método ao conjunto de métodos do ambiente. 
Observe que a inclusão de um método requer a especialização de quatro funções dentro de uma única classe criada pelo usuário. Neste processo, o usuário consegue definir a entrada de parâmetros, utilizando a interface gráfica fornecida pelo ProOF, e implementar o código do método. Após isso, um ajuste na classe fRun permite que o método seja adicionado ao ambiente.

De forma semelhante ao demonstrado com o GA, é possível incluir outros tipos de métodos metaheurísticos, heurísticos e exatos. Também é possível a combinação de métodos no ambiente, onde alguns trabalhos publicados, [26], [28] e [30], mostram essa possibilidade, conforme será apresentado no Capítulo 5. Um algoritmo genético multi-populacional combinado com redes neurais artificiais foi utilizado em [26]. Uma adaptação do mesmo algoritmo genético multi-populacional foi utilizada em [30] e [28], onde no primeiro trabalho o algoritmo foi combinado com uma heurística gulosa construída especificamente para o problema e com a metaheurística Simulated Annealing. No segundo trabalho, o mesmo algoritmo genético foi combinado com um método exato disponível no solver IBM ILOG CPLEX 12.2.

\subsection{Especializando o Caixeiro Viajante para o GA}

Agora um novo problema será incluído no ambiente: Traveling Salesman Problem (TSP) ou Problema do Caixeiro Viajante [36]. Suponha que os dados necessários para solucionar determinada instância ou exemplar do TSP estão armazenados em um arquivo. Dada as características do problema, tal arquivo conterá uma matriz de adjacência que informa os custos das viagens entre as cidades. A Figura 26 mostra um exemplo deste arquivo considerando cinco cidades.

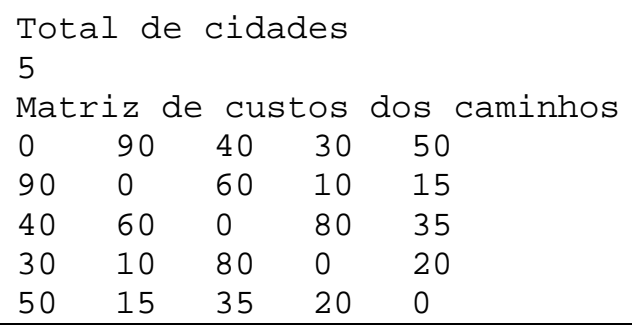

Figura 26: Exemplo de arquivo de entrada para o TSP.

O primeiro passo para inserir o problema no ProOF será a implementação de uma classe para ler e armazenar as informações do arquivo de entrada. Para isso, será necessária a criação de uma nova classe, aqui chamada de TSP Instance, herdada da classe Approach, onde será 
implementado o código para permitir a leitura do arquivo de instância do problema. A Figura 27 descreve como ficará o código da classe TSP Instance.

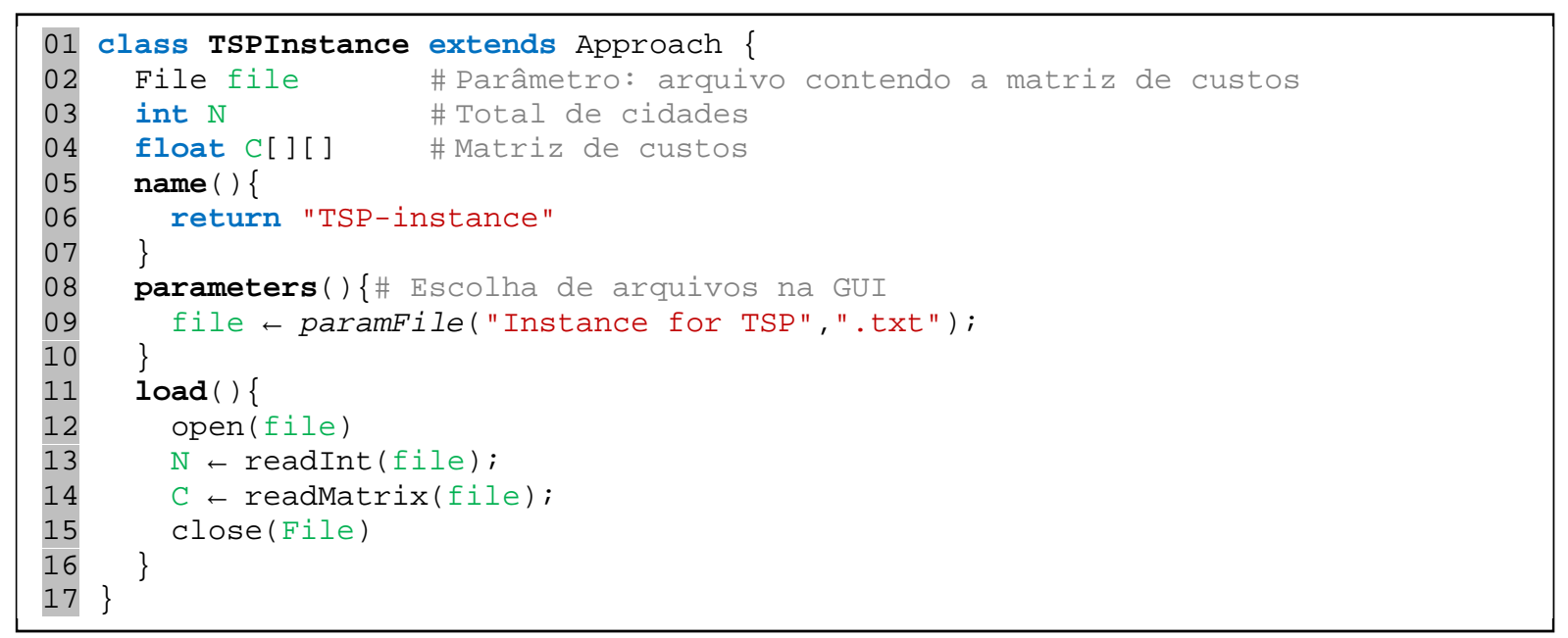

Figura 27: Classe para leitura de arquivo e armazenamento de instâncias do TSP.

O parâmetro file declarado na linha 2 é iniciado na linha 9 através de uma solicitação ao ProOF. Desta forma, o ambiente criará na interface gráfica uma opção para o usuário escolher os arquivos de instância do problema a serem solucionados. Observe que o usuário define a extensão (" . txt") dentro do método paramFile e também informa um nome que aparecerá na GUI ("Instance for TSP"). A Figura 28 ilustra como ficará esta parte da interface gráfica. Na linha 6, o usuário informa o nome que deseja dar a este componente. A função membro load é chamada pelo ProOF antes do início da execução dos métodos e é utilizada aqui para ler e armazenar os dados do problema que serão utilizados durante a execução.

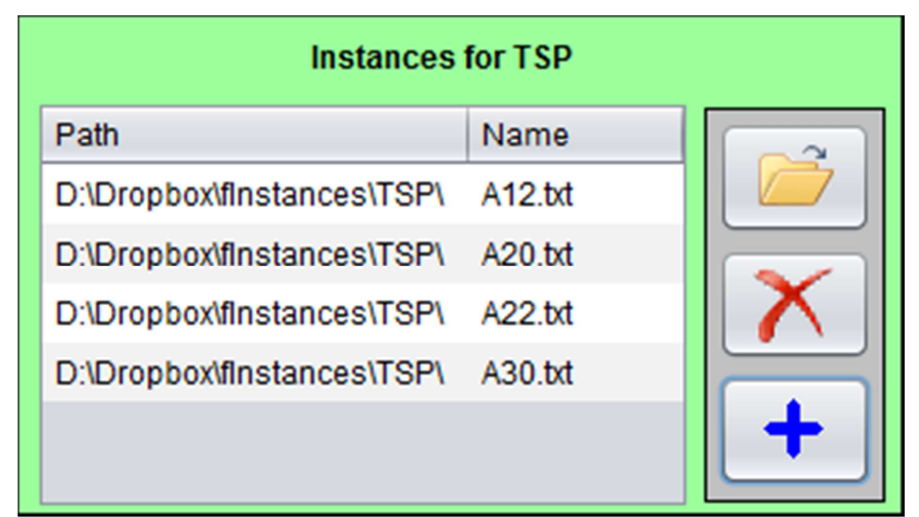

Figura 28: GUI montada pela solicitação do arquivo para o TSP.

O segundo passo é criar uma classe que representará uma solução do problema. Suponha que o usuário definiu que uma solução do problema será representada como um vetor de valores inteiros contendo os índices das cidades percorridas pelo caixeiro. Logo, a representação da solução (codificação) será uma permutação de $\mathrm{N}$ elementos do conjunto [0 . . N-1] . A Figura 29 exemplifica uma solução dado os custos definidos na Figura 26. 


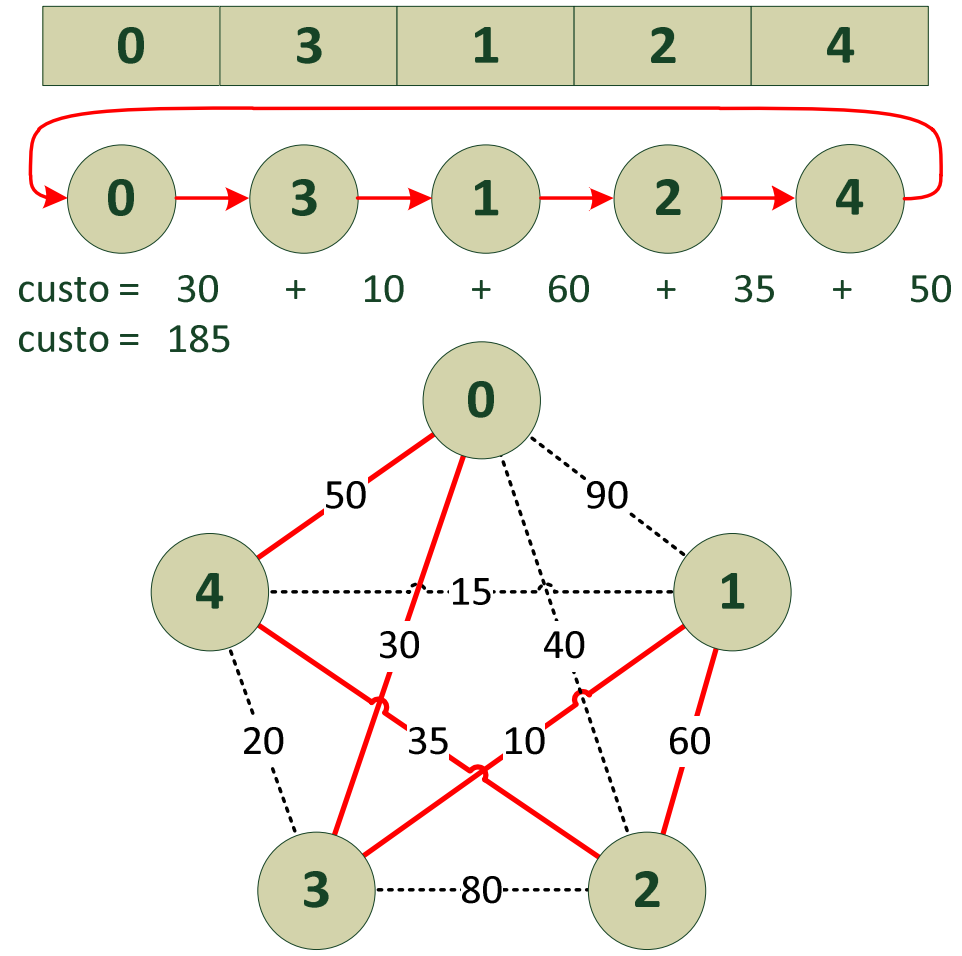

Figura 29: Exemplo de representação da solução (codificação) e sua rota (decodificação).

A Figura 30 contém a classe CTSP criada para implementar a representação da solução proposta para o TSP. Essa classe estende a classe abstrata Codification, conforme foi ilustrado anteriormente no diagrama da arquitetura abstrata para o ProOF, veja Figura 17 do Capítulo 3. Na linha 2 é declarado o vetor que armazenará as cidades percorridas. No construtor, linha 4, o vetor é alocado com tamanho N (parâmetro definido anteriormente em TSPInstance).

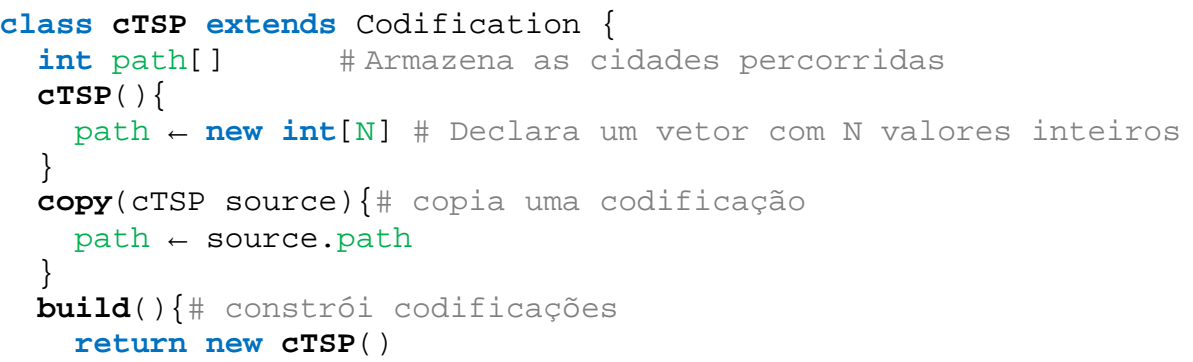

Figura 30: Codificação do problema TSP.

Basicamente, a implementação da classe de codificação para o problema deve conter: a estrutura de dados para representar a solução e as funções membro copy e build. Estas funções membro são utilizadas pelo ProOF, respectivamente para fazer cópias e novas alocações de memória da codificação implementada. Em conjunto estas funções habilitam a função membro clone no ProOF, definindo assim a implementação do padrão de projeto chamado Prototype. O padrão de projeto Prototype, como definido em [3], é utilizado para 
definir objetos capazes de si clonarem. As classes do ProOF que implementam este padrão de projeto são Codification, Objective e Solution, sendo a operação de clonagem herdada automaticamente para qualquer classe filha que seja futuramente criada, veja Figura 17 no Capítulo 3.

O terceiro passo é definir a função objetivo para avaliar as soluções do problema. A Figura 31 ilustra a classe que define a função objetivo do TSP. Como se trata de um problema monoobjetivo, a classe TSPObjective especializa SingleObj, conforme definido na Figura 17 no Capítulo 3, e deve implementar as funções membro evaluate e build. A primeira função é responsável por calcular o custo da codificação e a segunda é utilizada para alocar novos objetivos. As linhas de 2 - 10 calculam o custo do percurso partindo do último índice para o primeiro e fechando o ciclo no último índice. A função membro set (linha 9) armazena o valor do custo encontrado. A função membro build é utilizada pelo ProOF para alocar mais objetos desta mesma classe (linha 12).

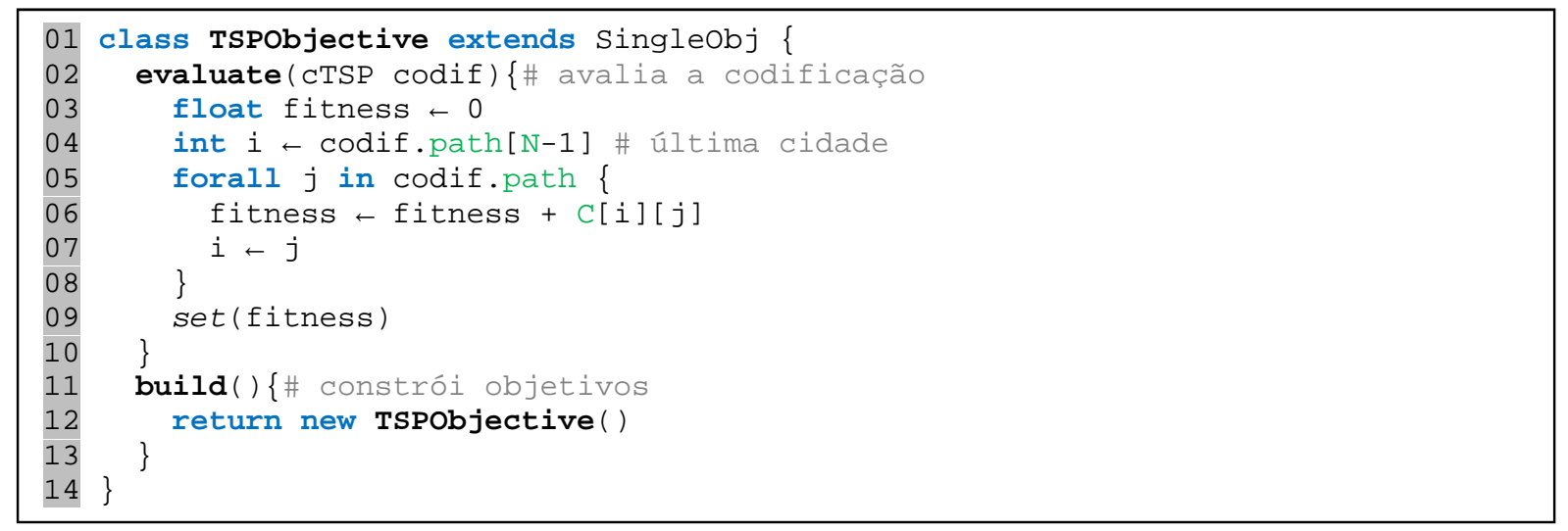

Figura 31: Função objetivo do problema TSP.

O quarto passo é definir os operadores que manipulam a codificação do problema. No exemplo, serão implementados os operadores de inicialização, crossover e mutação. A Figura 32 abaixo ilustra a geração de uma permutação aleatória pelo operador de inicialização.

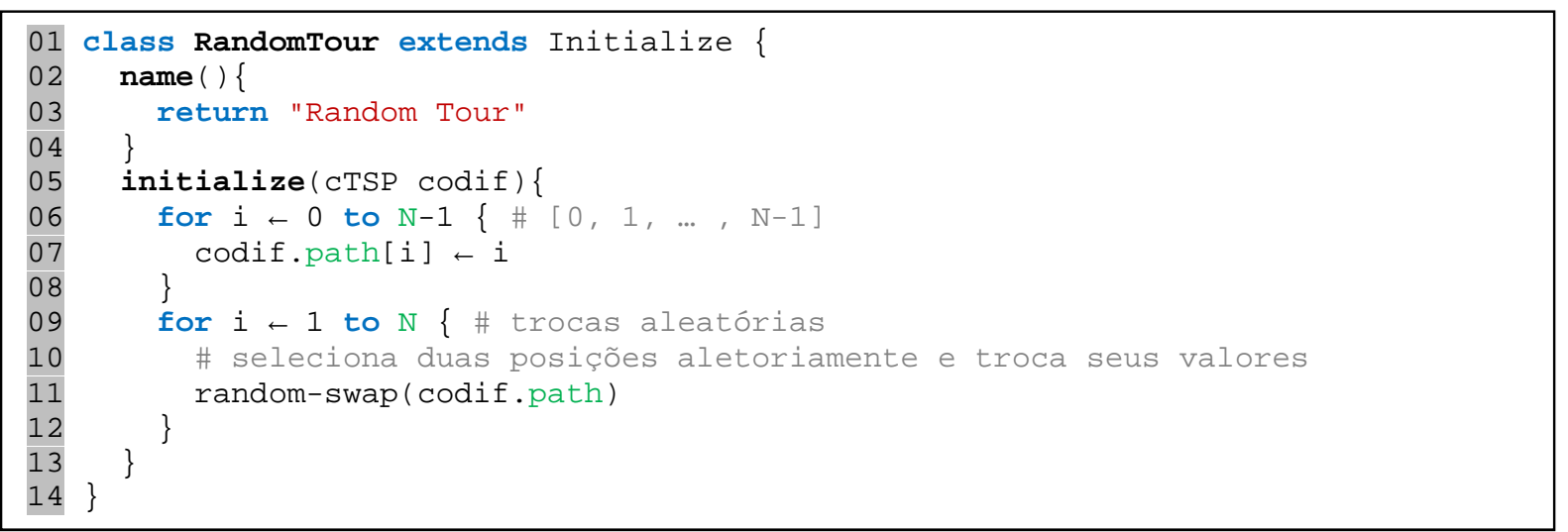

Figura 32: Operador de inicialização para o TSP. 
Na Figura 32, a classe RandomTour especializa a classe Initialize, onde deve ser informado um nome para o operador e sobrescrever a função membro initialize. A inicialização implementada garante que a codificação seja uma solução válida, pois gera uma permutação sem repetição de cidades. A função random-swap, linha 11, é disponibilizada pelo ProOF e faz uma troca aleatória dentro de qualquer vetor que seja passado como argumento para esta função.

A Figura 33 demonstra o operador de mutação. A classe Exchange especializa a classe Mutation e deve informar um nome para o operador e sobrescrever a função membro mutation. Para este operador foi adotado uma pequena perturbação na solução, trocando as posições de duas cidades aleatoriamente escolhidas, linha 7. Para isto foi utilizada um função do ambiente que aleatoriamente troca duas posições de um vetor qualquer.

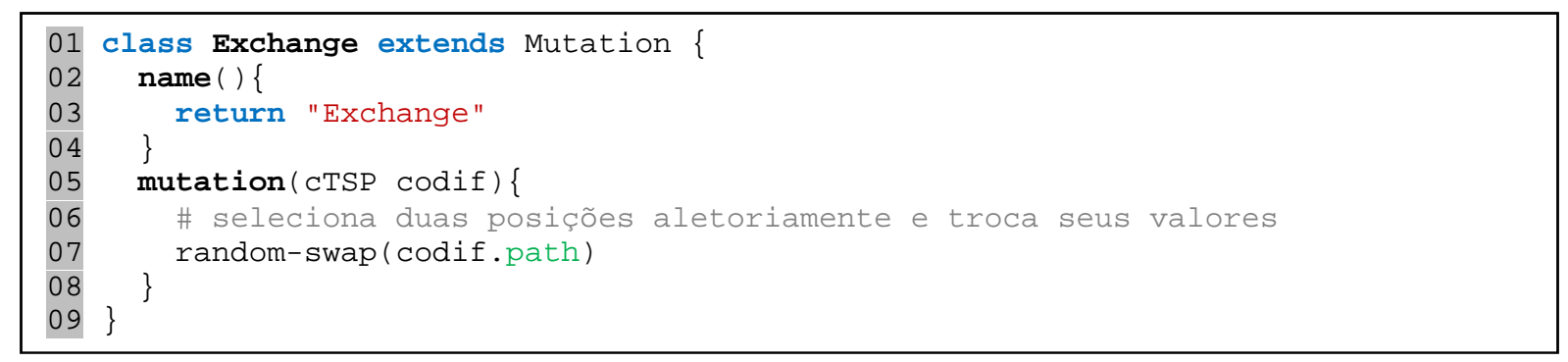

Figura 33: Operador de mutação para o TSP.

A Figura 34 ilustra um exemplo do operador de crossover que será implementado para o TSP. A classe criada especializa a classe Crossover e deve informar um nome para o operador e sobrescrever a função membro crossover. No exemplo considerado, primeiramente são selecionados dois pontos de corte. O filho (child) receberá do primeiro pai (ind1) todo o percurso entre os pontos (cidades 3 e 1). Em seguida, a partir do final do segundo ponto de corte, o filho receberá todas as cidades do segundo pai (ind2) que não foram selecionadas para o filho ainda (cidades 0, 4 e 2). Esse crossover garante que a solução seja válida para o problema já que também gera uma permutação sem repetições.

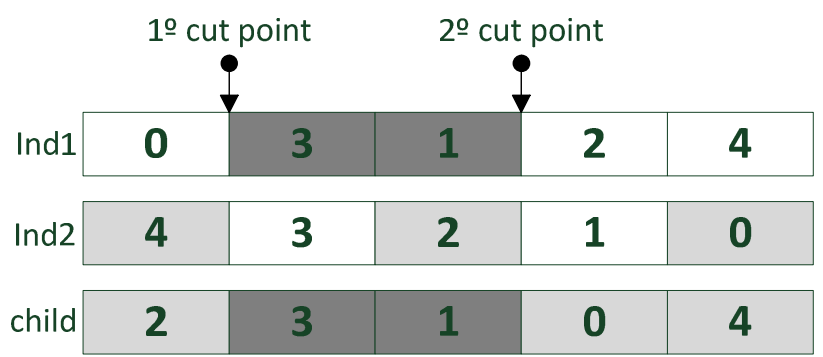

Figura 34: Exemplo do crossover de dois pontos para o TSP. 
Assim, a Figura 35 mostra como ficou o código do operador de crossover. Inicialmente, o novo espaço de memória para uma nova codificação (child) é alocado (linha 6) utilizando a função build definida anteriormente para a codificação CTSP. Em seguida, dois pontos de cortes (linhas 8 e 9) são selecionados e o filho recebe do primeiro pai (ind1) toda a representação que vai do ponto de corte c1 até c2 (linhas 11 até 17). Depois, partindo do ponto de corte $\mathrm{c} 2$ até o ponto de corte $\mathrm{c} 1$ (fechando o ciclo), o filho recebe as cidades que não foram escolhidas ainda do segundo pai (linhas 19 até 24). Por fim, a nova codificação preenchida é retornada (linha 25).

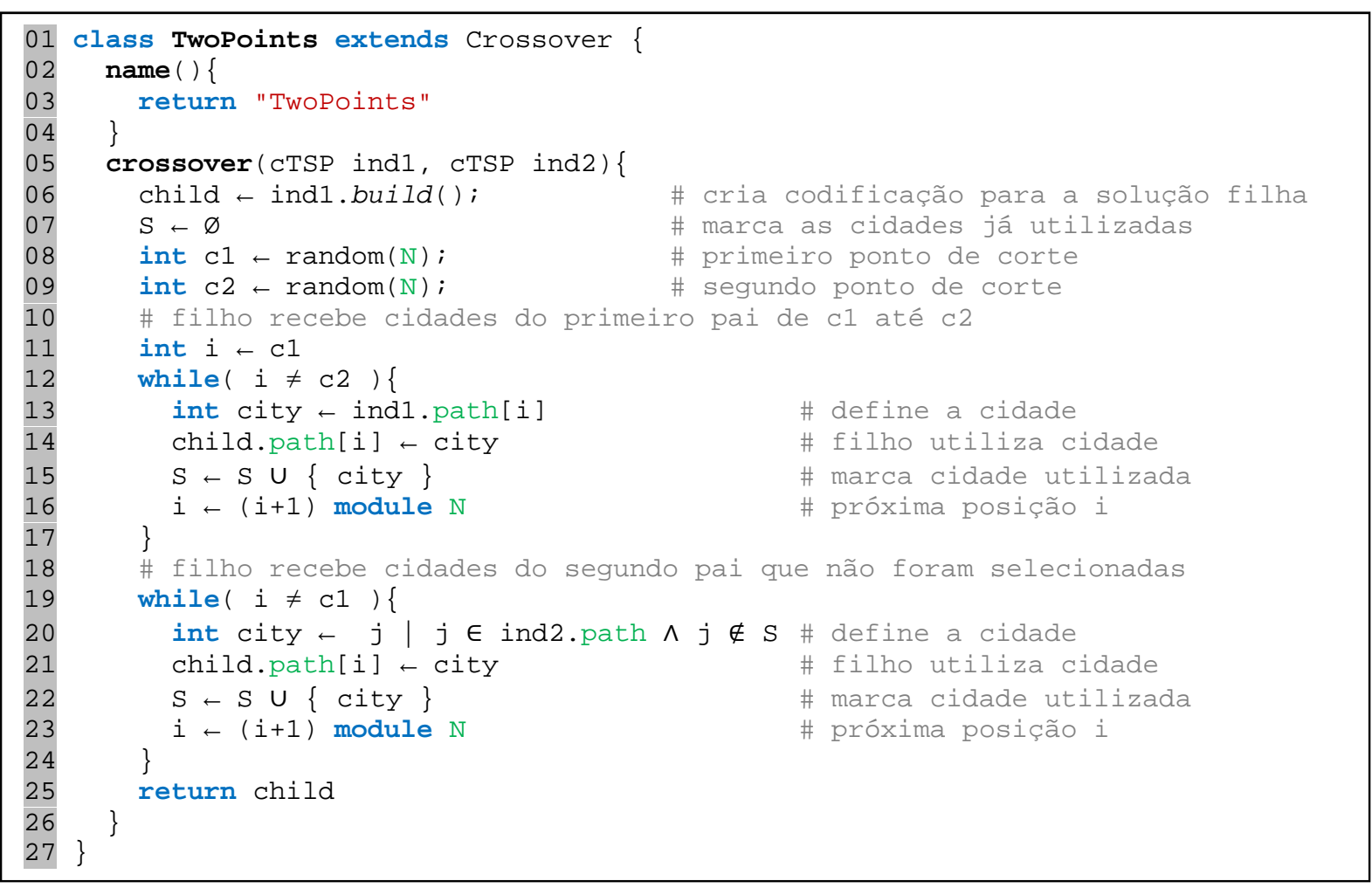

Figura 35: Operador de crossover para o TSP.

Ainda no quarto passo, deve-se criar uma classe que será responsável por criar as instâncias dos operadores para o problema (Figura 36). Nesta classe, deve-se definir um nome (linha 4) e sobrescrever a função membro build para instanciar objetos dos três operadores definidos anteriormente (linhas 9 até 11). Esta classe implementa o padrão de projeto chamado Singleton descrito em [3]. O padrão de projeto Singleton é utilizado para definir uma classe que possua apenas um objeto instanciado. A linha 2 define a instância única deste objeto que será utilizada pelo ProOF. As classes do ProOF que implementam este padrão de projeto são filhas de Factory. Todas as classes filhas de Factory devem definir um objeto estático (obj) como mostrado na linha 2 da Figura 36, veja as classes fRun, fProblem e fStop da Figura 17 no Capítulo 3. 


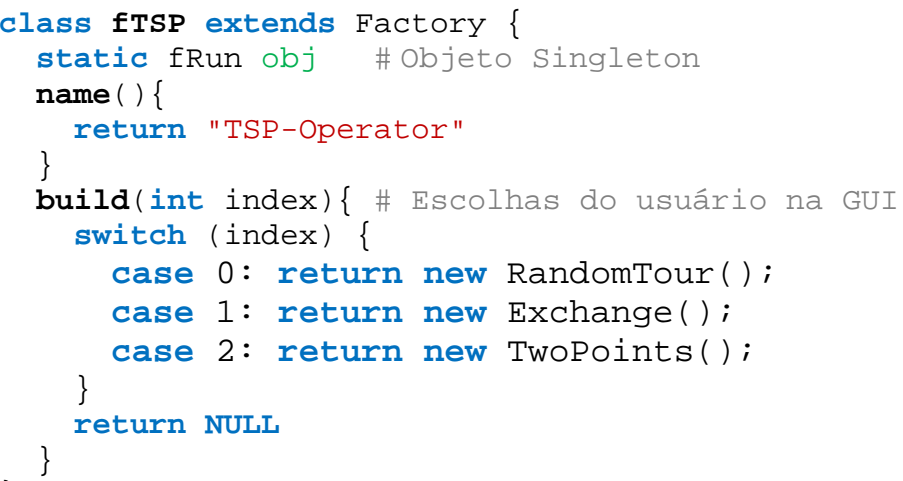

Figura 36: Classe para vinculação dos operadores do TSP.

O quinto passo é a criação da classe TSP responsável por ligar as diferentes partes do problema (Figura 37). Esta classe torna o problema TSP um componente dentro do ProOF com alta coesão e baixo acoplamento, como descrito no Capítulo 3. Todas as classes criadas para o problema tem uma forte ligação entre si (alta coesão). A comunicação deste componente com os métodos do ProOF ocorre através das classes abstratas (baixo acoplamento). Logo, tanto o TSP é independente do GA quanto o GA é independente do TSP. Juntando esta classe com as demais classes abstratas do ProOF, temos a implementação do padrão de projeto chamado Abstract Factory. Segundo [3], este padrão de projeto é utilizado para separar os detalhes de implementação da usabilidade de um conjunto de objetos. A implementação deste padrão de projeto é responsável por garantir a independência entre métodos e problemas dentro do ProOF, permitindo a alta coesão e baixo acoplamento indicados.

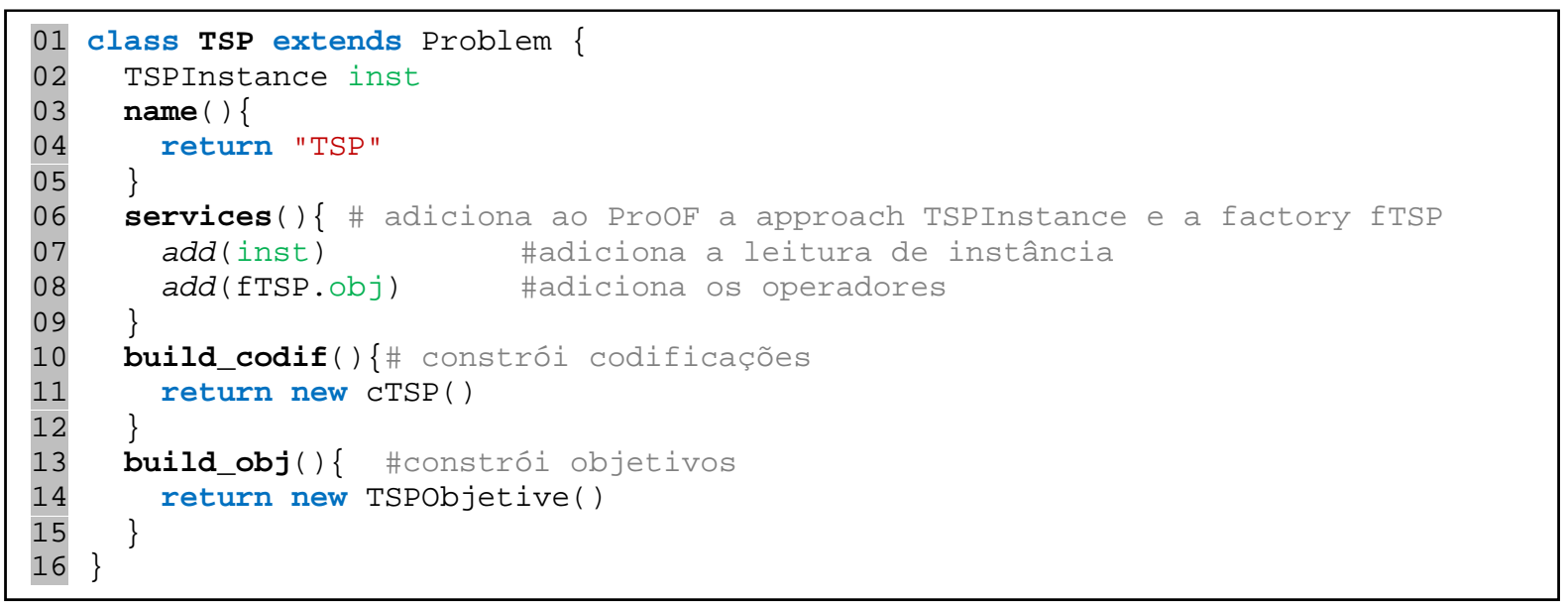

Figura 37: Classe para ligar as diferentes partes do problema TSP.

Na Figura 37 foi definido: um nome para o problema (linha 4), instanciada as novas codificações para o TSP (linha 11) e instanciada novos objetivos (linha 14). Também foi habilitado o acesso aos operadores do TSP (linha 8) e a classe que contém o arquivo de entrada do TSP (linha 7). Descrevendo melhor, a linha 14 aceita retornos de classes para os 
tipos Singleobj e Multiobj, que podem ser utilizados para problemas mono e multiobjetivo, respectivamente.

O sexto e último passo é adicionar o problema TSP criado ao conjunto de problemas do ambiente. Para isso, o novo problema será adicionado à classe fProblem. A Figura 38 mostra como ficou a classe fProblem após a inclusão da linha 8. A partir deste momento já é possível resolver o caixeiro viajante utilizando o algoritmo genético.

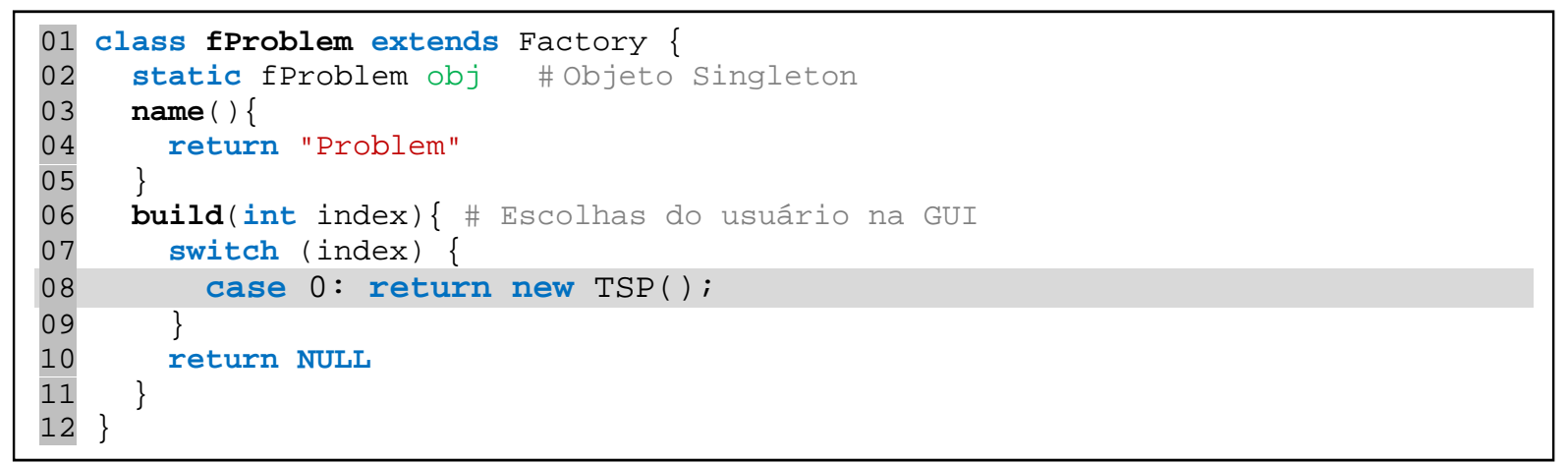

Figura 38: Incluindo TSP na classe Problem.

Assim, foi demonstrado acima como incluir o problema TSP no ambiente e aqui será feita uma breve discussão dos passos seguidos.

$1^{\circ}$ Passo: criar uma nova classe para a leitura de dados do problema: TSP Instance.

$2^{\mathbf{o}}$ Passo: definir uma classe para representar uma solução do problema: cTSP.

$3^{\mathbf{0}}$ Passo: uma classe para calcular/armazenar o custo da solução: tSPOb jective.

$4^{\mathbf{0}}$ Passo: definir uma classe factory fTSP e implementar operadores para o problema.

$5^{\circ}$ Passo: especializar a classe TSP como filha de Problem e nela realizar a vinculação com as demais classes que definem o problema.

$6^{0}$ Passo: modificar a classe do tipo Factory (fProblem) para adicionar o novo problema ao conjunto de problemas do ambiente.

Observe que foi necessário criar várias classes: TSPInstance, cTSP, TSPObjective, fTSP, TSP e mais uma classe para cada implementação de operador. A primeira classe TSPInstance é um componente para leitura e armazenamento de uma matriz de custos (uma forma de representar grafos com pesos nas arestas). Tal componente pode ser reaproveitado no futuro para outros problemas que trabalham com grafos.

A classe CTSP (Figura 30) representa uma permutação sem repetição dos elementos do conjunto $\left[\begin{array}{lll}0 & \ldots & \mathrm{N}-1\end{array}\right]$. Tal representação é comum em vários outros problemas, onde dois 
exemplos são: Problema de Agendamento [64] e o Problema Coloração de Grafos [65]. No caso de reaproveitamento de uma codificação já implementada no ProOF, os operadores definidos para a mesma também são reaproveitados. Isto cumpre o requisito proposto neste projeto de criar um ambiente de programação que facilite o reuso de códigos. Para justificar melhor este argumento, na seção 4.5 a seguir, incluiremos agora a função multimodal ACK que reaproveitará a codificação real já definida no ProOF.

\subsection{Função Multimodal Mono-Objetivo}

A fim de facilitar a inclusão de problemas com reuso de codificação real e seus operadores, uma estrutura FMS, tal como foi proposta na seção 3.6, foi desenvolvida como ilustrado na Figura 39. Para isso, a classe RealProblem foi criada, vinculando-se a codificação real e a todos os operadores para codificação real. Uma nova classe abstrata, RealSingle, também foi criada para que o usuário possa especializar determinada função de domínio real. Neste caso, deve ser informado um nome (name), número de variáveis no domínio (size) e o cálculo da função objetivo $(\mathrm{F})$. Um total de quatro problemas distintos são exemplificados na Figura 39: PID [26], ACK [37], Bohachevsky [66] e Rosenbrock [67].

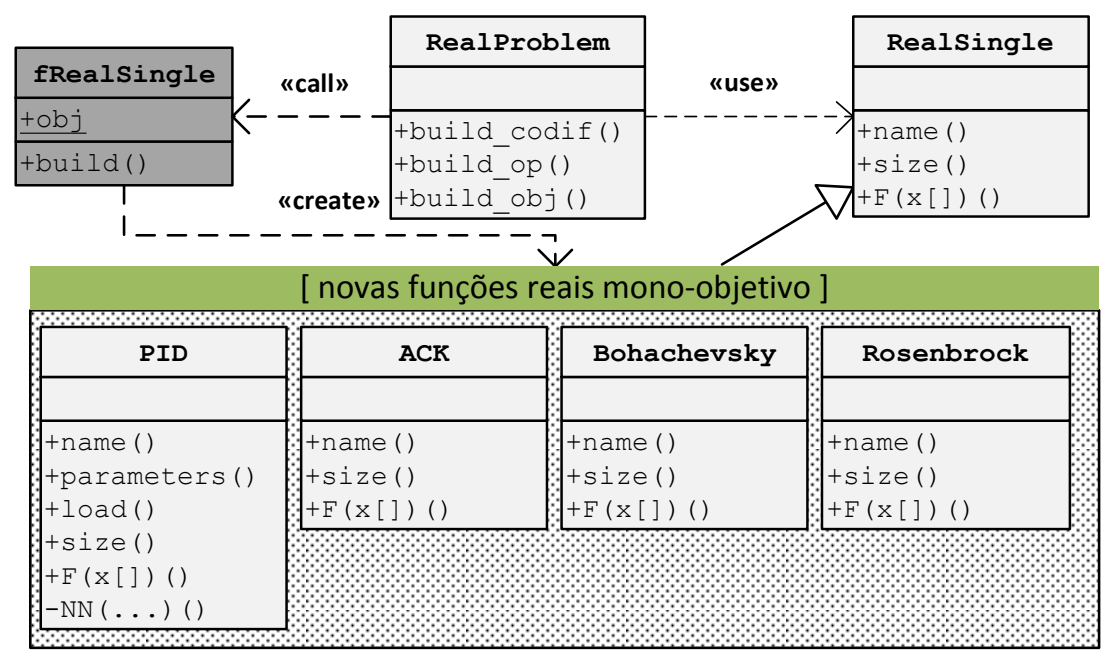

Figura 39: Arquitetura para os problemas reais mono-objetivo.

Conforme afirmado no Capítulo 1 deste texto, o ambiente também já possui quatro outras codificações implementadas: binary, binary-coded real, integer e permutation. E para simplificar o reuso de código com estas codificações, também foram criadas mais quatro outras estruturas FMS semelhante à estrutura para a codificação real ilustrada na Figura 39.

A Figura 40 ilustra a codificação Real implementada no ProOF, onde na linha 2 é declarado um vetor para armazenar os valores reais da codificação. No construtor (linha 5) é instanciado este vetor com um determinado tamanho ( $\mathrm{i}$ i ze). Em seguida, são sobrescritas as 
funções membros copy e build. Também já foram implementados vários operadores de inicialização, crossover, mutação e movimento local para codificação real.

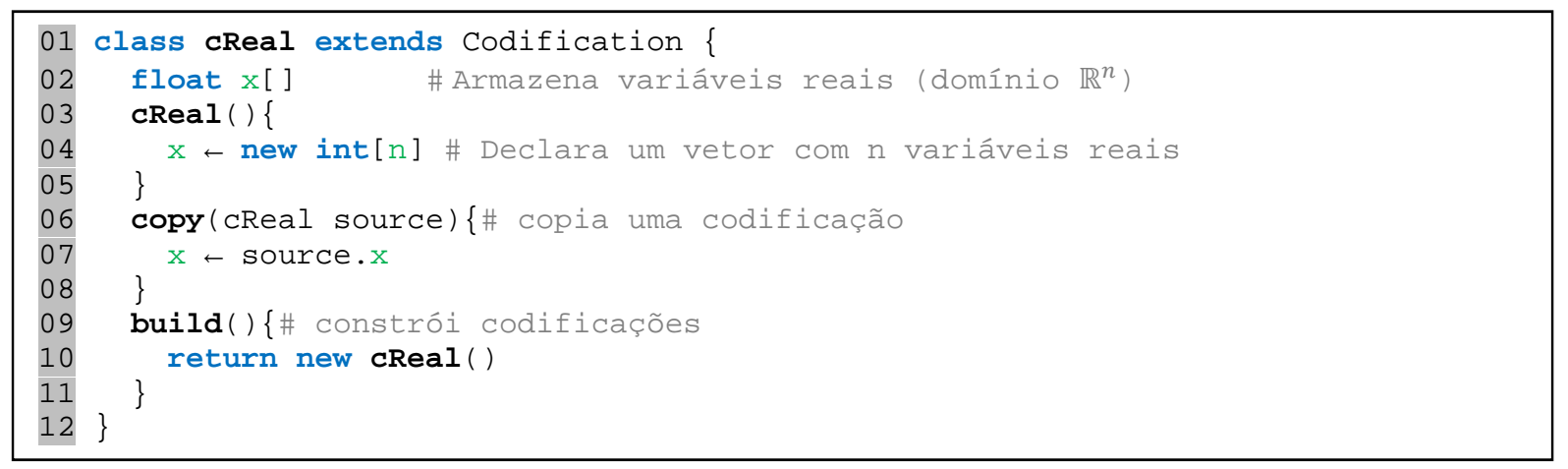

Figura 40: Codificação Real implementada no ProOF.

A Figura 41 exemplifica o crossover de média aritmética implementados no ProOF. A classe Average implementa o mesmo crossover de média definido em [65]. Basicamente, este crossover gera uma solução filha ( $\mathrm{child}$ ) que é o ponto médio entre os pontos ind1 e ind2 no espaço no espaço $\mathbb{R}^{n}$.

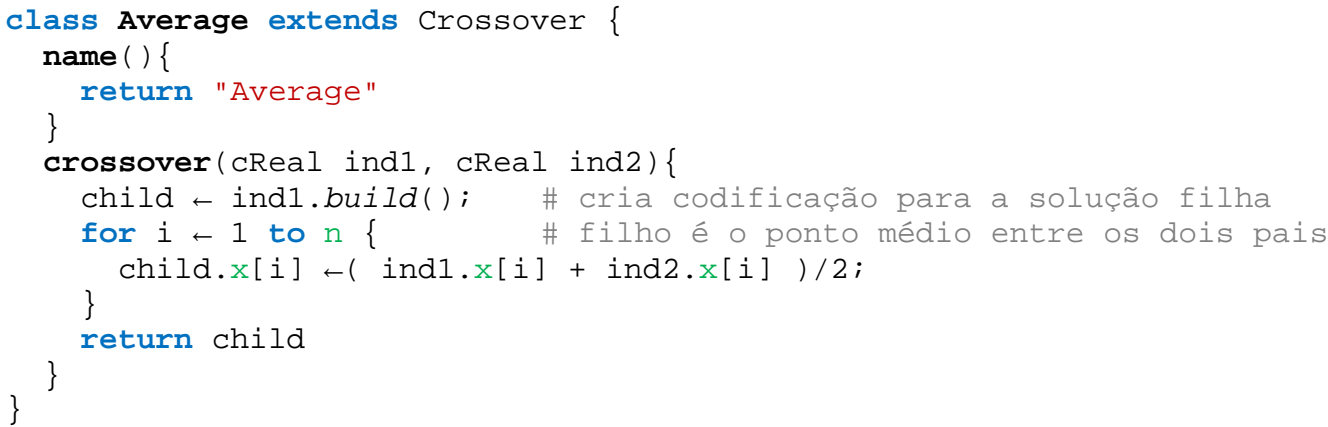

Figura 41: Crossover de média.

Feita esta revisão da codificação real já implementada, vamos à inclusão da função ACK descrita em [37] como estabelecido na equação (1).

$$
\begin{gathered}
f(y)=20+e-20 \exp \left(-2 \sqrt{\frac{\sum_{i=1}^{n}\left(\frac{y_{i}}{100}\right)^{2}}{n}}\right)-\exp \left(\frac{\sum_{i=1}^{n} \cos \left(2 \pi y_{i}\right)}{n}\right) \\
-30 \leq y_{i} \leq+30 \\
n=10
\end{gathered}
$$

Para acrescentar esta função no ambiente, deve-se primeiro implementar a classe ACK (Figura 42). A classe criada especializa a classe Realsingle e deve informar um nome para a função, o número de variáveis no domínio $(n=10)$ e sobrescrever a função membro $\mathrm{F}$. A linha 3 define um nome para a função e o número de dimensões no espaço é definido na linha 6. Em seguida, é descrita a função em $F$ onde um vetor x (codificação no espaço $\mathbb{R}^{n}$ ) é 
passado como argumento. Na linha 12 é utilizada a função decode para recuperar o valor de $y$ no intervalo de $[-30,+30]$.

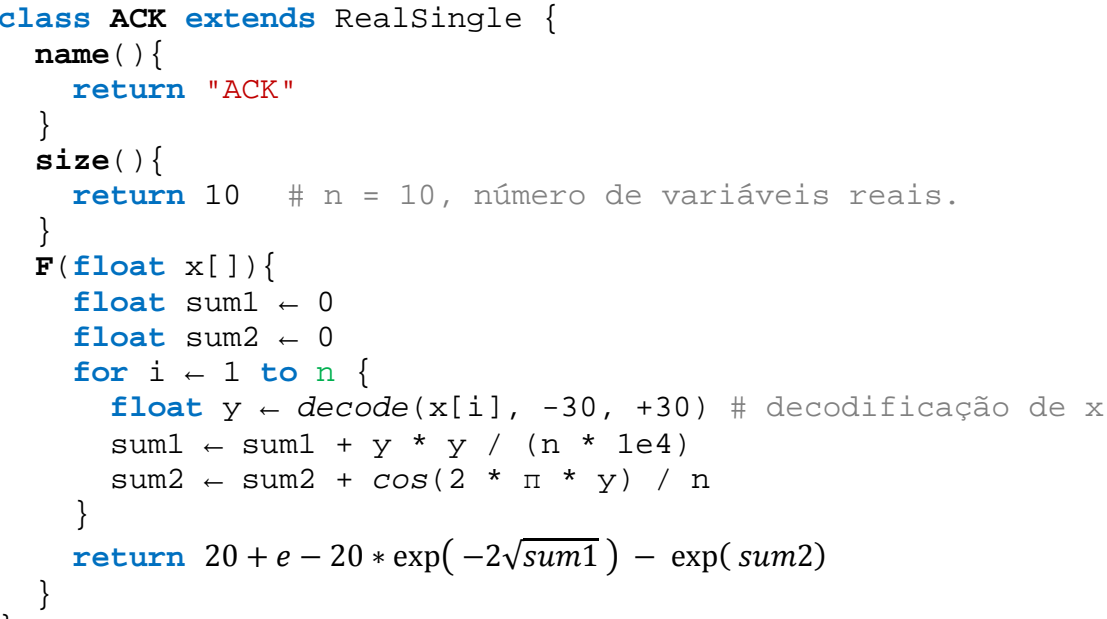

Figura 42: Implementação da classe ACK.

O segundo e último passo para incluir a função é modificar a classe fRealsingle para que o ambiente reconheça mais este problema, Figura 43 . Desta forma, conclui-se as etapas de implementação para o ambiente considerando problemas mono-objetivos (TSP e ACK) que serão resolvidos por métodos do tipo metaheurísticas como o GA.

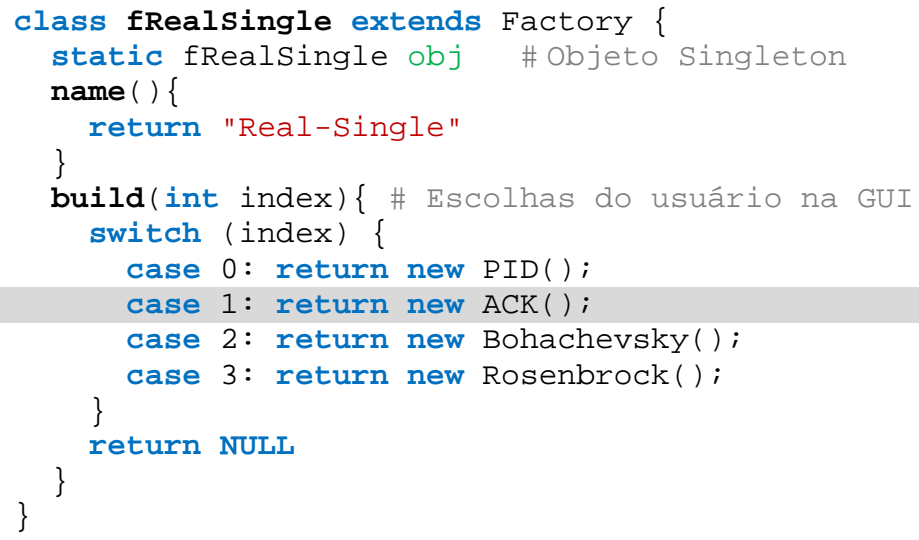

Figura 43: Incluindo ACK na classe fRealSingle.

\subsection{Método Multi-Objetivo: NSGA-II}

Nesta seção é apresentado como o método NSGA-II, usado para resolver problemas multiobjetivo, foi implementado no ProOF. Este método foi proposto em [33] e a Figura 44 ilustra como é o seu funcionamento. O método inicia criando e avaliando uma população aleatória de indivíduos (P). Em seguida, utilizando seleção por torneio, crossover e mutação, cria uma população de descendentes Q dos indivíduos em P. A partir deste ponto, as duas populações (P e Q) são unidas em uma única população $\mathrm{R}$ e uma comparação de não dominância é feita para toda a população $R$, formando assim o agrupamento $f_{1}$. Em seguida, outras comparações 
de não dominância são feitas sistematicamente para os indivíduos restantes, definindo mais grupos $\left(\mathrm{f}_{2}\right.$ e $\mathrm{f}_{3}$ ). Por fim, as menores distâncias entre as funções objetivos de cada grupo (f) são medidas e ordenadas em ordem decrescente de distância. Assim a próxima geração (P) é formada pelos indivíduos nos melhores grupos e mais distantes em cada grupo. Os agrupamentos promovem então uma métrica de intensificação das soluções, agrupando os indivíduos com os melhores objetivos. A distância é utilizada como métrica de diversificação das soluções, priorizando os indivíduos que estão distantes dos demais.

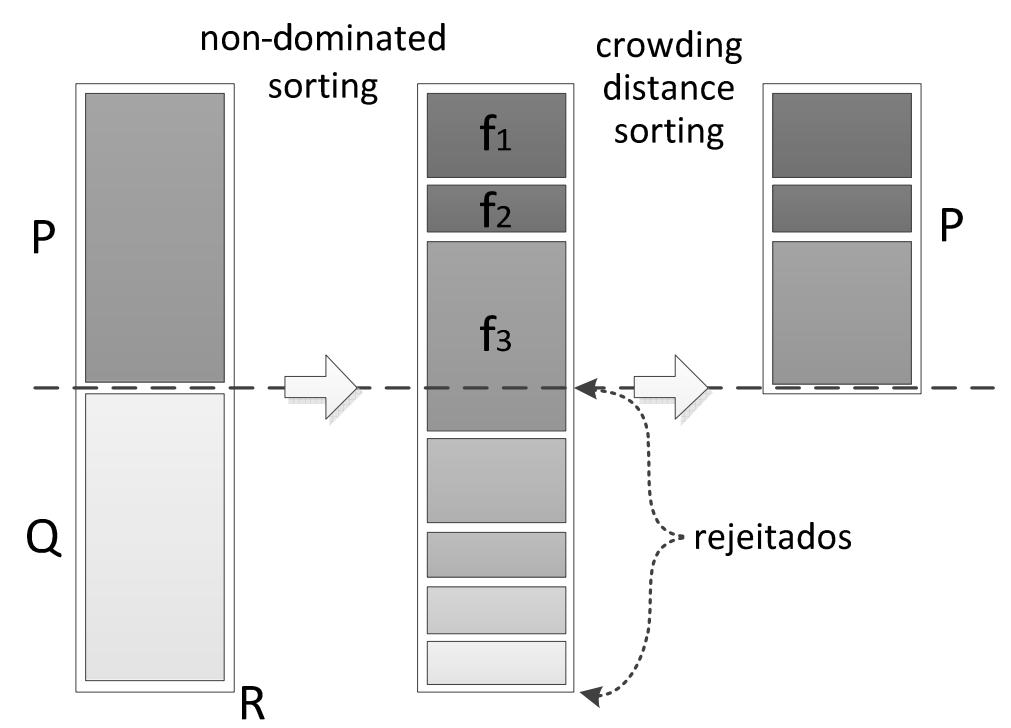

Figura 44: Método NSGA-II (adaptada de [33]).

A Figura 45 apresenta o NSGA-II implementado no ProOF. De forma muito semelhante ao GA, o NSGA-II utilizará um problema, um critério de parada, operadores de inicialização, crossover e mutação (linhas 2 - 6). O NSGA-II também utiliza os mesmo parâmetros do GA: tamanho da população e torneio (linhas 7, 8, 20 e 21). Sendo que a única diferença entre as linhas de 2 a 22 do GA para o NSGA-II são as linhas 2 e 13. Nota-se que o problema será agora do tipo Multiproblem (linha 2) e para o pedido get (linha 13) são indicados dois argumentos. Assim, o ProOF já fornece mecanismos para apresentar na GUI somente os problemas multi-objetivo para o usuário escolher para este método.

$\mathrm{Na}$ função execute (linhas 23 - 49), está o funcionamento interno do NSGA-II. Inicialmente são declaradas as duas populações de indivíduos $\mathrm{P}$ e $\mathrm{Q}$, e em seguida a população P é inicializada e avaliada. Nas linhas de 31 até 48 está o laço principal, onde a população de descendentes Q é gerada a partir da população P aplicando seleção por torneio, crossover, mutação e fazendo a avaliação dos indivíduos. A linha 40 define que R será a união das duas populações e em seguida é utilizada a função fast_non_dominated_sorting, apresentada em [33], para fazer os agrupamentos de todos os indivíduos em $\mathrm{R}$ segundo o 
critério de não dominância. A função crowding_distance_assignment também apresentada em [33] é utilizada para calcular a distâncias entre os indivíduos de cada grupo. Por fim, os indivíduos em R são ordenados (sort) segundo estes dois critérios e os melhores (best) irão compor a população $\mathrm{P}$ na próxima geração. $\mathrm{O}$ procedimento termina quando o critério de parada for atingido (linha 48).

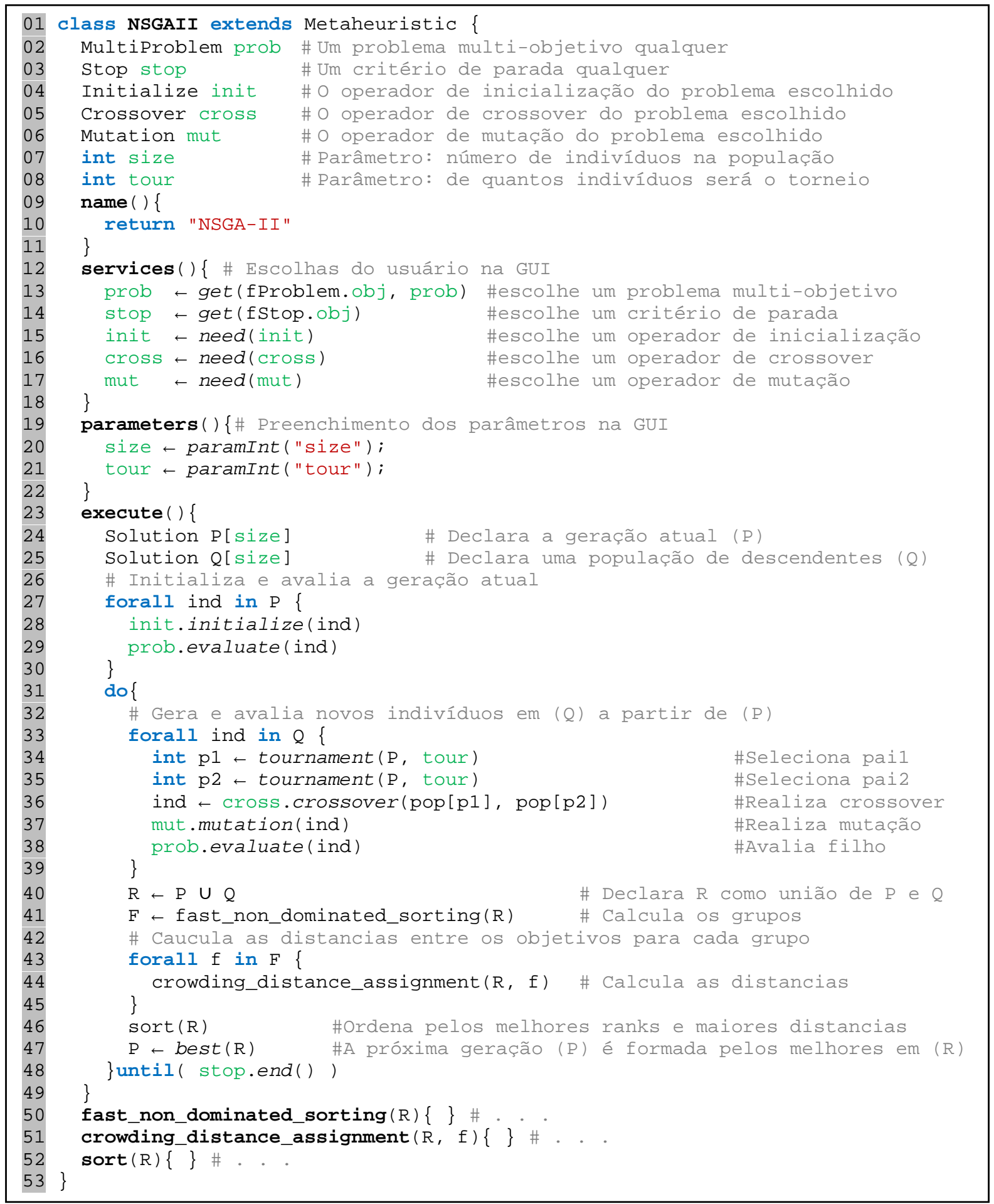

Figura 45: Incluindo o método NSGA-II no ProOF. 
As linhas 50 até 52 indicam que as implementações das funções definidas em [33] foram omitidas aqui, mas sua implementação estará na mesma classe do NSGA-II. Elas foram omitidas, pois não são relevantes para o entendimento do uso do ProOF na inclusão de métodos para problemas multi-objetivo. Após a implementação do NSGA-II, este será adicionado ao conjunto de métodos do ambiente modificado a classe fRun, conforme apresentado também para o GA (Figura 25). O NSGA-II será então o terceiro método incluído no ambiente.

\subsection{Função Multimodal Multi-Objetivo}

Na seção 4.5 foi apresentado como uma estrutura FMS foi desenvolvida para facilitar a implementação de problemas mono-objetivos que especificamente utilizam a codificação real. De forma análoga, também foi desenvolvida uma estrutura FMS para problemas multiobjetivos. Isso possibilitará a implementação de problemas multi-objetivo com a codificação real de forma muito semelhante à apresentada na seção 4.5.

A equação (2) abaixo apresenta a função Schaffer (SCH) definida em [39]. Devido à forma como o ProOF foi projetado, os passos para incluir uma função multi-objetio são muito parecidos com aqueles utilizados na função mono-objetivo.

$$
\begin{aligned}
& f_{1}(x)=x^{2} \\
& f_{2}(x)=(x-2)^{2} \\
& x \in\left[-10^{3} ; 10^{3}\right]
\end{aligned}
$$

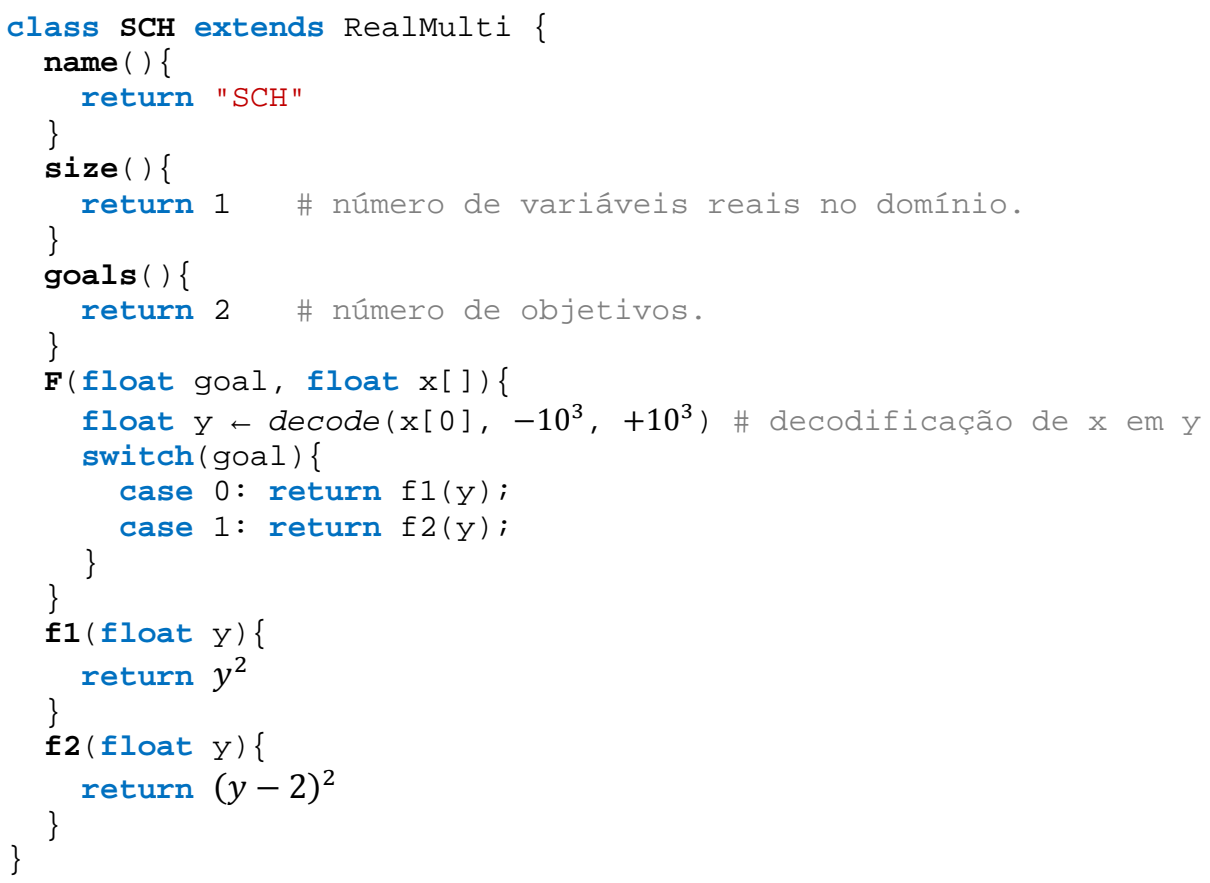

Figura 46: Implementação da função multi-objetivo SCH. 
$\mathrm{Na}$ Figura 46, é ilustrado como problema SCH foi implementado no ProOF. A linha 1 define o SHC como multi-objetivo no ambiente, e o número de variáveis e objetivos são indicados, respectivamente, nas linhas 6 e 9. Em seguida, em F é realizada a decodificação (linha 12) e selecionado um dos objetivos ( $f 1$ ou f2) para ser avaliado. As principais diferenças entre uma função mono ou multi-objetivo no ProOF estão em (goals e F), pois o usuário deve definir quantos objetivos (goals) compõem o problema e qual objetivo será calculado a cada chamada de $\mathrm{F}$.

\subsection{Método Exato: Branch \& Bound}

Conforme definido anteriormente, no ProOF seria possível projetar métodos exatos, heurísticos e metaheurísticos. Nesta seção será apresentado como o método exato Branch \& Bound [34] foi integrado ao ProOF. Expandindo a arquitetura apresentada na Figura 17 da seção 3.5, foi definida uma estrutura FMS conforme apresentada na Figura 47. Também foram definidas duas novas formas de operadores chamadas de Expand e LowerBound para serem utilizados no funcionamento do método Branch \& Bound. Também foi definido uma nova classe abstrata para representar os problemas (BranchProblem) e outra abstração (Branch) que corresponderá ao estilo de representação a ser utilizada.

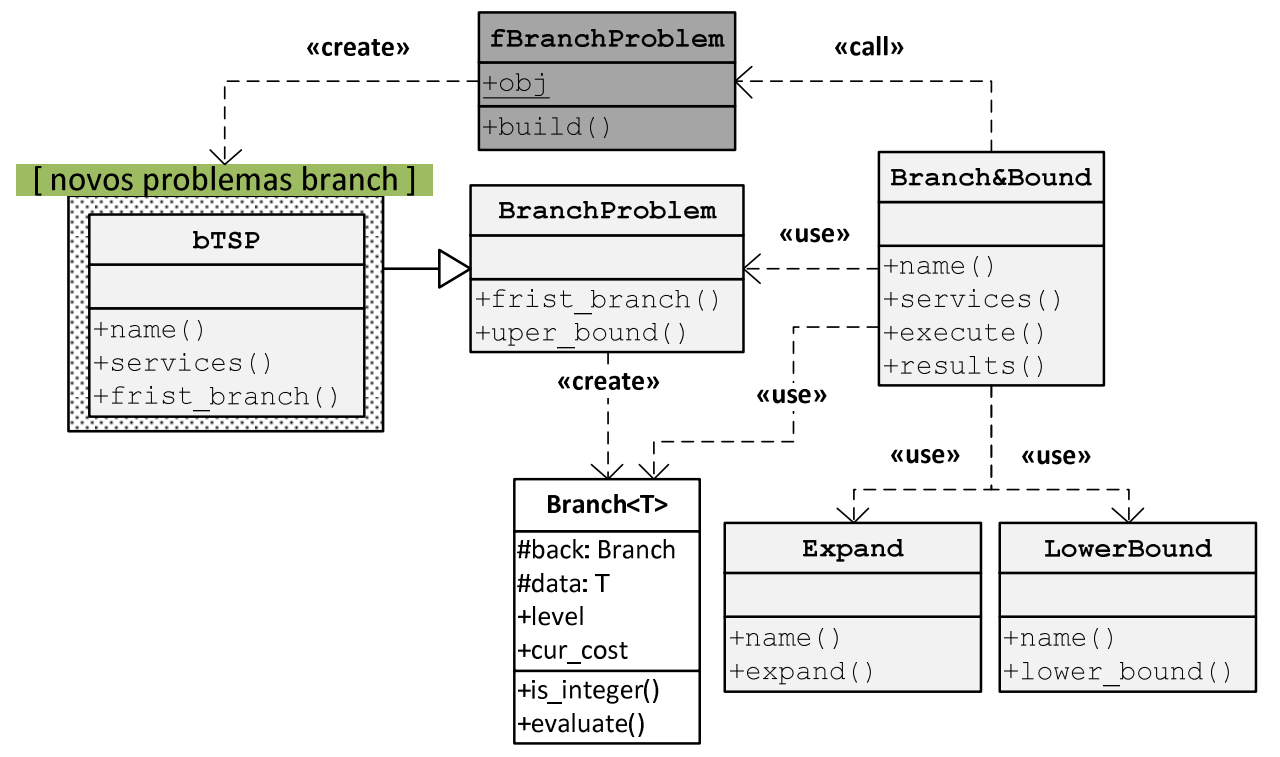

Figura 47: Arquitetura do método Branch \& Bound implementado.

Basicamente, a classe Branch corresponde a um subproblema, o operador LowerBound é utilizado para avaliar qual o seu custo e o operador Expand gera novos subproblemas a partir de um outro subproblema. Logo, a arquitetura apresentada na Figura 47 impõe que para adicionar um novo problema do tipo BranchProblem no ProOF, o usuário deve especializar as classes (Branch, BranchProblem). Para resolver o problema com o método Branch \& 
Bound, o usuário deve implementar os operadores Expand e LowerBound. Na seção 4.9 será apresentado como o TSP vai ser especializado para este método exato. Devido ao caráter abstrato desta arquitetura, o método Branch \& Bound será capaz de resolver problemas de otimização variados: TSP, VRP e KP.

A Figura 48 ilustra a classe principal do método Branch \& Bound inserido no ProOF. O método deve especializar a classe Exact e, semelhante aos métodos GA e NSGAII, vai solicitar um problema, um critério de parada e os operadores necessários ao seu funcionamento. Devido ao princípio de funcionamento deste método ser bem diferente dos anteriores, este resolverá uma classe diferente de problemas que aqui foram chamados de BranchProblem. Isto se faz necessário uma vez que a forma de codificar e manipular as soluções é diferente dos métodos anteriores.

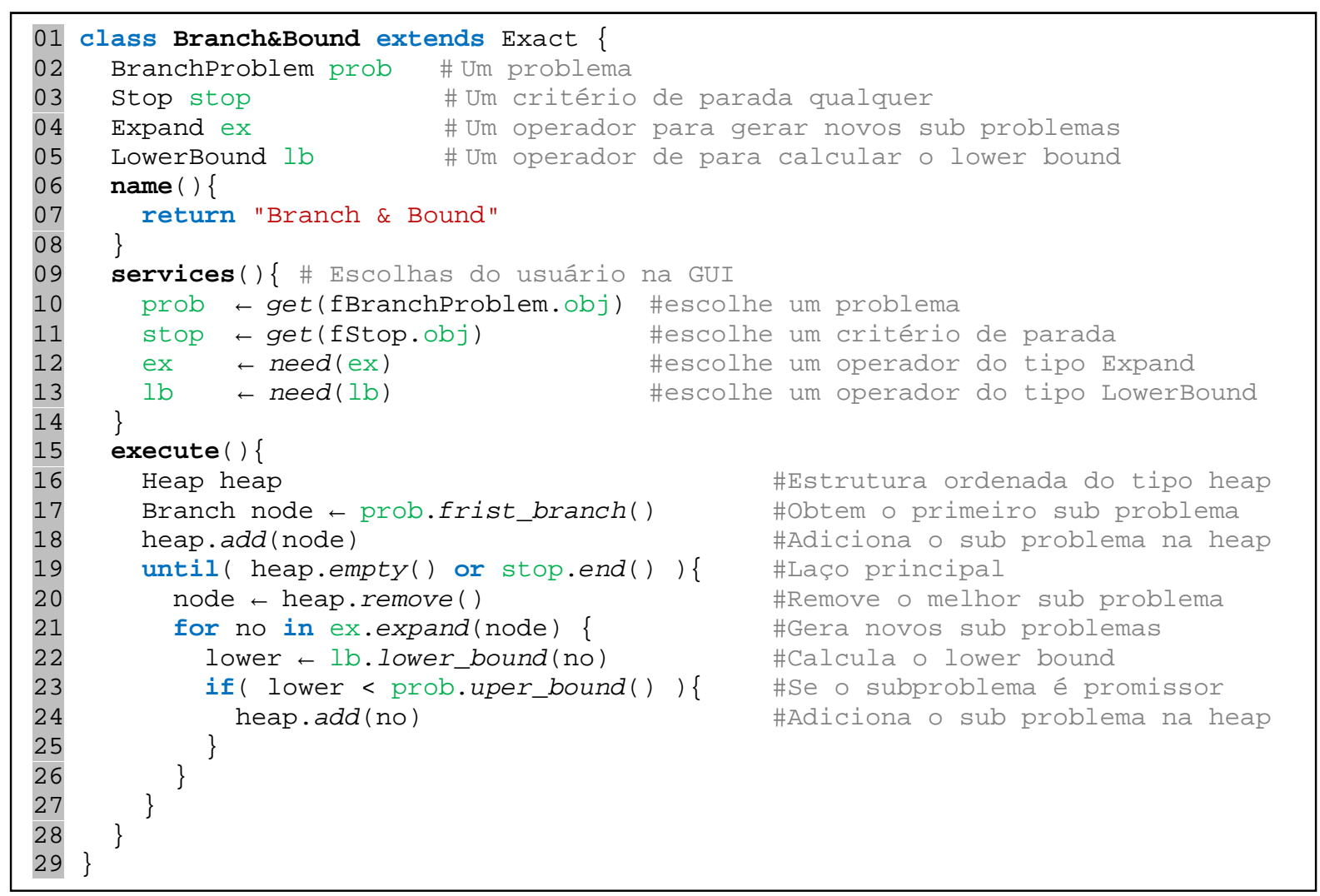

Figura 48: Implementação do método exato Branch \& Bound no ProOF.

Nas linhas de 15 até 28, encontra-se como é o funcionamento do Branch \& Bound. O método utilizará uma estrutura chamada heap que consiste em manter uma lista ordenada de subproblemas, onde os melhores candidatos são removidos primeiro. Assim na linha 17, é solicitado ao problema para criar seu primeiro subproblema (node) e este é adicionado na heap, linha 18. O método então sistematicamente vai gerando e resolvendo novos subproblemas até que o critério de parada seja atingido ou que todos os subproblemas já tenham sido resolvidos, linha 19 até 27 . Na linha 20, o melhor subproblema é removido da 
heap para ser resolvido e na linha 21 o operador Expand é utilizado para gerar novos subproblemas a partir deste, caso este subproblema ainda não seja uma solução inteira (ou completa). Em seguida, o operador LowerBound é utilizado para estimar um custo mínimo para cada um dos subproblemas gerados (linha 22) e os subproblemas promissores são adicionados na heap. A implementação destes dois operadores descritos aqui será realizada durante a fase de especialização dos problemas para o Branch \& Bound, sendo assim é o problema que deve garantir que as propriedades esperadas para estes operadores sejam respeitadas, isto será exemplificado na seção 4.9 a seguir.

\subsection{Especializando o Caixeiro Viajante para o Branch \& Bound}

Nesta seção é apresentado como o problema do Caixeiro Viajante (TSP) pode ser especializado no ProOF para o método Branch \& Bound. Isto é feito de forma semelhante ao que foi realizado com a especialização do TSP para o GA, ver seção 4.4, onde era preciso definir a leitura de instância, uma codificação e sua avaliação, além de implementar os operadores do GA e criar uma classe que ligava todas as outras classes definidas para o problema. Os passos agora serão: reaproveitar a mesma classe de leitura de instância, implementar uma nova codificação/avaliação seguindo o paradigma definido pela classe Branch (Figura 47), implementar os operadores do Branch \& Bound, criar uma classe que liga todas as demais classes segundo o paradigma definido pela classe BranchProblem (Figura 47). Como a classe criada para a leitura de instância definida na Figura 27 será reaproveitada, nenhuma implementação se faz necessária nesta etapa. Em seguida, a Figura 49 apresenta a codificação deste problema (classe City).

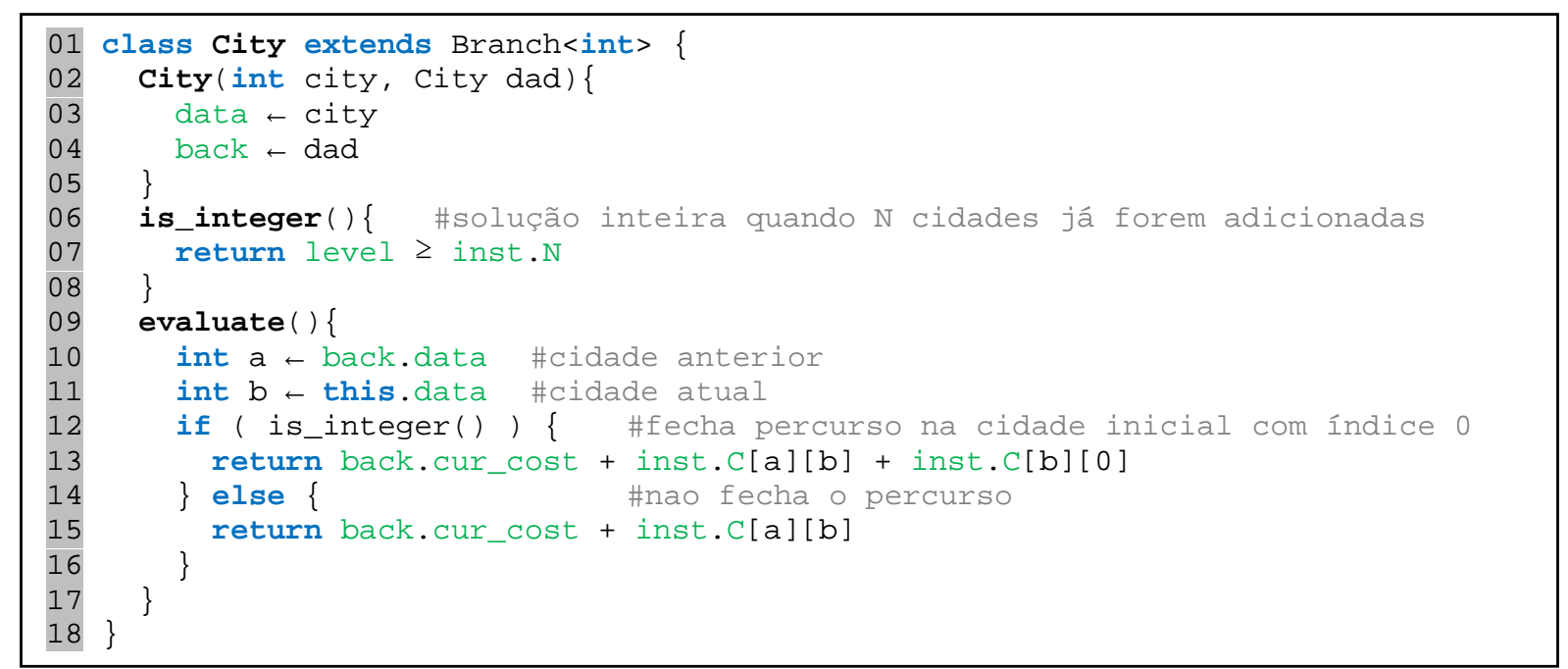

Figura 49: Especializando a classe Branch para o TSP. 
A classe City especializa a classe Branch e define que a estrutura de dados utilizada é formada por um valor numérico inteiro <int> representado cada cidade numa rota a ser percorrida. Assim, uma classe City é construída indicando qual cidade esta representa (linha 3) e qual é a cidade que existia na rota antes desta (linha 4). A função is_integer é utilizada para definir quando a rota do caixeiro viajante está completa (linha 7). A função evaluate avalia o custo atual (cur_cost) da rota que está sendo construída. Assim, se a rota está incompleta (linha 15), o custo será o custo até a cidade anterior (back.cur_cost) mais o custo de ir da cidade anterior (a) para a cidade atual (b). Quando a solução estiver completa, adiciona-se o custo de ir da cidade atual (b) para a primeira cidade de onde iniciou a rota. Sem perda de generalidade, ficou definido para o TSP que a cidade inicial é a cidade 0 .

Após definir a codificação, deve-se implementar os operadores capazes de manipular esta codificação. A Figura 50 ilustra o operador Expand que é utilizado para definir as próximas cidades possíveis, a partir de uma subrota conhecida (subtour). Assim as possíveis cidades que podem ser utilizadas para o caixeiro viajante são todas as cidades que ainda não estão no percurso que está sendo atualmente construído (subtour).

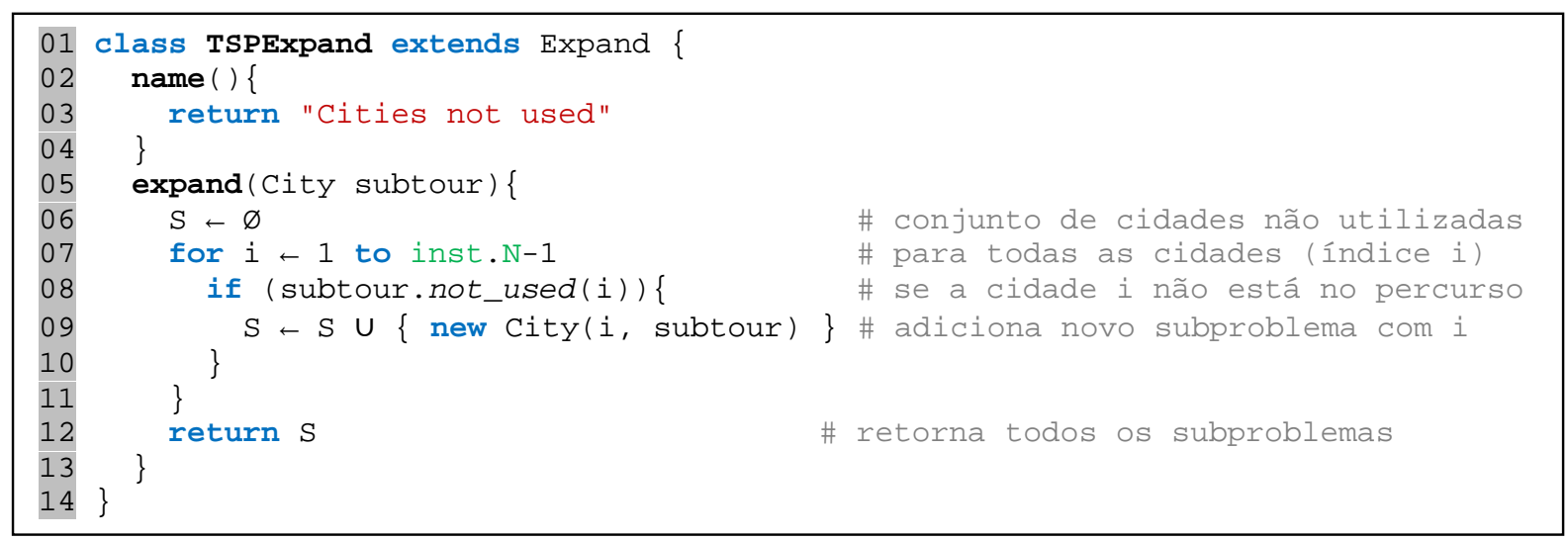

Figura 50: Implementação do operador Expand para o TSP.

O operador de LowerBound é definido na Figura 51. Se a rota já estiver completa, o custo de lower bound é exatamente o custo da rota (cur_cost). Caso ainda seja uma rota parcial, o lower bound inicia com o custo parcial da rota (linha 9) e incrementalmente adiciona o menor custo possível para todas as demais cidades que não estão no percurso (linhas de 10 até 14). 


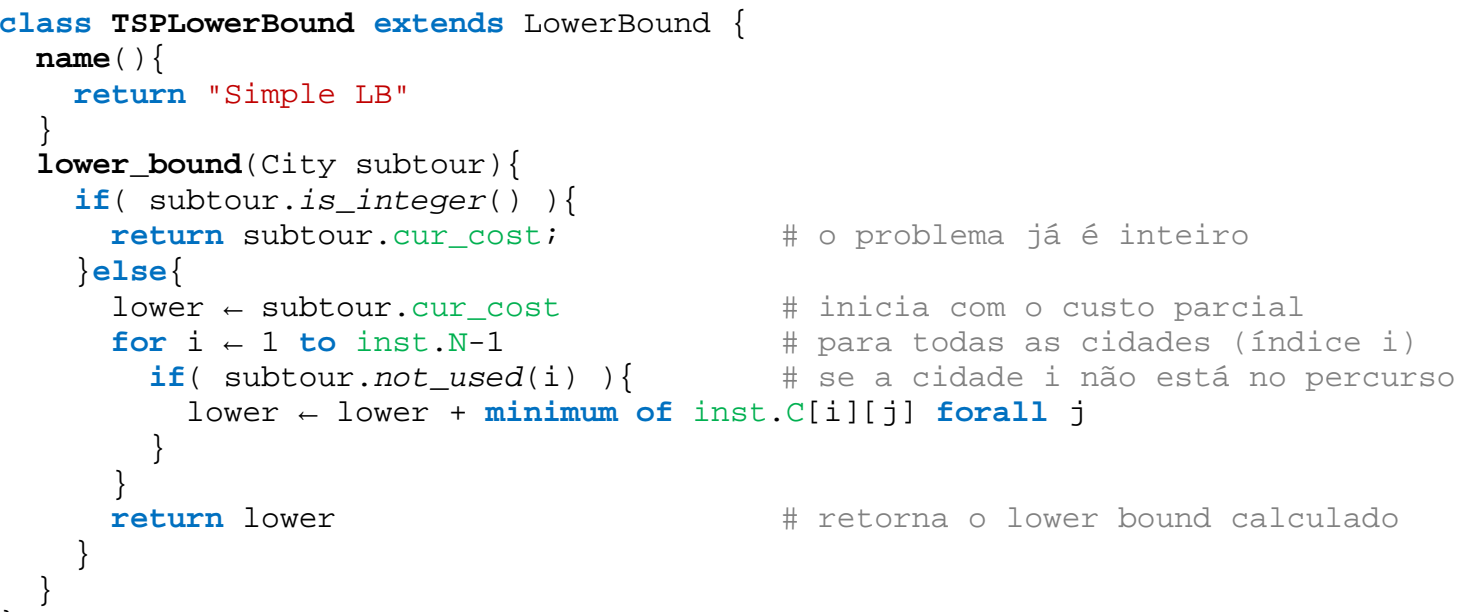

Figura 51: Implementação do operador LowerBound para o TSP.

Ainda no passo de criação dos operadores, deve-se criar uma classe do tipo Factory que será responsável por criar as instâncias dos operadores para o problema (semelhante ao que foi feito no TSP para o GA na seção 4.4). Por fim, a Figura 52 apresenta a classe bTSP que liga todas as demais classes, sendo responsável por adicionar a leitura das instâncias (linhas 2 e 7) e os operadores (linha 8). Depois de implementada esta classe, ela deve ser adicionada em fBranchProblem. Também é nesta classe que deve ser criado o subproblema inicial como indicado na linha 11 , onde foi definida que a representação sempre vai partir da cidade 0 como cidade inicial.

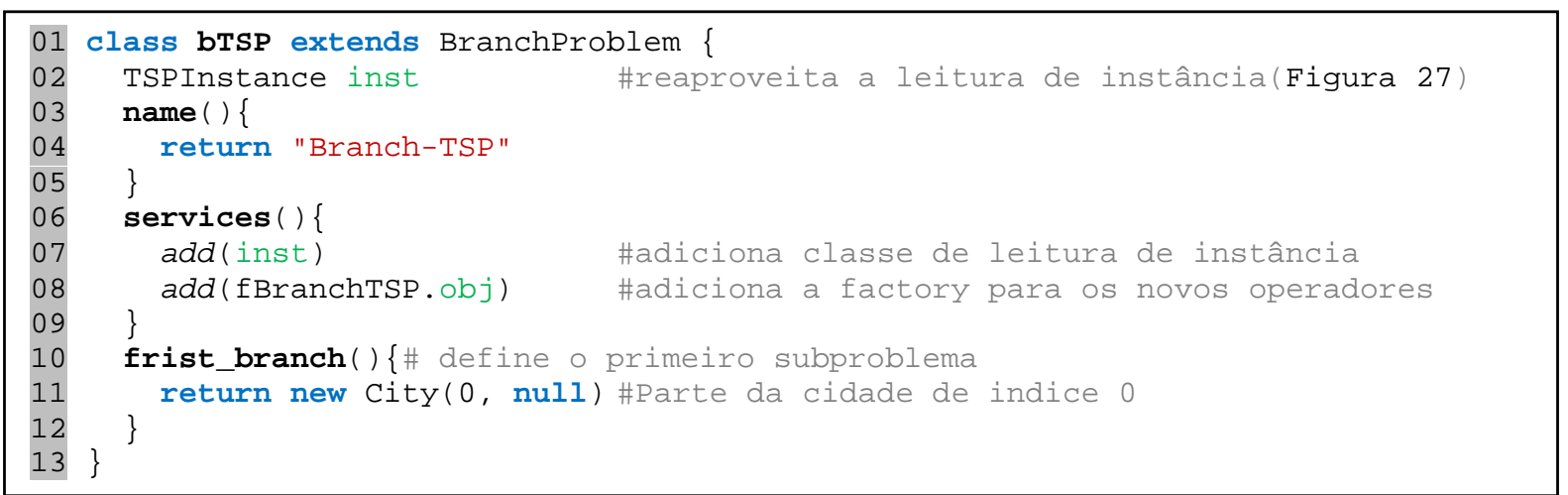

Figura 52: Especializando a classe BranchProblem para ligar as diversas classes do TSP.

\subsection{Método Heurístico Guloso}

Reaproveitando a mesma estrutura FMS definida para o Branch \& Bound na seção 4.8 (Figura 47) é possível projetar facilmente uma heurística gulosa (greedy). A Figura 53 descreve a única classe que precisou ser desenvolvida para implementar uma heurística gulosa simples no ProOF (Greedy). Nas linhas $2-4$ e 9 - 11 são solicitados ao ambiente um problema do tipo BranchProblem, um critério de parada e o operador Expand. Logo, este método poderá resolver qualquer problema que seja especializado de BranchProblem e 
possua implementado uma especialização do operador Expand. Portanto, este método é capaz de resolver o mesmo caixeiro viajante implementado na seção 4.9 anterior, também nota-se que o método guloso não precisará do operador LowerBound. A função execute apenas cria o subproblema inicial e chama uma função recursiva (recursive). Esta por sua vez executará o procedimento guloso através de uma busca em profundidade nas possibilidades do problema. A busca termina quando todas as combinações de soluções inteiras forem encontradas ou o critério de parada for atingido, linha 18. A linha 20 define a chamada recursiva para todos os subproblemas (no) a partir do subproblema atual (node) fazendo primeiramente a recursão pelos nós de menor custo.

O funcionamento deste algoritmo guloso dependerá fortemente do critério de parada adotado. Sendo que é possível escolher qualquer dos critérios de parada mencionados para os métodos anteriores. Entretanto, dois outros novos critérios são possíveis para este método: forever e integer. O primeiro define um critério que nunca chega ao fim (forever), logo o método funcionará como um algoritmo de força bruta, parando apenas quando todas as soluções inteiras forem avaliadas. O segundo critério (integer) vai parar quando certo número de soluções inteiras definidas pelo usuário for encontrado. Se o usuário definir que vai parar após encontrar a primeira solução inteira, este método vai funcionar como um algoritmo heurístico guloso padrão.

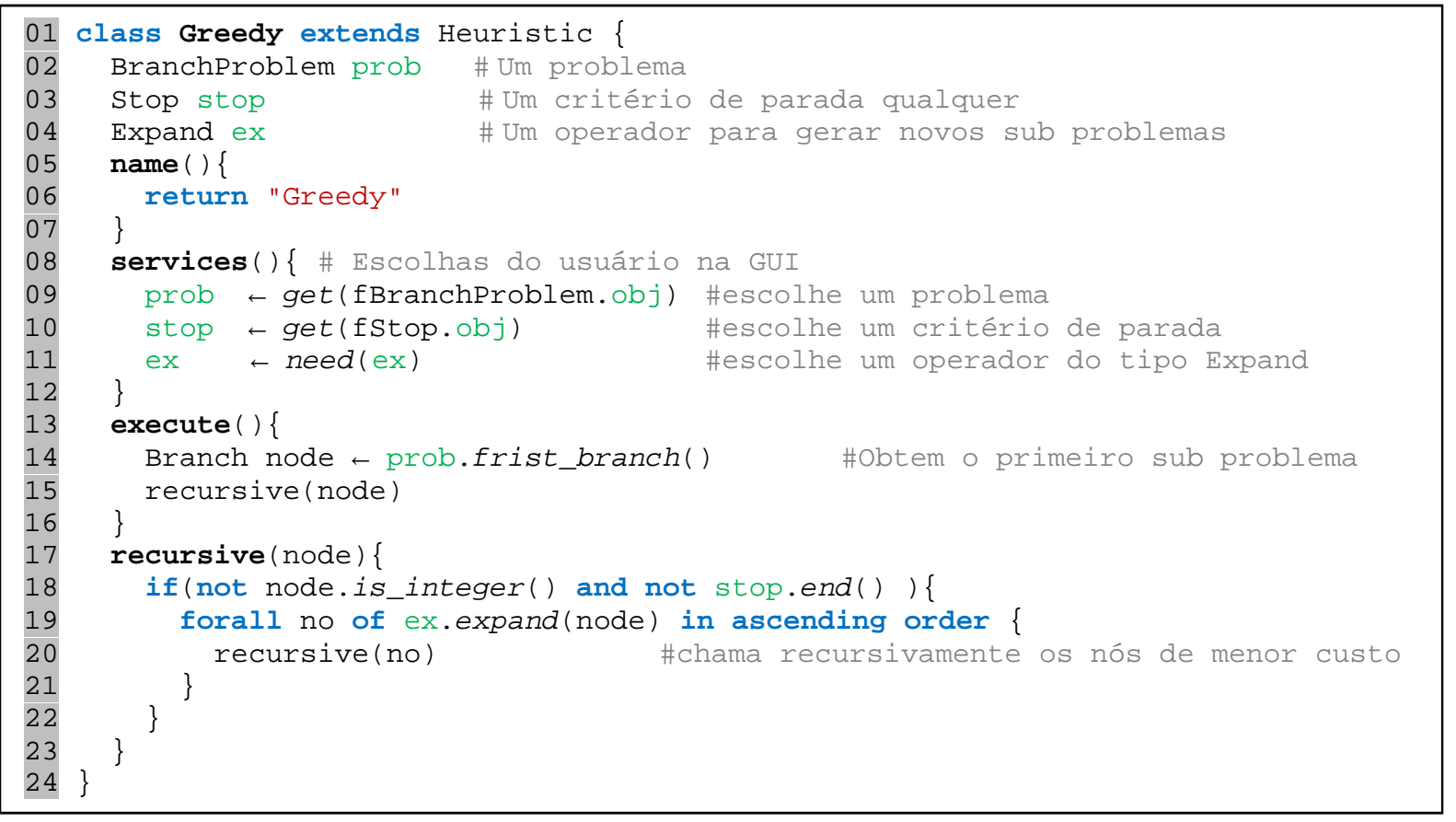

Figura 53: Implementação do método heurístico Greedy no ProOF. 


\subsection{Montando e Executando Tarefas}

Após a implementação de métodos e problemas no ambiente, o usuário poderá montar e executar seus testes computacionais (tarefas). Na seção 3.2 foi apresentada uma visão geral sobre o uso do ProOF, onde a Figura 10 previa que o módulo Client seria utilizado para catalogar o código desenvolvido pelo usuário e para realizar montagem das tarefas. Sendo assim, o primeiro passo será catalogar a versão e disponibilizar uma GUI como ilustrado na Figura 54. Nesta GUI, o usuário vai indicar para o ProOF onde está o seu projeto (Project) com o código dos métodos e problemas implementados. Sempre que forem adicionados novos métodos e problemas ao ambiente, ou feita modificações em algum destes, é preciso catalogar a nova versão do código. Neste momento, é realizada a compilação do código e a interpretação dos parâmetros solicitados pelos métodos e problemas do usuário.

$\mathrm{Na}$ Figura 54, está exemplificado que quatro versões de código foram catalogados no ProOF, cada linha na tabela no lado esquerdo representa uma versão, onde são indicados a linguagem de programação utilizada, a data da última modificação, o nome atribuído aquela versão, quantos bytes e componentes possuem o código e o caminho (path) de onde está o projeto.

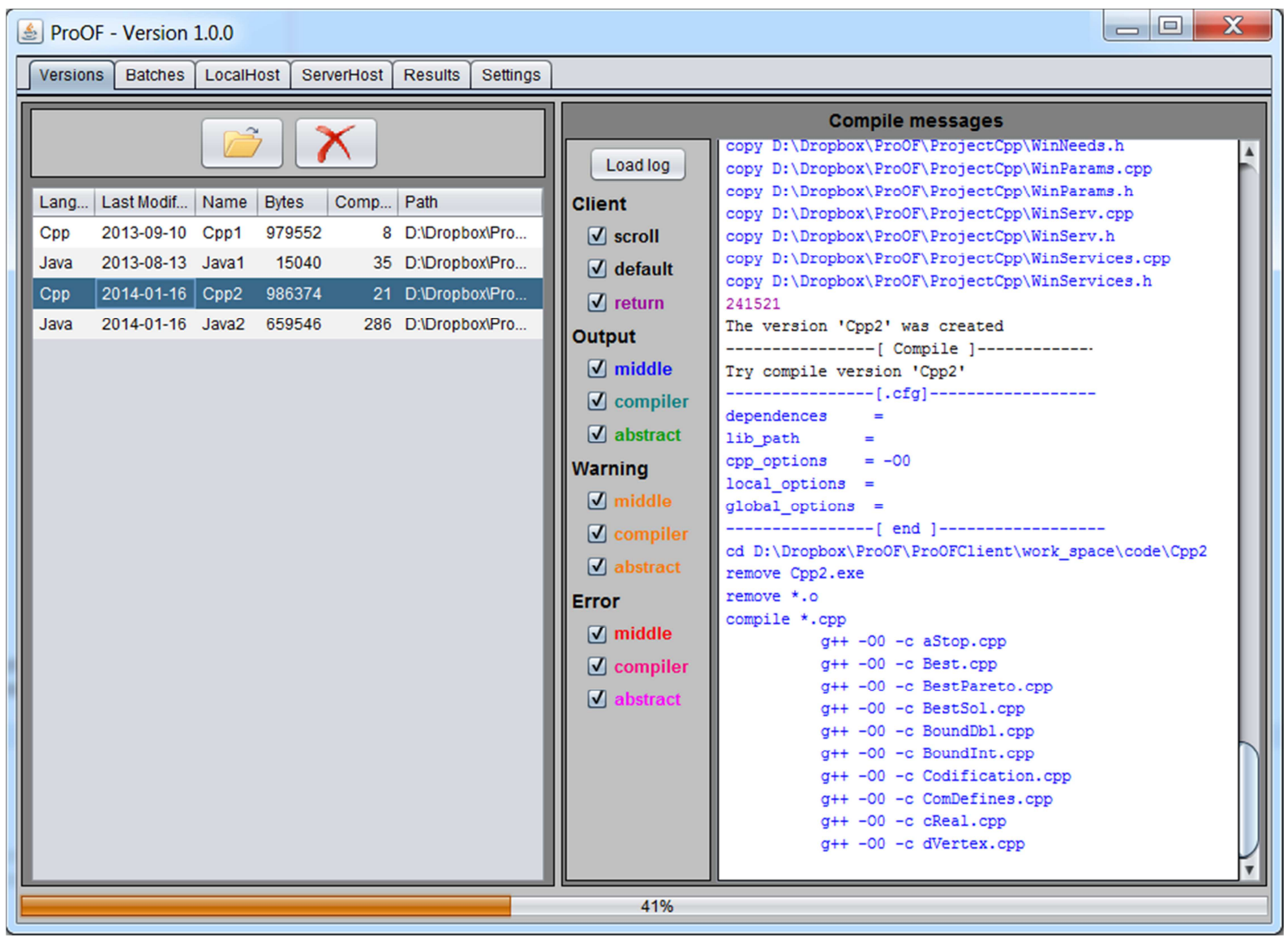

Figura 54: GUI para catalogar os códigos do usuário. 
Na tabela da Figura 54, pode ser observado que existem duas versões na linguagem Java (nomeadas como Java1 e Java2) e duas versões na linguagem $\mathrm{C}++(\mathrm{Cpp} 1$ e Cpp2). Na tela ao lado direito da tabela, também são mostradas as mensagens e erros de compilação. No momento em que foi salva esta imagem, estava ocorrendo a compilação da versão Cpp2 em C++. A barra de progresso em $41 \%$ indica o avanço da compilação. O botão Abrir $(\because)$ é utilizado para adicionar/atualizar novas versões dentro do $\operatorname{ProOF}$ e o botão $\operatorname{Excluir}(\boldsymbol{X})$ é utilizado para excluir versões catalogadas. Terminada esta etapa, o usuário será guiado para a definição dos testes computacionais utilizando também o módulo Client (aba Batches no lado superior da Figura 54).

Se existir um código já devidamente catalogado no ProOF, o usuário poderá montar as tarefas das versões já catalogadas a serem executadas. Uma interface gráfica será gerada automaticamente para obter os parâmetros utilizados nas implementações realizadas pelo usuário. Esta interface gráfica automática começa perguntando ao usuário qual das versões catalogadas este vai utilizar para montar um conjunto de tarefas. Assim, o ProOF disponibilizará uma caixa de seleção para o usuário escolher uma versão, Figura 55 (a).

Neste exemplo, a versão Java2 corresponde à versão que contém todos os códigos já desenvolvidos para o ProOF, constando também os exemplos já apresentados nas seções anteriores. Depois de selecionada a versão, a interface gráfica automática irá pedir para o usuário escolher um dos métodos adicionados, Figura 55 (b). Neste exemplo, o GA implementado na seção 4.3 foi escolhido. A partir da escolha do método, o conteúdo na interface gráfica poderá variar bastante e dependerá dos parâmetros e vinculações solicitadas pelo código do usuário. No código da Figura 24 (seção 4.3), foi solicitado para o funcionamento do GA: um problema, um critério de parada, e operadores para inicialização, crossover e mutação.

\begin{tabular}{|l|l|l|l|l|l|}
\hline Version & Run \\
\hline $\begin{array}{l}\text { Java1 } \\
\text { Java2 }\end{array}$ \\
\hline Java2
\end{tabular}

Figura 55: Montando os testes computacionais. 
Ao solicitar o problema e o critério de parada, foi utilizada a função get (Figura 24) e assim serão criadas duas caixas de seleção na interface gráfica para seleciona um problema e um critério de parada respectivamente como ilustrado na Figura 55 (c). Neste exemplo, o problema caixeiro viajante (TSP) e o critério de parada por tempo (Time) foi escolhido. Em seguida, os pedido da função need (Figura 24) são processados. levando a montagem de 3 caixas para se escolher os operadores de inicialização, crossover e mutação (Figura 56).

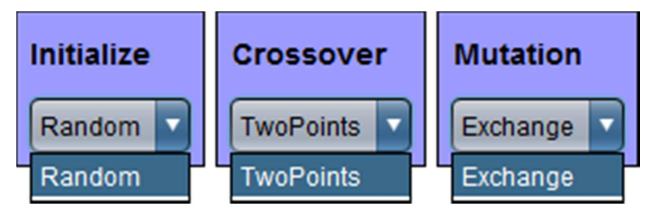

Figura 56: Escolhendo os operadores a serem utilizados.

Após a escolha dos operadores na interface gráfica, ficará faltando apenas a escolha dos valores para os parâmetros (Figura 57). Os parâmetros size e tour foram solicitados pelo GA (ver Figura 24 na seção 4.3). O parâmetro time é solicitado pelo critério de parada por tempo já disponível no ProOF (ver Figura 12 na seção 3.4) e que foi reaproveitado pelo GA. O parâmetro Instance for TSP foi solicitado pelo caixeiro viajante na implementação da classe TSP Instance na seção 4.3 (ver Figura 27).

Na Figura 57, quatro arquivos de instância para o caixeiro viajante foram selecionados. Como pode ser observado, no campo para preenchimento do parâmetro size, mais que um valor pode ser incluído desde que separados por ponto e vírgula. A caixa de seleção de arquivos (Instance for TSP) também aceita múltiplos arquivos. Assim será feita uma combinação dos valores para montagem de múltiplas tarefas. O cálculo do número de tarefas geradas para os parâmetros preenchidos desta forma seria: size $*$ tour $*$ time $*$ instance $\rightarrow$ $2 * 1 * 1 * 4=8$. Desta forma, a aplicação Client interpretará todos estes valores, gerando um total agora de 8 tarefas distintas. Todas as possibilidades de combinar os dois valores para size com as quatro instâncias selecionadas foram consideradas. Isto possibilita uma forma rápida de montar vários teste e fazer uma análise de sensibilidade de parâmetros.

Uma caixa de parâmetros não prevista também apareceu (Number of Executions) na Figura 57. Esta caixa sempre estará disponível no ProOF e define quantas vezes uma mesma tarefa será executada, sendo útil para avaliar a média no desempenho para métodos estocásticos. 


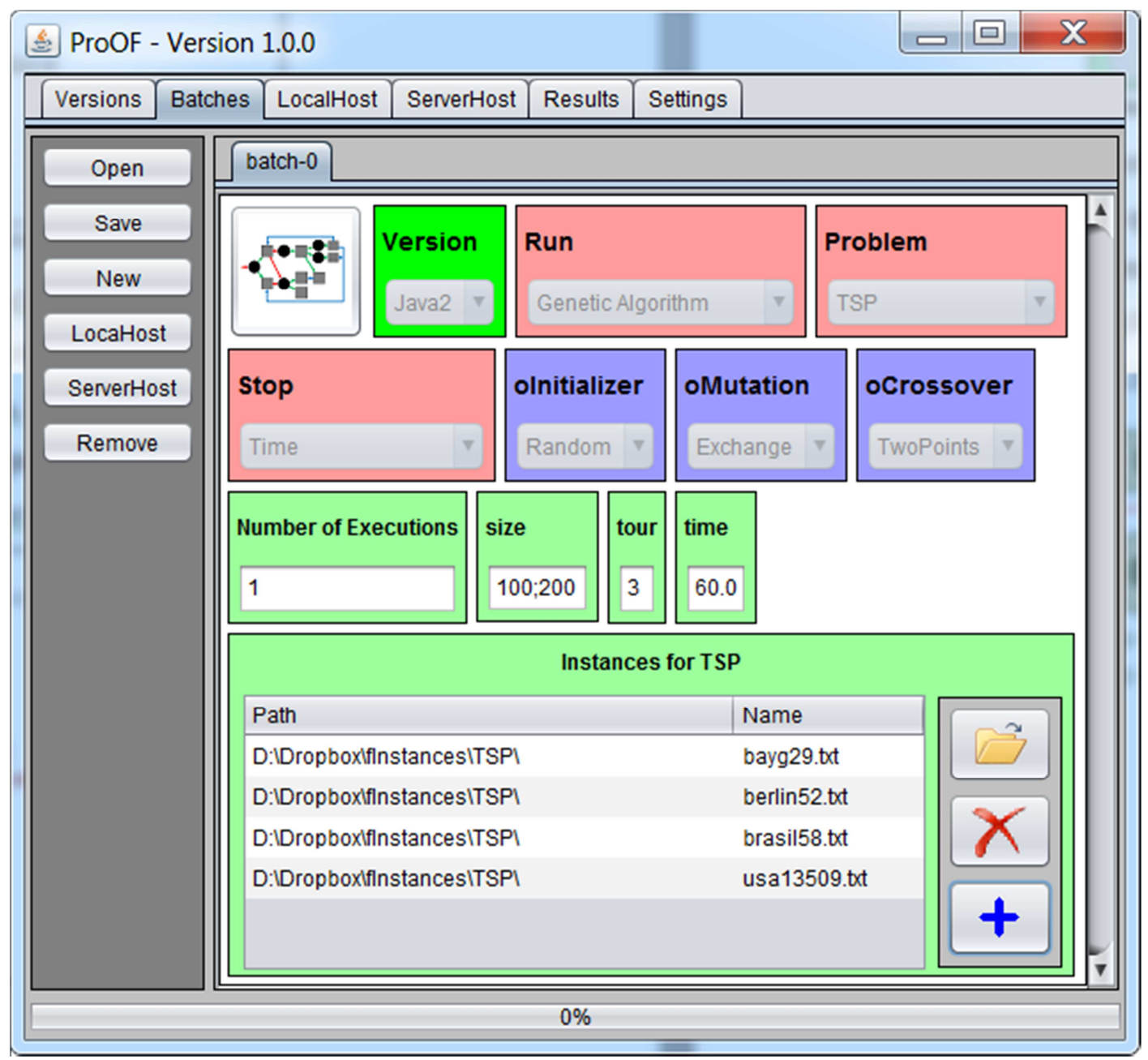

Figura 57: Interface gráfica para montagem das tarefas.

No painel à esquerda na Figura 57 temos os botões: Open, Save, New, LocalHost, ServerHost e Remove. O botão Open permite abrir um conjunto de tarefas (bathes) salvas anteriormente. A opção Save guarda o conjunto de tarefas que está sendo montado atualmente. O botão New cria um novo batch para montagem de tarefas. Note na imagem que existe 1 batch (batch-0) em processo de montagem. Este botão criará mais abas (batch-1, batch-2, ...) para que sejam escolhidos outras versões de código, métodos e problemas para serem montados e que serão executados simultaneamente. A opção LocalHost envia todas as tarefas montadas para serem executadas no próprio computador e o botão ServerHost envia as execuções para serem distribuídas por um servidor. O botão Remove exclui um batch selecionado.

Após a montagem das tarefas e seu envio para serem executadas no modo Localhost, haverá uma tela para configurar e gerenciar as execuções. A Figura 58 mostra esta interface gráfica que contém: um conjunto de botões (painel à esquerda), um conjunto de threads para execução das tarefas (painel no centro) e uma tabela (Tasks) listando as tarefas montadas (painel à direita). 


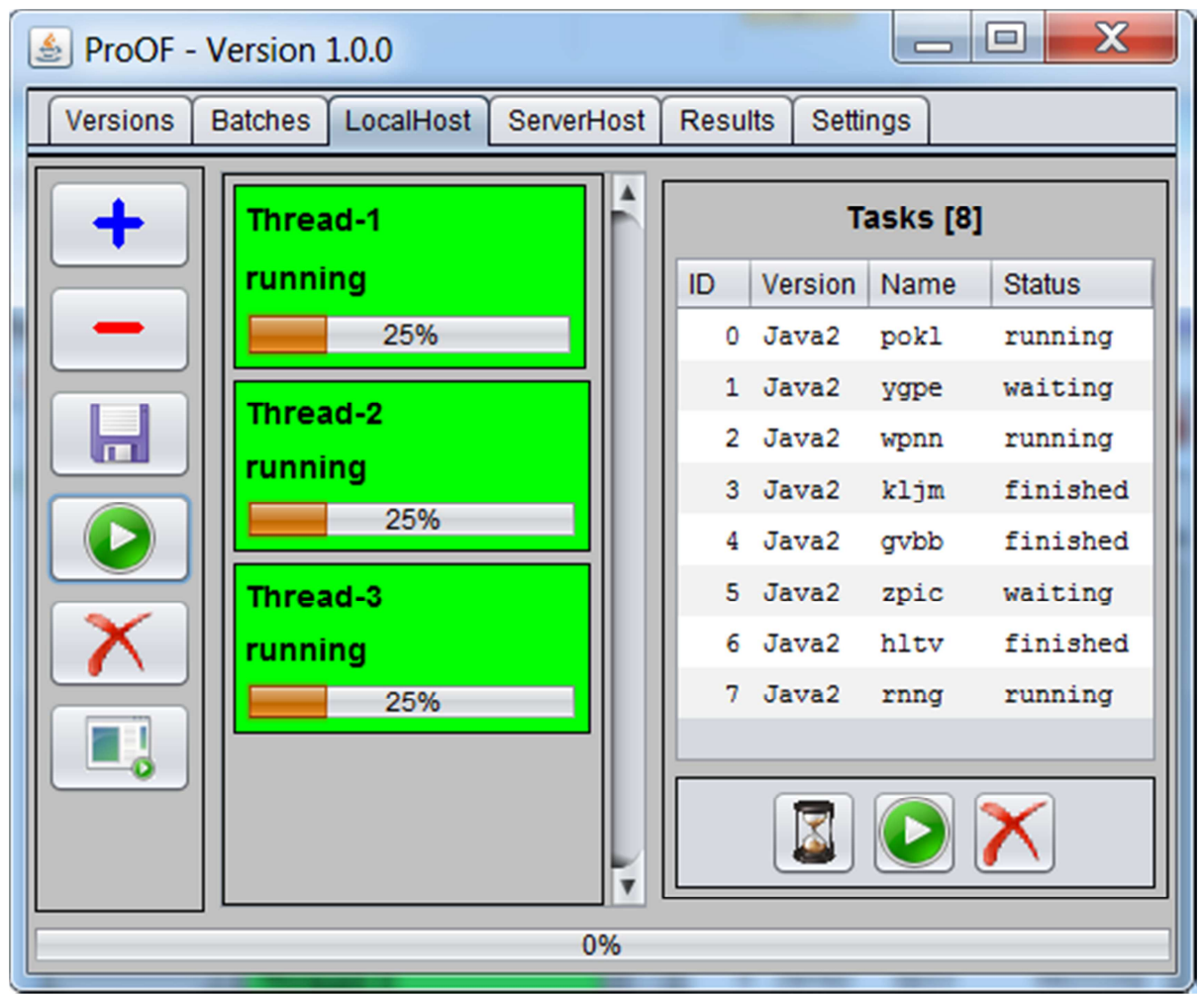

Figura 58: Interface gráfica para gerênciar a execução das tarefas em modo LocalHost.

No painel que contém as tarefas montadas, são informados um número de identificação (ID), a versão do código (Version) que corresponde aquela tarefa, um nome atribuído pelo ProOF para a tarefa (Name) e o estado da tarefa (Status). O estado pode informar se a tarefa está esperando para ser executada (waiting), se está executando naquele momento (running) ou se já foi executada (finished). Nesta figura são ilustradas as 8 tarefas montadas anteriormente (ver Figura 57). Os dois primeiros botões $(+$ e - ) são utilizados para configurar o número de threads que executarão em paralelo as tarefas listadas. $\mathrm{O}$ botão $(\boldsymbol{\dagger})$ adiciona mais uma thread para execução e o botão (-) remove uma thread. O botão () inicia a execução do conjunto de tarefas e o botão $(\mathcal{X})$ cancela todas as execuções. O último botão $(\square+$ ! $)$ abre outra tela que mostra os detalhes da execução de cada tarefa em particular.

Assim, o último botão (回) apresentará uma tela como na Figura 59, onde a primeira thread estava executando a última tarefa (rnng) em 21\% na Thread-1. Esta tela contém uma aba para cada thread em execução (Thread-1, Thread-2 e Thread-3). Na parte superior da tela, existe uma barra de progresso que informa o andamento da evolução do algoritmo. Na parte inferior, existe uma área com as impressões na tela pelo algoritmo genético. Toda vez que ocorre uma melhoria na melhor solução, uma nova linha é impressa informando o número de funções avaliadas até aquele momento (eval), o tempo em segundos decorrido do início da execução até o presente momento (time) e o valor de custo da função objetivo (objective). 
Nas seções 4.3 e 4.4, foram inseridos o métodos algoritmo genético e o problema caixeiro viajante, mas em nenhum momento foi definida estas impressões na tela. Também não foi definido em momento algum como o algoritmo genético pode armazenar a melhor solução. Não foi preciso fazer isto, pois o ProOF armazena a melhor solução, faz as impressões na tela e atualiza a barra de progresso automaticamente, através da classe Problem herdada pelo caixeiro viajante (Figura 37). Entretanto, apesar de o ProOF automatizar as impressões na tela e coleta de resultados, é permitido ao usuário fazer suas próprias impressões e coletar seus resultados como queira. Assim o ambiente não limita o que o usuário pode fazer.

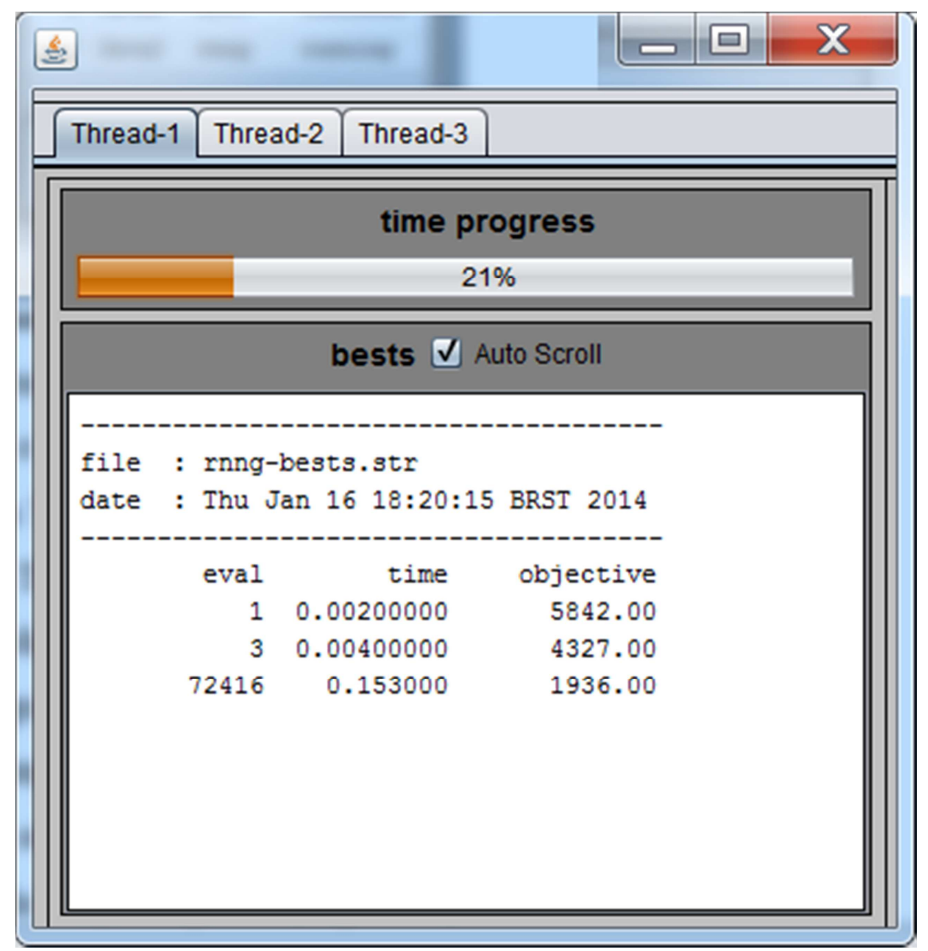

Figura 59: Uma tarefa sendo executada.

\subsection{Conclusão}

Este capítulo apresentou a usabilidade da ProOF, indicando os passos necessários para a implementação de métodos e problemas variados dentro do ambiente. Dois métodos metaheurísticos (GA e NSGA-II) para resolver problemas mono e multi-objetivos foram implementados e também foi apresentada uma adaptação do método exato Branch \& Bound e de uma heurística gulosa Greedy. O problema TSP foi especializado para os métodos GA, Branch \& Bound e Greedy e duas estruturas FMS foram desenvolvidas para auxiliar na implementação de problemas mono e multi-objetivos no domínio real. Ao final, foi ilustrada a usabilidade do ambiente na montagem e execução de testes computacionais, onde o exemplo solucionado utilizou o GA para resolve o problema TSP, ambos implementados neste capítulo. 


\section{CAPÍTULO 5}

\section{Publicações Utilizando o ProOF}

"Faça as coisas o mais simples
que puder, porém não as mais
simples."

Albert Einstein

\subsection{Introdução}

O ProOF foi utilizado como ferramenta de desenvolvimento em alguns trabalhos recentemente publicados na literatura [26]-[30]. A forma como dois destes trabalhos, [26] e [30], foram implementados no ProOF será apresentada neste capítulo. Na seção 5.2 é apresentado um algoritmo evolutivo híbrido implementado, onde o mesmo foi aplicado como método de resolução em dois problemas distintos descritos em [30] e [26] e que serão detalhados nas seções 5.3 e 5.4 respectivamente.

\subsection{Algoritmo Genético Multi-Populacional Híbrido}

No Capítulo 4 foi apresentado o ProOF com uma arquitetura definida (Figura 17) e como utilizar o conceito estabelecido como estrutura FMS (Figura 18). Assim, partindo da arquitetura já definida e dos conceitos da estrutura FMS, o método Multi-Population Genetic Algorithm (MPGA) foi adicionado à ferramenta. Neste método, as soluções (indivíduos) estão organizadas em estruturas variadas que representarão cada população. O MPGA é combinado com uma metaheurística de busca local para intensificar a busca na vizinhança das melhores soluções encontradas.

A Figura 60 apresenta a arquitetura do MPGA, onde quatro novas estruturas FMS foram criadas para o funcionamento deste método. O início destas estruturas é indicado por fPopulation, fLocalsearch, fStructure e fTemp que representam um vértice do tipo Factory. A classe MPGA foi vinculada a um problema (Problem) e a um critério de parada (Stop). Assim, o método adicionado poderá resolver qualquer especialização de Problem dentro do ambiente bem como utilizar diferentes critérios de parada, ou seja, o MPGA se torna um componente reutilizável do ProOF. Além disto, o método tem como especificidade 
utilizar uma busca local e trabalhar com várias populações. Logo, a classe MPGA também está vinculada a uma busca local (LocalSearch) e a um conjunto de populações (Population). Estas duas classes iniciam estruturas FMS criadas para viabilizar o funcionamento das especificidades deste método proposto.

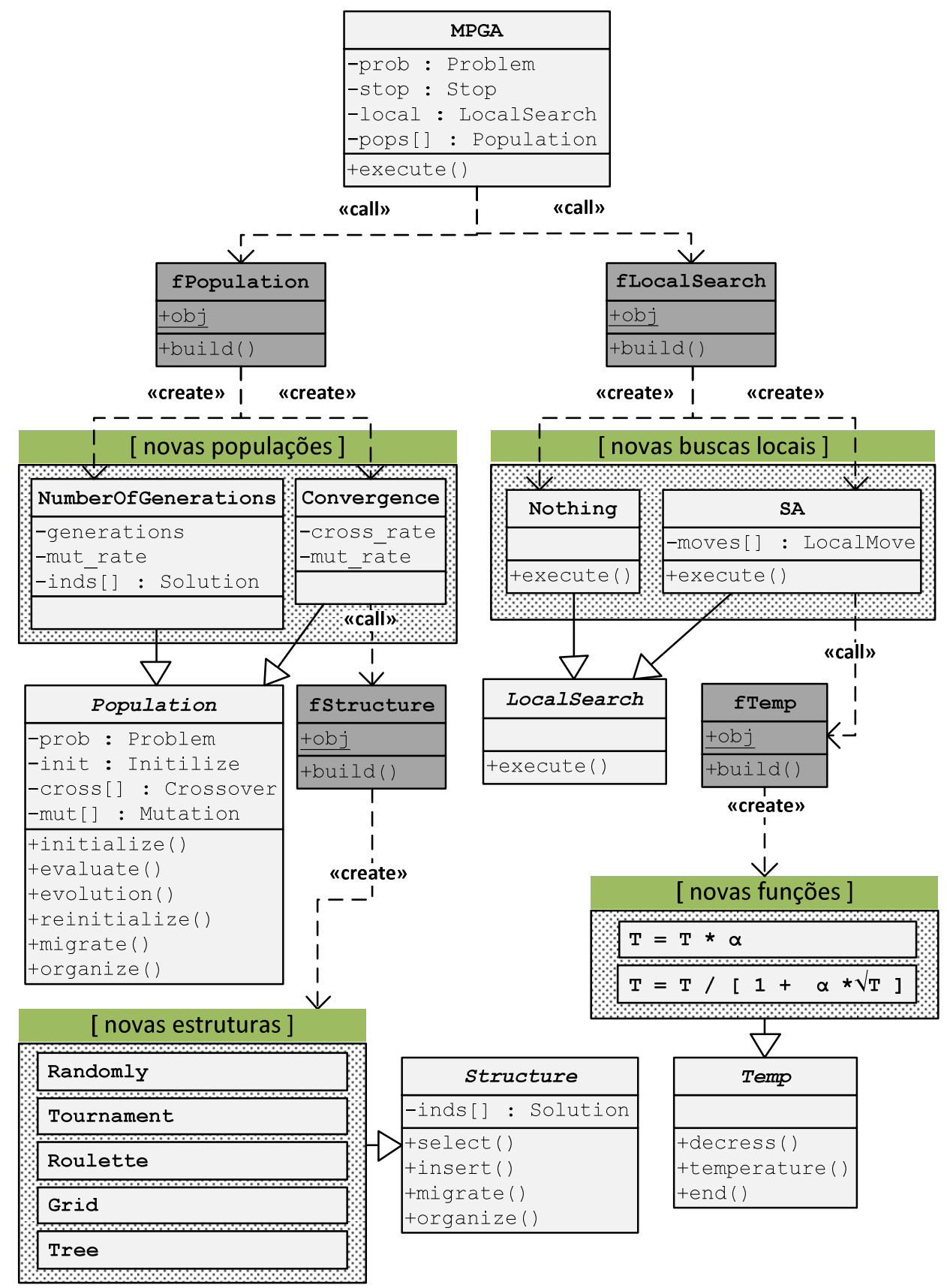

Figura 60: Arquitetura para o algoritmo evolutivo híbrido.

Na Figura 61, é apresentado um pseudocódigo do MPGA que ilustra os principais aspectos de sua implementação no ProOF. Nas linhas de $2-5$, é declarado que o MPGA vai solicitar um problema, um critério de parada, uma busca local e um conjunto de populações para seu 
funcionamento. Nas linhas 10 - 13, estas solicitações são realizadas ao ProOF através da função get que chama cada uma das estruturas FMS necessárias.

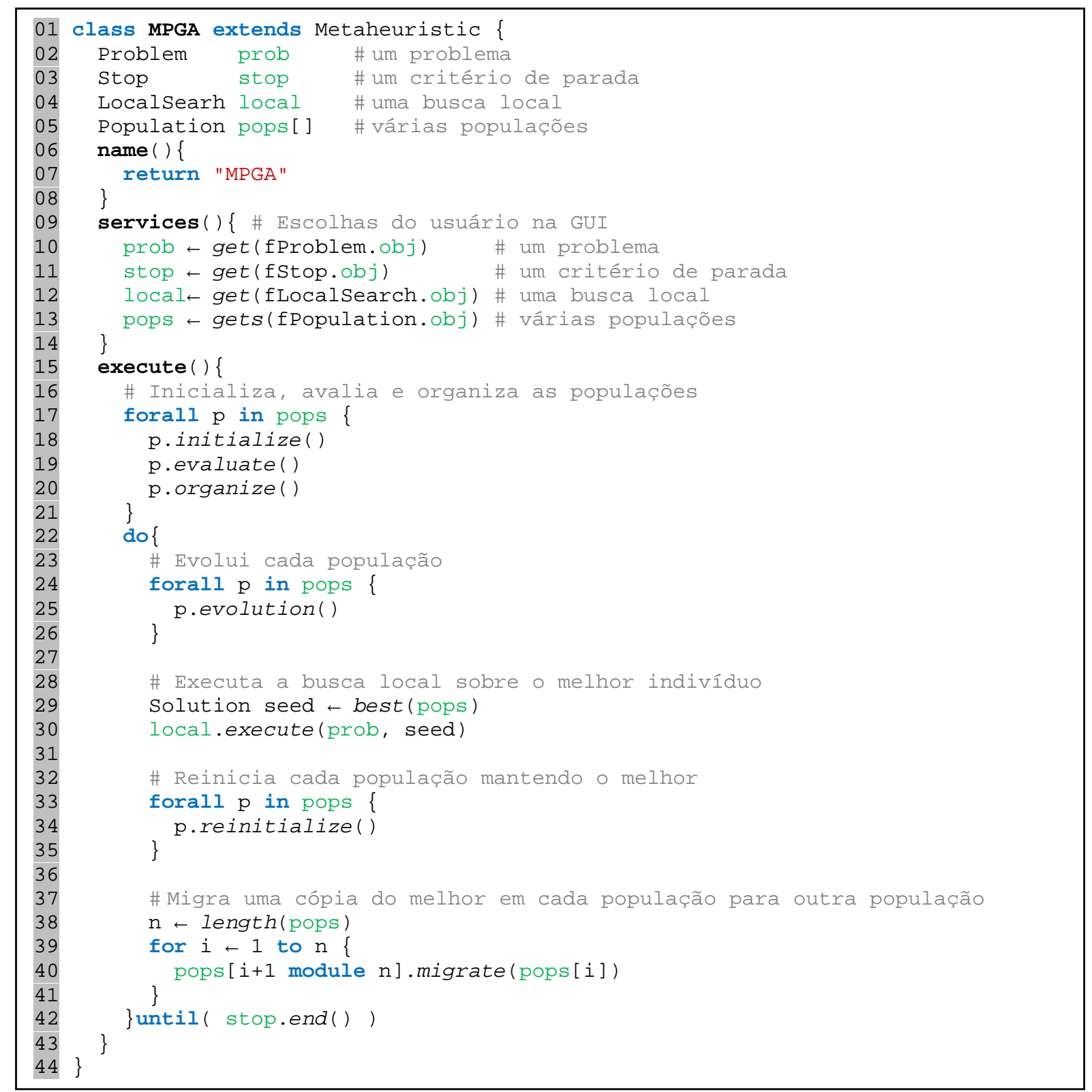

Figura 61: Pseudocódigo do algoritmo evolutivo híbrido.

O método define sua execução (execute) iniciando, avaliando e organizando todas as populações (linhas 17-21). A evolução de cada população ocorre em seguida (linhas 24-26) e uma busca local intensifica a busca na vizinhança da melhor solução (linhas 29 - 30) ao final da evolução de todas as populações. Todas as populações são reinicializadas (linhas 33 - 35) em seguida, preservando apenas o melhor indivíduo em cada uma delas. Também há migrações dos melhores indivíduos entre as populações (linhas 38 -41). A operação módulo (a module b) retorna o resto da divisão de a por b com a e bo números inteiros. 
O MPGA trabalha com as interfaces abstratas das classes Population e Localsearch. Logo, a definição de como uma população está organizada, evolui e migra seu melhor indivíduo é definida posteriormente com a implementação de classes concretas. O mesmo ocorre com a busca local utilizada, onde inicialmente qualquer busca local pode ser implementada para trabalhar com o MPGA.

A estrutura FMS iniciada por fLocalsearch pode ser utilizada para definir diversas formas de busca local. Na Figura 60, apenas duas implementações foram realizadas: Nothing, que é selecionado quando não se deseja executar uma busca local no MPGA, e SA, que implementa a metaheurística SA [32]. O método SA utiliza uma função de resfriamento da temperatura do sistema, sendo definida outra estrutura FMS para implementar variados tipos de funções (Temp). A Figura 62 ilustra o funcionamento do Simulated Annealing que é utilizado pelo MPGA. O SA especializa a classe Localsearch e precisa de uma função de resfriamento (linha 2) e operadores de movimento local para executar (linha 3). Os detalhes de como funciona a função de resfriamento e os operadores de movimento local implementados podem ser encontrados em [30].

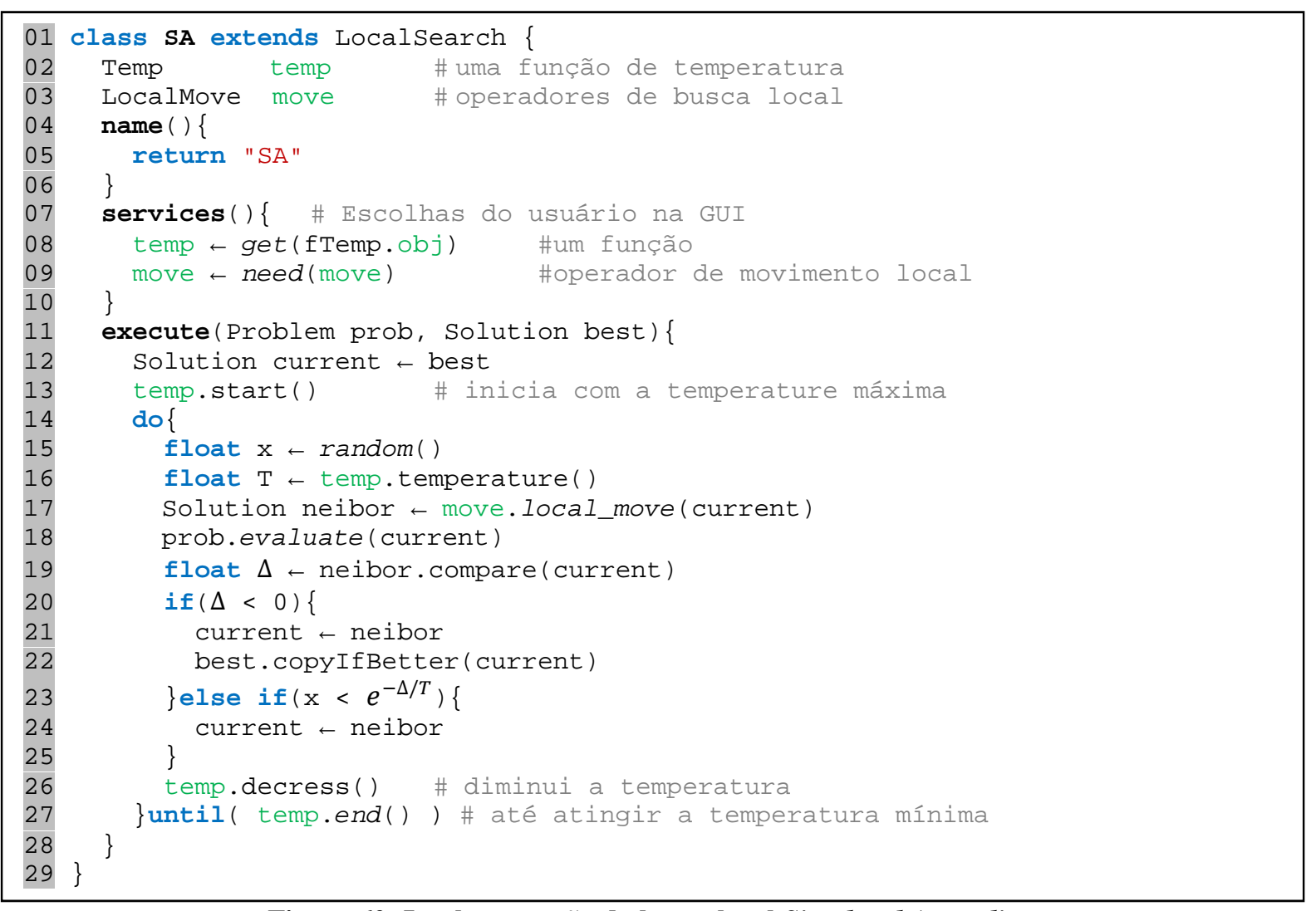

Figura 62: Implementação da busca local Simulated Annealing.

As populações do MPGA foram implementadas para evoluir de duas formas diferentes. Na primeira forma (NumberofGenerations), o método executa o processo evolutivo (seleção, 
crossover e mutação) durante um certo número de gerações. Na segunda forma (Convergence), o método executa o processo evolutivo enquanto não ocorrer convergência. A convergência ocorre quando um novo indivíduo não é inserido na população, tal como descrito em [30]. Na Figura 60, pode ser visto que a classe Convergence chama mais uma estrutura FMS, fStructure, que fornece implementações diferentes para definir como será a seleção, inserção, migração e organização das soluções de uma população.

Dentro do ProOF, existe a possibilidade de que qualquer classe filha de Approach reutilize as estruturas FMS. O usuário também pode definir novas estruturas FMS a serem utilizadas em qualquer parte do código. Isso permite tanto o reuso do código quanto a integração de novos códigos reaproveitáveis. O MPGA implementado trabalha com a definição abstrata de um problema e de um critério de parada. Logo, ele poderá resolver qualquer problema adicionado ao ambiente utilizando qualquer critério de parada do ambiente.

A Figura 63 indica todas as 18 diferentes formas de executar o MPGA. É como se existissem 18 diferentes implementações do algoritmo MPGA. Em [30] foram selecionadas as opções de execução: Convergence $\rightarrow$ Tree $\rightarrow \mathrm{SA} \rightarrow \mathrm{T}=\mathrm{T}^{\star} \alpha$. Também foi selecionado $\mathrm{O}$ critério de parada por tempo com corte (Time\&Cut). Em [26], foram selecionadas as abordagens: Convergence $\rightarrow$ Tree $\rightarrow$ Nothing. O critério de parada escolhido foi o número de avaliações (Eval). Nas próximas seções, a inserção no ProOF de dois problemas, [30] e [26], solucionados utilizando o MPGA será descrita.

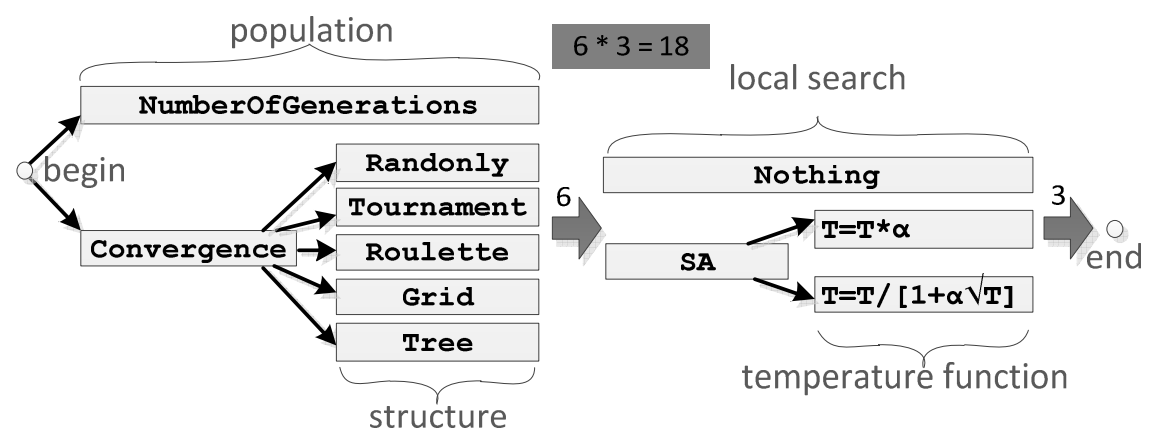

Figura 63: Dezoito combinações possíveis para uso do MPGA.

\subsection{Problema: Glass Container Industry}

O MPGA descrito na seção 5.2 foi aplicado para solucionar um problema real encontrado em uma indústria de produção de garrafas de vidro, Glass Container Industry (GCI). O GCI é um problema de planejamento e programação da produção no curto prazo como estabelecido em [68] e [69]. Neste problema, o MPGA é combinado com a metaheurística de busca local 
Simulated Annealing (SA) e outra heurística chamada Cavity Heuristic $(\mathrm{CH})$, especificamente desenvolvida para resolver parte do problema GCI. O SA é aplicado para intensificar a busca nas melhores soluções encontradas pelo MPGA e a $\mathrm{CH}$ determina os valores para uma parte das variáveis de decisão relevante ao GCI. Os detalhes sobre SA e CH podem ser encontrados em [30].

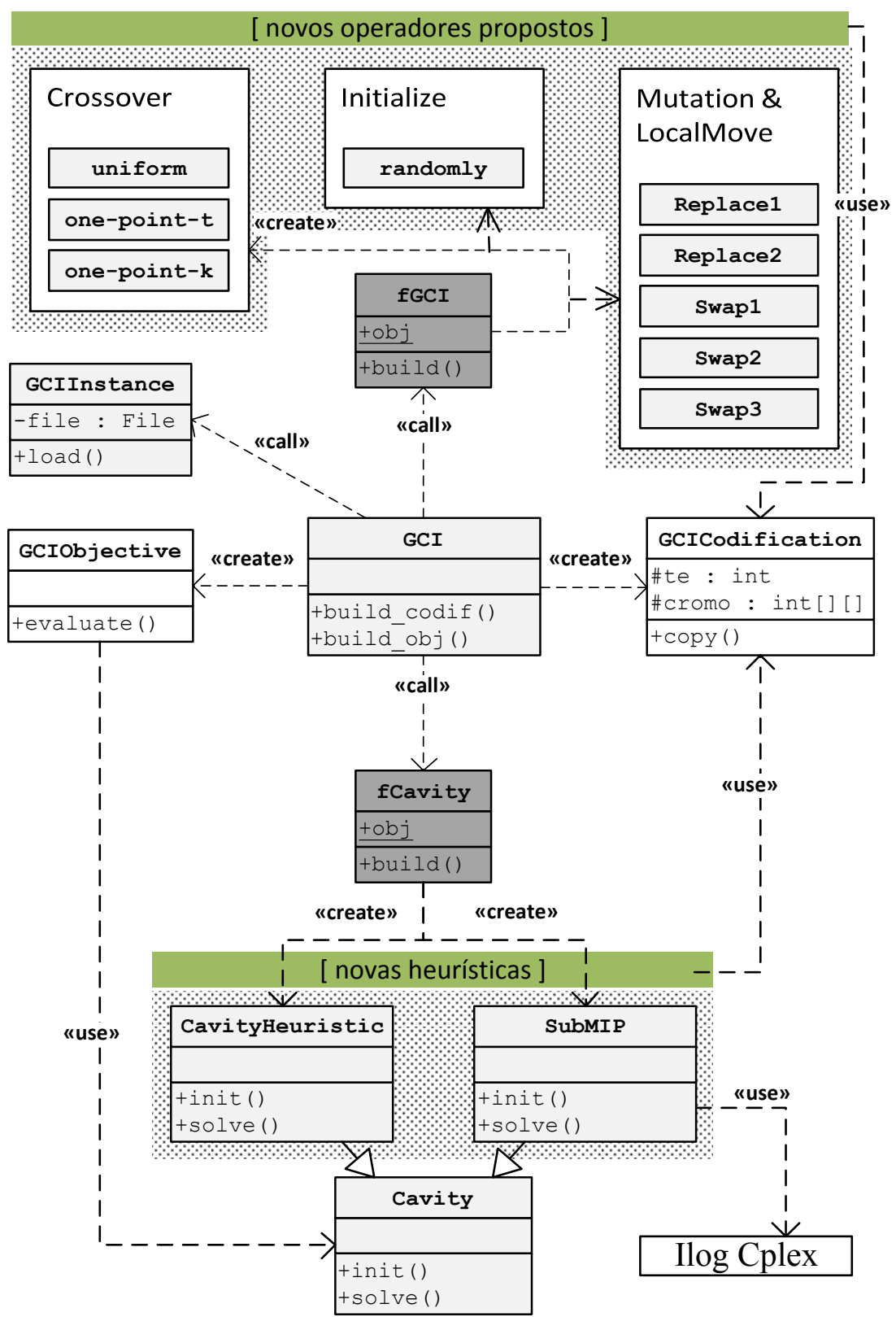

Figura 64: Arquitetura para o problema Glass Container Industry.

A Figura 64 apresenta a arquitetura do GCI, onde foi definida uma nova codificação (GCICodification) e função objetivo (GCIObjective). Uma estrutura FMS (fGCI) foi desenvolvida para definir a implementação de diferentes operadores para a nova codificação do problema. Em [30], foram implementados um operador de inicialização, três operadores de 
crossover e cinco mutações diferentes. As implementações definidas como mutações no MPGA foram utilizadas como operadores de busca local no SA.

Outra estrutura FMS (fCavity) foi utilizada para a implementação de duas diferentes heurísticas para calcular parte das variáveis de decisão do GCI: CavityHeuristic e SubMIP. A CavityHeuristic $(\mathrm{CH})$ é uma heurística de construção determinística desenvolvida especificamente para a realidade deste problema industrial. SubMIP utiliza de técnicas de programação matemática para resolver um modelo inteiro misto, encontrando soluções ótimas para parte das variáveis de decisão. Logo, um modelo matemático reduzido (SubMIP) foi proposto em [30] e implementado no ProOF para ser solucionado utilizando o solver CPLEX 12.2 da IBM-ILOG. Apesar da heurística CH não garantir as soluções ótimas, ela é rápida e o desempenho combinado com MPGA foi superior ao obtido usando a combinação com o SubMip.

Visto que a arquitetura desenvolvida para o estudo do problema GCI é composta por diversas classes, será apresentada aqui apenas a classe principal (GCI) que representa o problema. Na linha 1 da Figura 65, definimos GCI como um novo problema dentro do ProOF. Este problema utilizará, dados industriais que estão armazenados em um arquivo de instância da classe GCIInstance, linhas 2. Na linha 8, é adicionado ao ProOF este componente para que uma solicitação do arquivo seja feita. A linha 9 torna disponível os operadores implementados para o GCI e a linha 10 define que uma abordagem Cavity deve ser escolhida. Na linha 13, é instanciada a classe GCICodification responsável por armazenar a representação das soluções e na linha 16 é instanciada a classe GCIObjective responsável por avaliar uma codificação e armazenar seu custo.

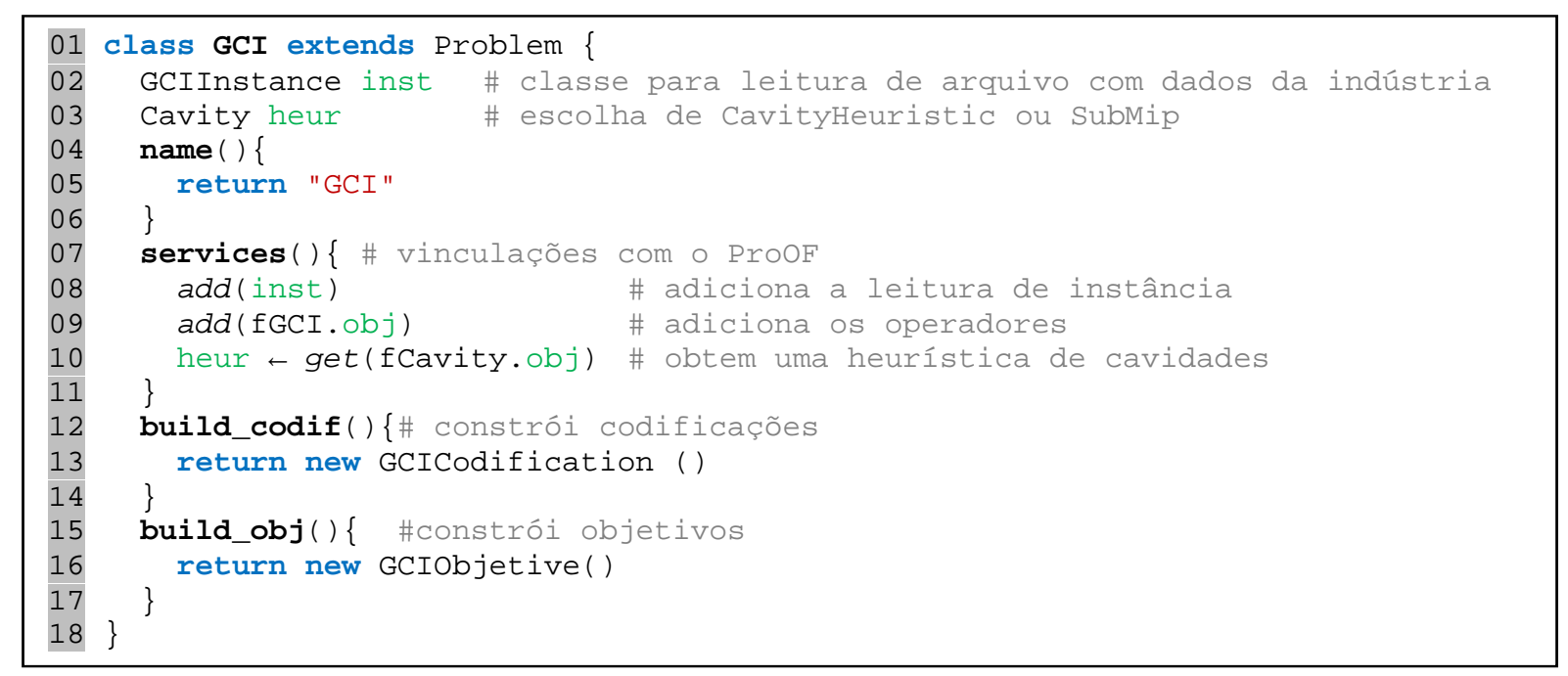

Figura 65: Classe principal do problema GCI. 


\subsection{Problema: Proportional, Integral and Derivative}

O MPGA descrito na seção 5.2 também foi aplicado para solucionar um problema de ajuste de controle Proporcional, Integral e Derivativo (PID) [70]. Uma solução do problema é definida por três variáveis reais: $K c, T i$ e $T d$. Dois critérios de controle PID foram otimizados: ITAE (integral do tempo multiplicada pelo erro absoluto) e ITAY (integral do tempo multiplicada pela saída absoluta). Duas redes neurais foram treinadas para cálculo de cada um dos critérios. Logo, o MPGA foi utilizado para otimizar os parâmetros de entrada $(K c, T i$ e $T d$ ), onde as redes neurais atuaram como função de fitness. Os resultados computacionais obtidos atestaram um desempenho superior do MPGA em relação a outras abordagens da literatura.

No caso do problema PID, o MPGA foi executado sem hibridização com método de busca local. Logo, a classe Nothing foi utilizada neste caso. Também foi reaproveitada a codificação real (cReal, na Figura 40) com todos os operadores desta codificação já disponíveis no ProOF. A fim de facilitar a inclusão de problemas com reuso da codificação real e seus operadores, na seção 4.5 vimos que foi desenvolvida uma FMS para a codificação real. Sendo assim, o PID será um problema no ProOF tal como exemplificado na seção 4.5.

A Figura 66 descreve o código completo para incluir o problema PID ao ProOF. O PID utiliza um arquivo file (linha 2) onde estão armazenados os pesos das duas redes neurais. Na linha 9, é solicitado como parâmetro este arquivo e na função load o arquivo é lido e armazenado em duas matrizes (ITAE e ITAY). A linha 18 define que uma solução do problema é representada por três variáveis reais $(K c, T i$ e $T d)$. Na linha 21 , é definido que a função objetivo do problema é uma ponderação da saída das duas redes neurais. A função NN (Neural Network) é utilizada para a propagação do sinal de cada rede neural (ITAE e ITAY) e retorna a saída para cada rede neural.

Por fim, o problema é incluído no ambiente ao se modificar a classe fRealsingle como foi ilustrado na linha 8 da Figura 43. Resumindo, as etapas de implementação do trabalho publicado em [26] foram apenas implementar a classe PID e modificar a classe fRealsingle. O trabalho reaproveitou toda a infraestrutura do algoritmo genético multipopulacional (MPGA) já criado anteriormente para o problema GCI, não sendo preciso implementar novas linhas de código relativas ao métodos no ProOF. Também foi reaproveitada a classe da codificação real inserida anteriormente no ambiente, bem como 
todos os operadores de mutação e crossover para codificação real também previamente definidos no ProOF.

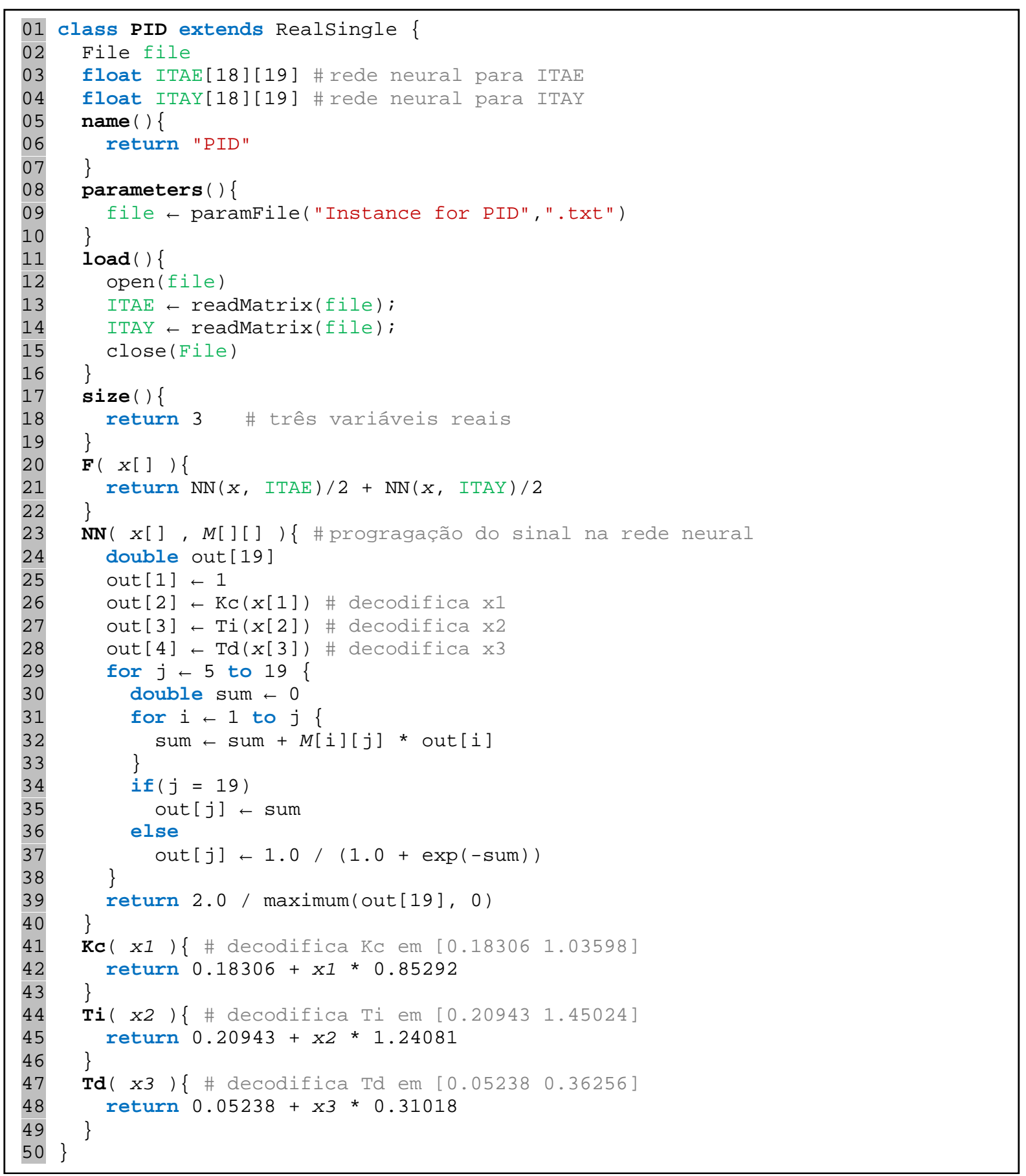

Figura 66: Problema PID.

\subsection{Conclusão}

Neste capítulo, foi inicialmente apresentado que o ProOF auxiliou no desenvolvimento de cinco trabalhos publicados, onde dois destes trabalhos foram detalhados. Foi visto que é permitido ao usuário criar novas estruturas FMS conforme suas necessidades, incentivando assim que o usuário incorpore na ferramenta novos códigos que mantenham as características 
de reusabilidade, flexibilidade e extensibilidade. A seção 5.2 apresentou o método MPGA e destacou a capacidade do ProOF de projetar e combinar métodos. O usuário pode definir que o mesmo projeto do MPGA se comporte de formas variadas, através das escolhas na interface gráfica promovidas pelas estruturas FMS. Assim, novas buscas locais podem ser incorporadas, e formas de organizar e evoluir as populações podem ser implementadas posteriormente. Na seção 5.3, foi implementado o problema GCI que definiu uma nova estrutura FMS, resultando em maior flexibilidade ao possibilitar que as variáveis do problema fossem particionadas. Por fim, o problema PID na a seção 5.4 exemplificou o potencial de reusabilidade dos códigos dentro do ProOF, uma vez que apenas uma classe com poucas linhas de código foi necessária para sua implementação. 


\section{CAPÍTULO 6}

\section{Avaliando o ProOF}

"Todas as coisas são números."

Pitágoras

\subsection{Introdução}

Neste capítulo, será realizada uma avaliação do ProOF como uma ferramenta computacional. Uma comparação das características do ProOF com a de outros frameworks de otimização será realizada inicialmente na seção 6.2, utilizando os critérios apresentados no capítulo 3 adaptados de [59]. A seção 6.3 apresentará os resultados envolvendo testes de desempenho no ProOF, destacando as perdas no desempenho que ocorrem ao utilizar o ProOF em comparação com uma implementação otimizada diretamente em linguagem de programação fora do ProOF, e a eficiência alcançada com o uso da computação paralela. A seção 6.3 conclui este capítulo.

\subsection{Comparação com outros Frameworks}

Na seção 3.2 foram apresentados 10 ambientes voltados para a área de otimização que mais se aproximaram desta proposta. Porém havia dificuldades em avaliar ferramentas de software como estas, pois faltava uma padronização nas avaliações. Sendo comum cada trabalho definir seus próprios critérios como em [8], [46] e [49]. Porém, recentemente um survey em [59] estabeleceu um conjunto de características de interesse para serem avaliadas, considerando seis áreas distintas. Os mesmos critérios levantados em [59] foram adaptados nesta dissertação, a fim de comparar os ambientes. Na seção 3.3 foram verificadas as características que não estavam presentes em cada ambiente, visando projetar o ProOF para suprir a ausência de algumas delas.

As características de interesse visavam definir quais ambientes abrangiam o maior escopo na capacidade de implementação de novos Métodos (área C1) e Problemas (C2), possuíam características Avançadas (C3) como paralelização, hibridização e hyper-heurísticas, forneciam mecanismos de Suporte (C4) como montagem de batch, interface gráfica. Tais 
características também contemplavam uma avalição do Projeto/licenciamento/implementação (C5) e por último avaliavam a Maturidade/popularidade (C6) do ambiente. Um total de 29 características específicas a serem avaliadas foi definido, conforme ilustrado na Figura 1 na seção 3.3 .

Um gráfico apresentando a percentagem de integralização para cada uma das seis características de interesse definidas por [59] é ilustrado na Figura 67. O valor 100\% indica que todas as características foram atingidas para aquela área, onde também é apresentada a porcentagem média considerando os 10 ambientes, a percentagem do melhor para cada área e a percentagem alcançada pelo ProOF. Apenas as características binárias foram consideradas para esta comparação, não sendo contemplado o número de classes (Tam) e publicações geradas (Publ), as quais serão comentadas no texto posteriormente.

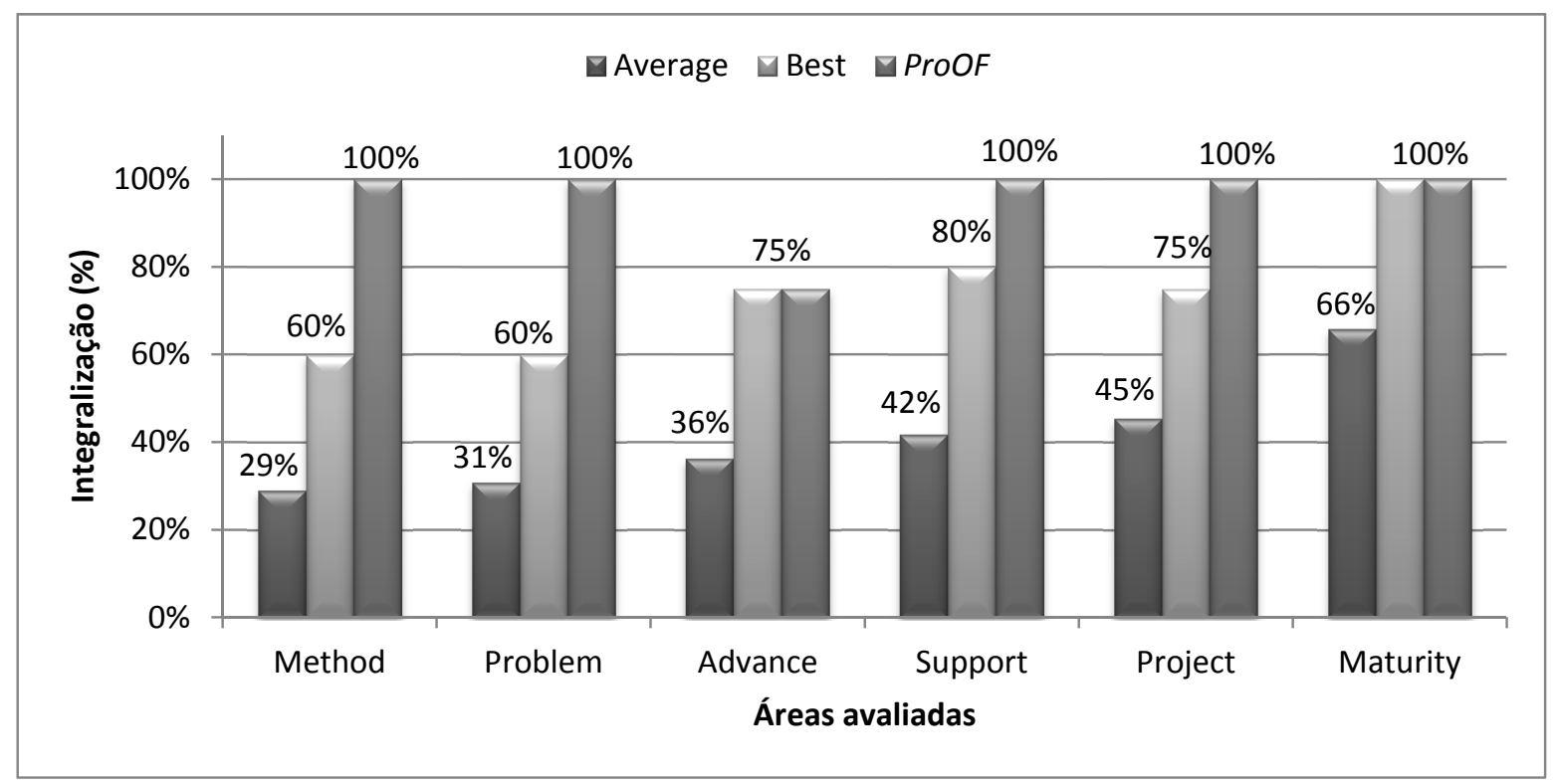

Figura 67: Percentagem de integralização para cada área de interesse.

Considerando a área de Método (C1), o ProOF contemplou todas as características, sendo capaz de trabalhar com metaheurísticas de busca local (BL) e baseadas em população (BP), além de ser utilizado para implementar heurísticas específicas (Heur), técnicas de programação matemática (Mat) e métodos exatos (Exat). Nas seções 1.3, 4.3, 5.2 e 5.3 foi destacado o método de busca local Simulated Annealing implementado no ambiente e que foi utilizado em uma publicação [30] com o ProOF. Para métodos baseados em população de soluções foram apresentados os métodos GA, NSGA-II e MPGA descritos nas seções 4.3, 4.6 e 5.2, respectivamente. Duas heurísticas específicas (Heur) foram projetadas, na seção 4.10 foi apresentada a heurística Greedy e na seção 5.3 a heurística chamada Cavity Heuristic foi especialmente construída para o GCI, onde também foi definida a resolução de um modelo de programação matemática (Mat) usando CPLEX [17]. Ao fim, na seção 4.8, é apresentada a 
implementação no ProOF do método exato (Exat) chamado Branch \& Bound. Sendo assim, o ProOF foi capaz integralizar (100\%) na área de Método, onde na média os ambientes conseguem preencher apenas $29 \%$ deste escopo e o melhor framework nesta área foi o FOM com $60 \%$.

Ao avaliar a área de Problema a média foi $31 \%$ e houve três ambientes (ParadisEO, jMetal e Open Beagle) com 60\% e apenas o ProOF com 100\%. Na seção 4.4, foi apresentado como o ProOF pode ser utilizado para projetar novas codificações (Codif) ao implementar o problema TSP como exemplo. O ProOF também é capaz de trabalhar com problemas mono e multi-objetivo (Obj) conforme foi apresentado nas seções 4.5 e 4.7, respectivamente, onde foi ilustrado como definir restrições (Rest) individuais para cada variável utilizando a função decode. O ProOF foi o único ambiente que apresentou mecanismos para facilitar (Fac) a inclusão de problemas específicos conforme descrito nas seções 4.5 e 4.7. O ProOF também foi o único que apresentou como utilizar suas funcionalidades para implementar novas abstrações de operadores (Oper), conforme descrito na seção 4.8 ao incluir o método Branch \& Bound.

Considerando a área de características Avançado, a média considerando todos os ambientes foi de $36 \%$, onde os melhores ambientes foram ParadisEO e NP-Opt com $75 \%$. O ProOF também conseguiu os mesmos $75 \%$, ao ilustrar que pode ser utilizado para projetar métodos híbridos (Hibri) nas seções 5.2 e 5.3, e também utiliza recursos de paralelização (Paral) e distribuição (Dist) como apresentado na seção 3.7. O ProOF não possui implementações nem oferece mecanismos para implementar hyper-heurísticas (Hyper) ainda, sendo isto deixado como trabalho futuro.

$\mathrm{Na}$ área de Suporte global, a média é de $42 \%$ das características atendidas pelos ambientes avaliados. Os melhores ambientes, jMetal, oMetah e FOM, obtiveram 80\% e o ProOF conseguiu 100\%. O ProOF é capaz de definir os seus critérios de parada (Crit) como componentes reutilizáveis pelos métodos, ou seja, seus critérios de parada não são fixos ou vinculados, assim na implementação dos métodos não é preciso se preocupar com estes detalhes. Na seção 1.3, foi descrito que o ProOF já possui implementado quatro critérios de parada e nas seções 4.3, 4.6, 4.8 e 5.2 foi explicado como reutilizar estes para os métodos implementados. Na seção 4.11, foi ilustrado como montar e executar um conjunto de tarefas em batch. O ambiente possui suporte a análise estatística (Est) com a técnica Mann-Whitney U Tester [71], para comparar o desempenho dos métodos, o programa para análise estatística é encontrado junto com o ProOF na sua página web de divulgação [63], onde está disponível também tutorial de uso. A seção 4.11 apresentou a GUI fornecida pelo ProOF e sua 
usabilidade. A interoperabilidade (Inter) do ProOF, está no uso conjunto com o solver CPLEX [17] e por disponibilizar seus resultados finais como um arquivo .csv que é um formato padrão para ser aberto em qualquer software de planilha eletrônica.

Para a área de Projeto, licenças e implementação, a média foi de $45 \%$ e os melhores foram jMetal e Open Beagle com 75\%. O ProOF alcançou $100 \%$ pois suporta a implementação em mais de uma linguagem de programação (Ling: C++ e Java), seu código funciona em sistemas operacionais (Sist) Linux e Windows, sendo uma iniciativa de código aberto/livre (Lic) e seu projeto foi construído considerando práticas de engenharia de software (Eng). No total, o ProOF é o ambiente com maior número de classes, sendo sua atual versão composta por 601 classes considerando os seus quatro módulos. O ambiente que mais se aproximou do ProOF foi o ParadisEO com 579 classes.

Na última área ilustrada na Figura 67, está a avaliação da Maturidade e popularidade dos ambientes, onde a média é de $66 \%$ e o ProOF com $100 \%$ se iguala aos quatro melhores ambientes neste critério: ParadisEO, jMetal e Open Beagle. O ProOF já foi aplicado em problemas de aplicação real (Rel) conforme apresentado no Capítulo 5, possui documentação, tutorial e página web para divulgação. Como indicado também no Capítulo 5, o ProOF foi utilizado como ferramenta de desenvolvimento em cinco publicações recentes (Publ.).

Na Figura 68 é apresentada a média geral (Pontuação) para todas as áreas discriminadas em cada ambiente. Os ambientes foram organizados em ordem crescente de pontuação onde os ambientes com maior pontuação são os que abrangem maior escopo para implementar métodos e problemas variados, considerando também as demais áreas de interesse definidas em [59]. O ProOF atingiu 96\% indicando que consegue suprir quase todas as características consideradas. Em seguida temos, com 64\% e 61\%, os ambientes jMetal e ParadisEO, respectivamente, que são ambientes com maior maturidade, estão em uso na atualidade e sendo bem divulgados. Os demais ambientes se possuem páginas web são mais rudimentares e quase sempre desatualizadas, não divulgam ou não constam publicações com o uso do ambiente. Por fim, estão os ambientes que trabalham com métodos ou problemas muito específicos, falhando em mais da metade das características levantadas.

O ambiente proposto neste trabalho se diferencia dos demais também ao permitir ao usuário inserir códigos em mais que uma linguagem de programação. Conforme descrito na seção 2.4, o ProOF já oferece suporte às linguagens $\mathrm{C}++$ e Java e o usuário ainda pode inserir códigos em uma nova linguagem. Para isso, deve implementar um novo módulo Abstract nesta linguagem para se comunicar com o módulo Client, conforme indicado na seção 3.3. Há uma diferença em relação ao jMetal que também suporta códigos em C++ e Java, uma vez que 
o jMetal trata os códigos em cada linguagem como projetos independentes. No ProOF, há um único projeto onde os módulos Client, Server e Slave são sempre os mesmos e não precisam sofrer modificações para aceitar uma nova linguagem.

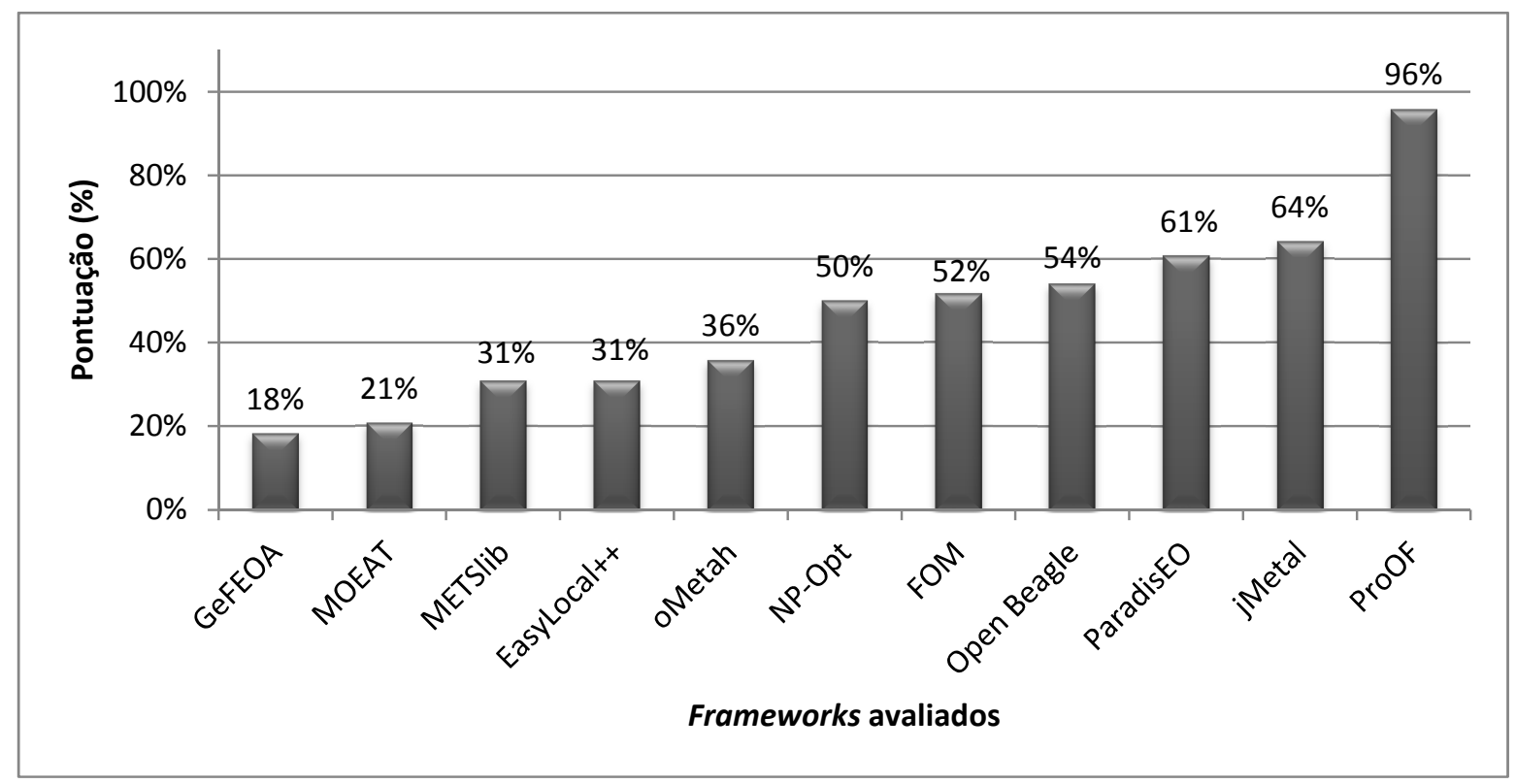

Figura 68: Pontuação/média geral de integralização das áreas para cada framework.

Uma característica pouco explorada em outros trabalhos, considerada nesta proposta, é guiar os usuários na implementação de métodos e na resolução de problemas através de alto reuso de códigos e bibliotecas. Na seção 4.4 foi explicado como o uso dos padrões de projeto Factory Method e Singleton foram utilizados para construir a estruturas chamadas FMS que viabilizam tal reaproveitamento de código. Esta estrutura também é responsável por definir o ProOF como um ambiente extensível e flexível, auxiliando para que nele seja mantida uma arquitetura abstrata o suficiente para permitir a implementação de vários métodos (heurísticos, metaheurísticos e exatos) e problemas (mono e multi-objetivo com domínios contínuos, discretos e variados).

Por fim, o ProOF auxilia os usuários ao definir uma Graphical User Interface (GUI) automática para parametrização dos códigos inseridos. A interface é gerada da mesma forma, independente da linguagem de programação que o usuário utilize, não exigindo que o usuário projete códigos para que seu método tenha uma interface gráfica.

\subsection{Testes de Desempenho}

Ao utilizar o ProOF, considerações a respeito do seu desempenho precisam ser feitas. Tal como foi projetado, este ambiente define a montagem de tarefas a partir do módulo Client e nesta etapa o código do usuário não está em execução, assim o custo computacional para 
manter uma interface gráfica não entra na contagem de tempo dos métodos, pois é uma etapa prévia e que envolve uma espera para que o usuário defina as configurações que deseja executar. No momento em que uma tarefa é executada, um processo é criado e apenas o módulo Abstract é executado junto com o código do usuário (Project). Sendo assim, o desempenho final do ProOF dependerá apenas da eficiência na implementação do módulo Abstract e do código do usuário.

O módulo Abstract foi implementado visando fornecer um nível de abstração suficiente para incorporar métodos e problemas variados no ambiente, e fornecendo o máximo de funcionalidades gerais como critérios de parada e coleta de resultados automática. Porém o desempenho pode se tornar um problema quando há muitas abstrações em um código orientado a objetos. Isto ocorre por causa de um processo chamado dynamic dispatch que define em tempo de execução qual será a função membro chamada por um objeto polimórfico. Em linguagens como C++ e Java, este processo é implementado com o uso de uma tabela virtual, onde a tabela virtual é consultada antes de cada chamada a funções membro de um objeto, causando uma perda de desempenho [72]. Além de possuir muitos níveis de abstrações, o módulo Abstract também possui mecanismos internos implementados para o funcionamento do ProOF, fornecendo uma coleta automática de resultados, definindo as impressões na tela, permitindo o reaproveitamento dos critérios de parada que fazem as atualizações da barra de progresso. Tudo isto pode comprometer o desempenho.

Para fazer a avaliação do desempenho do ProOF, foi implementado todo o MPGA descrito na seção 5.2 diretamente na linguagem Java e sem o uso do ProOF. A implementação foi diretamente utilizada para resolver o problema de otimização da função multi-modal ACK descrita na seção 4.5. A configuração do MPGA foi a mesma utilizada em [58], o critério de parada adotado foi o tempo de execução e a avaliação do desempenho será pelo número de funções avaliadas dentro do mesmo tempo. Logo os dois códigos vão executar pelo mesmo tempo, porém o que conseguir maior número de funções avaliadas será considerado o melhor. O código diretamente em Java foi implementado visando o máximo da eficiência e utiliza o mínimo de orientação a objetos possível, visando reduzir perda de desempenho, e também não utiliza o ProOF e nenhum de seus mecanismos internos de gerenciamento.

Assim duas medições serão feitas, a primeira vai medir a perda causada pelas abstrações do ProOF e a segunda mede a perda pelo gerenciamento interno do ProOF. Por causa do dynamic dispatch, muitas abstrações fazem com que as chamadas às funções membro de uma classe se tornem mais demoradas. Como o critério de parada adotado é o tempo de execução, uma forma de medir este efeito é escalar o número de variáveis utilizadas no cálculo da 
função $\operatorname{ACK}(1,2,4,8,16,32,64,128$ e 256 variáveis). Assim, com mais variáveis, o crossover e o cálculo da função objetivo se tornará mais lento, o que vai atrasar a evolução do MPGA que executará um número menor de iterações dentro do tempo dado. Isso vai levar a um número menor de chamadas a funções membro, reduzindo as perdas de desempenho por este efeito.

Para medir o efeito do gerenciamento interno do ProOF, será preciso um artifício menos óbvio. É natural acreditar que se for dado 1 segundo a um método e este conseguir fazer 1000 avaliações, então se dermos 60 segundos este conseguirá 60000, uma vez que o computador utlilzado é o mesmo e o algoritmo implementado também é o mesmo. Porém, dentro do ProOF será visto que isto não é verdade. Assim também será escalado o tempo de execução para medir a eficiência do ProOF à medida que o tempo aumenta em segundos $(1,2,4,8,16$, $32,64)$. A equação (3) ilustra como será calculada a eficiência de codificar no ProOF em relação a uma codificação feita diretamente na linguagem de programação para as duas medições.

$$
\text { Eficiência }(\%)=\frac{n^{\text {o }} \text { de funçõs avaliadas com o código no ProOF }}{n^{0} \text { de funções avaliadas com o código puro }} \cdot 100
$$

Para cada teste foram realizadas 20 execuções, onde foi utilizado o melhor número de avaliação em cada código para comparação. Pois havia maior estabilidade neste valor que no valor médio devido a interferências no escalonamento do sistema operacional. Foi utilizado um computador com processador i7 de 2.2GHz, 8GB de RAM e sistema operacional Windows 7.

Na Figura 69, é ilustrada a eficiência alcançada pelo ProOF considerando valores crescentes no tamanho do problema e no tempo de execução. Pode-se perceber que, quando o problema possui poucas variáveis e o tempo de execução do método é menor, a eficiência do ProOF fica bastante comprometida. Porém, quando o problema cresce em tamanho junto com o tempo dado para sua execução, implementar no ProOF ou diretamente na linguagem se torna equivalente em termos de desempenho do código. Algumas vezes, a eficiência se apresentou maior que $100 \%$, atribui-se este efeito a pequenas variações nas medições. Como esperado, o ProOF é uma ferramenta de auxílio na implementação, não sendo capaz de tornar um código mais eficiente, uma vez que não foi projetado com este propósito. Também é importante notar que no ProOF o módulo Client com sua interface gráfica não influenciou no desempenho, conforme foi afirmado no início desta seção, ao prever que o módulo Abstract com o código do usuário (Project) seria o único a interferir no desempenho. A prova disto é que durante o experimento, o módulo Client precisava estar funcionando para gerenciar a 
execução das tarefas em modo LocalHost. Por exemplo, todas as impressões de resultados exibidos em tempo real eram gerenciadas pelo Client. Apesar disso, o ambiente conseguiu atingir a eficiência de $100 \%$. Caso o Client gerasse uma perda de desempenho relevante, o ambiente teria um limite superior de eficiência menor que 100\% em relação ao código puro, onde não havia interface gráfica.

\begin{tabular}{|l|l|l|l|l|}
\hline \multicolumn{5}{|c|}{ Legenda } \\
\hline$<70 \%$ & $<80 \%$ & $<90 \%$ & $<95 \%$ & $\geq 95 \%$ \\
\hline
\end{tabular}

\begin{tabular}{|c|c|c|c|c|c|c|c|c|c|c|}
\hline & \multicolumn{9}{|c|}{ Tamanho do problema/Número de variáveis $(n)$} \\
\hline & & 1 & 2 & 4 & 8 & 16 & 32 & 64 & 128 & 256 \\
\hline \multirow{7}{*}{ 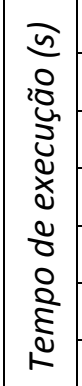 } & 1 & $66 \%$ & $70 \%$ & $74 \%$ & $77 \%$ & $77 \%$ & $78 \%$ & $82 \%$ & $83 \%$ & $85 \%$ \\
\hline & 2 & $72 \%$ & $78 \%$ & $84 \%$ & $92 \%$ & $91 \%$ & $91 \%$ & $93 \%$ & $94 \%$ & $96 \%$ \\
\hline & 4 & $79 \%$ & $84 \%$ & $89 \%$ & $95 \%$ & $95 \%$ & $95 \%$ & $96 \%$ & $97 \%$ & $97 \%$ \\
\hline & 8 & $83 \%$ & $88 \%$ & $93 \%$ & $99 \%$ & $99 \%$ & $98 \%$ & $96 \%$ & $96 \%$ & $99 \%$ \\
\hline & 16 & $81 \%$ & $88 \%$ & $93 \%$ & $98 \%$ & $99 \%$ & $99 \%$ & $100 \%$ & $100 \%$ & $101 \%$ \\
\hline & 32 & $84 \%$ & $89 \%$ & $94 \%$ & $99 \%$ & $99 \%$ & $100 \%$ & $101 \%$ & $99 \%$ & $101 \%$ \\
\hline & 64 & $84 \%$ & $89 \%$ & $94 \%$ & $99 \%$ & $100 \%$ & $101 \%$ & $101 \%$ & $100 \%$ & $100 \%$ \\
\hline
\end{tabular}

Figura 69: Eficiência calculada escalando o tempo e o tamanho do problema.

Nota-se na Figura 69 que quando o problema contém 8 ou mais variáveis e o tempo de execução é maior ou igual a 4 segundos o ProOF possui um desempenho de $95 \%$ ou superior. Assim justifica-se o uso do ProOF para a grande maioria dos problema de aplicação real pois normalmente possui um espaço de busca com muitas variáveis. Também deve ser considerado que o ProOF é melhor aplicado em problemas que levam mais tempo computacional para serem resolvidos de forma satisfatória.

Outro aspecto que deve ser levado em consideração no desempenho, é o fato do ProOF permitir que as tarefas sejam executadas em paralelo. Sendo assim, o mesmo experimento anterior com a função ACK foi refeito dentro do ProOF, definindo a execução utilizando 2, 3, 4, 5, 6, 7 e 8 threads. O valor foi limitado em 8 threads pois o processador i7 utilizado no experimento possui 4 núcleos de processamento com tecnologia de Hyper-Threading que permite simular duas unidades de processamento em um único núcleo. As comparações agora são realizadas apenas dentro do ProOF e o cálculo de eficiência segue a formula abaixo.

$$
\text { Eficiência }(\%)=\frac{n^{\circ} \text { de funçõs avaliadas com } \boldsymbol{N} \text { threads no ProOF }}{N * n^{\mathbf{o}} \text { de funçõs avaliadas com } \mathbf{1} \text { thread no ProOF }} \cdot 100
$$

Nestes novos experimentos, percebeu-se que tanto a escalabilidade do tempo de execução quanto do tamanho do problema definiam uma eficiência constante comparado com o ProOF com apenas uma thread. Assim, perdas de eficiência ocorriam apenas quando eram ativadas mais threads no ProOF para executar tarefas juntas em modo paralelo. A Figura 70 apresenta 
a queda na eficiência do ProOF ao executar mais de uma tarefa ao mesmo tempo. Percebe-se que com até 4 tarefas sendo executadas em paralelo no processador i7, a perda de desempenho é reduzida e próxima de 5\% (eficiência de 94.9\%). Porém, com valores acima disto, as perdas são consideráveis. Assim é recomendável utilizar o paralelismo do ProOF com threads até certos limites. Uma vantagem é obtida quando é realizado um grande conjunto de testes, pois se 4 threads fossem ativadas, o processo todo de realização de testes computacionais ficaria 4 vezes mais rápido e o desempenho do método ficaria prejudicado em apenas $5 \%$.

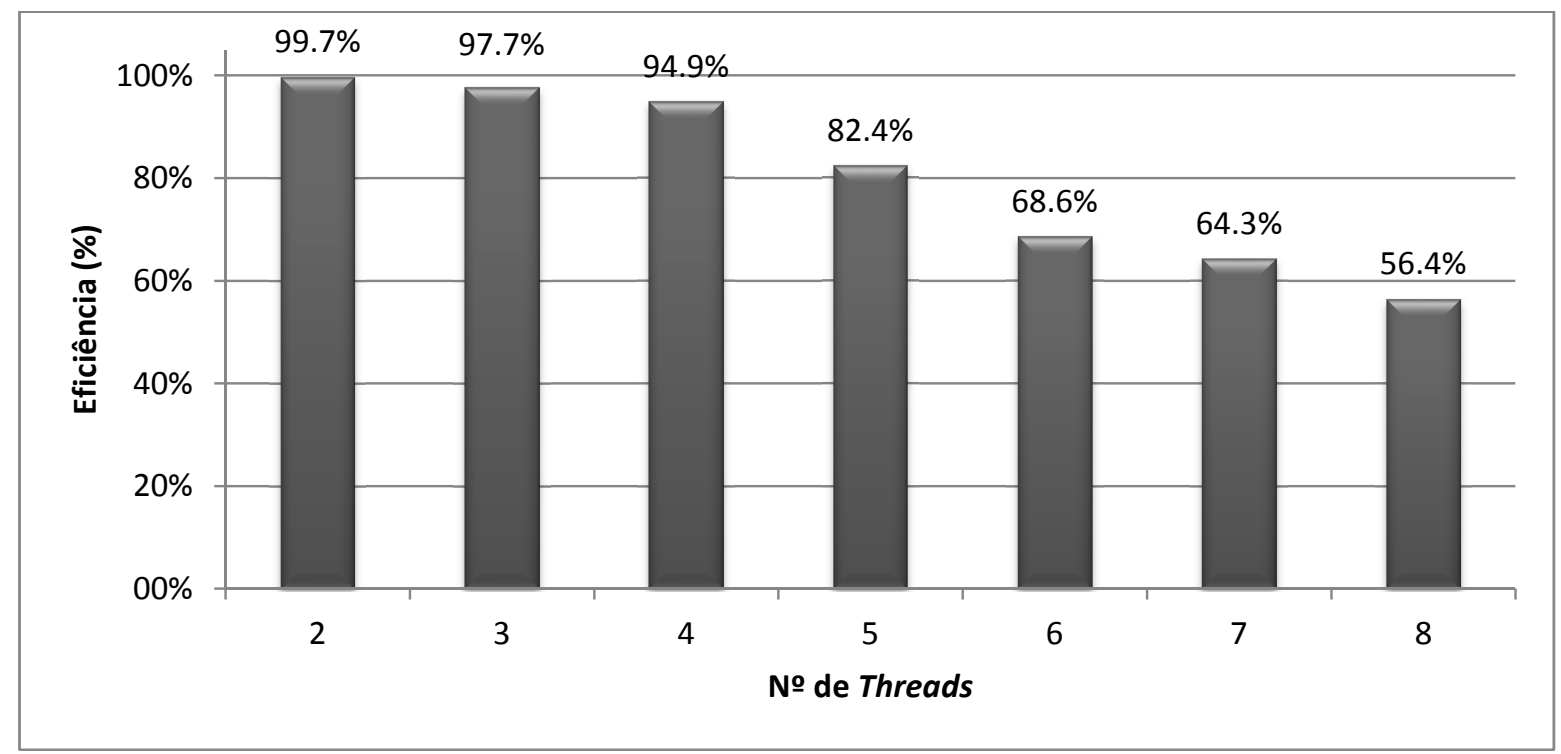

Figura 70: Eficiência quando é utilizado paralelismo.

\subsection{Conclusão}

Neste capítulo, foi realizada uma avaliação do ProOF apresentado as vantagens de seu uso e quais são as perdas de desempenho ao projetar códigos dentro do ambiente. Primeiro, foi realizada uma comparação do ProOF com outros frameworks de otimização, utilizando critérios estabelecidos na literatura, onde foi visto que o ProOF abrange um número maior de características sendo recomendado para projetar códigos variados e específicos. Na seção 6.2, alguns testes de desempenho foram realizados, destacando o que ocorre ao utilizar o ProOF em comparação com uma implementação otimizada sem o uso do ProOF. Também foi avaliado o desempenho do ambiente quando se deseja utilizar os recursos de paralelismo disponíveis. Os testes de desempenho indicaram que o ambiente aqui proposto tem seu foco em resolver problemas com maior número de variáveis e que demandem mais tempo de computação para sua resolução. O ProOF também apresenta eficiência satisfatória ao utilizar os recursos de paralelismo, diminuindo a espera pela realização dos testes considerando várias tarefas dentro de certos limites no uso de threads. 


\section{CAPÍTULO 7}

\section{Considerações Finais}

Nesta dissertação foi apresentado o ProOF, um framework para auxiliar profissionais da área de otimização na implementação de métodos e resolução de problemas. A ferramenta foi projetada para incorporar as principais características encontradas em outros frameworks. Inicialmente, o ambiente permite que o usuário desenvolva códigos em duas linguagens de programação: Java e C++. Através do uso de padrões de projeto, Factory Method e Singleton, definiu-se uma estrutura chamada FMS que guia o usuário na geração de códigos reutilizáveis, mostrando-se um ambiente extensível, com alta flexibilidade e fácil de manter, capaz de guiar o desenvolvimento de códigos com alta coesão e baixo acoplamento. $\mathrm{O}$ trabalho descreveu os principais conceitos e passos que levam à implementação de método e problemas. Uma vez seguidos esses passos, o ProOF consegue gerar uma Graphical User Interface (GUI) automática para parametrização dos códigos inseridos pelo usuário. Foi discutido também o funcionamento do ProOF como um sistema distribuído, permitindo o gerenciamento das diversas execuções em vários computadores. No total, cinco trabalhos recentemente publicados utilizaram o ProOF no seu desenvolvimento, assim atestando a robustez da ferramenta, onde detalhes de dois destes trabalhos foram apresentados neste texto.

Como trabalho futuro, novos módulos Abstract podem de ser desenvolvidos para dar suporte a outras linguagens de programação. Tal como foi projetado, o ProOF deverá aceitar a princípio qualquer tipo ou paradigma de linguagem de programação. Seja a linguagem interpretada ou compilada, seja orientada a objetos ou não. Entretanto, alguns tipos de linguagens podem limitar certas características da ferramenta. Por exemplo, em linguagens estruturadas como $\mathrm{C}$ será complicado definir uma estrutura FMS tal como descrito neste texto, visto que esta estrutura foi desenvolvida visando uma orientação a objetos. Assim, o reaproveitamento de código em $\mathrm{C}$ teria que ser realizado por outro paradigma. Para linguagens interpretadas, o que já está definido no ProOF continuará sendo o mesmo, onde a etapa de compilação de código será apenas ignorada. 
No ProOF não foi contemplada a característica de projetar hyper-heurísticas que seriam capazes de encontrar os parâmetros ideais para os códigos desenvolvidos no ambiente. Incorporar este tipo de estratégia no ambiente seria perfeitamente possível, através de algumas adaptações internas. Atualmente o usuário deve definir empiricamente os valores para os parâmetros serão utilizados em seus experimentos. De forma semelhante, técnicas baseadas em aprendizado de máquina podem ser estudadas para prever os melhores parâmetros de um método ao resolver um problema.

Uma política simples de usabilidade para seu sistema distribuído foi descrita neste projeto, onde as tarefas são escalonadas como uma fila. Melhorias nesta política de escalonamento foram deixadas como trabalho futuro. Em um sistema que compartilha recursos computacionais com vários usuários, seria interessante que houvesse formas diversas de permissões que um usuário pode ter e que prioridades fossem definidas entre os usuários. Isso permitiria fazer com que alguns usuários (administradores) pudessem controlar como os seus recursos seriam utilizados e por quem. Esta proposta não tinha o foco em aprofundar o desenvolvimento nesta direção, buscando apenas simplificar e agilizar a realização dos testes computacionais, onde o ProOF faria toda a distribuição dos testes computacionais e recuperaria os resultados automaticamente.

A última versão do ambiente descrito nesta dissertação encontra-se disponível no site do ProOF http://lcrserver.icmc.usp.br/projects/release/wiki. Os detalhes dos requisitos de sistema para instalação e também tutoriais específicos para programar no ProOF nas linguagem $\mathrm{C}++\mathrm{e}$ Java estão disponíveis no site. 


\section{Referências Bibliográficas}

[1]. M. A. Sahman, M. Cunkas, S. Inal, F. Inal, B. Coskun, U. Taskiran., 2009, Cost optimization of feed mixes by genetic algorithms, Advances in Engineering Software, pp. 965-974.

[2]. T. Sag, M. Cunkas, 2009, A tool for multiobjective evolutionary algorithms, Advances in Engineering Software, pp. 902-912.

[3]. E. Gamma, R. Helm, R. Johnson, J. Vlissides, 1995, Design Patterns: Elements of Reusable Object-Oriented Software, Addison-Wesley.

[4]. M. E. Fayad, E. C. Schmidt, R. E. Johnson, 1999, Building Application Frameworks: Object-Oriented Foundations of Framework Design, Wiley.

[5]. E. Shakshuki, O. Prabhu, I. Tomek, 2006, FCVW agent framework, Information and Software Technology, pp. 385-392.

[6]. L. D. Gaspero, A. Schaerf, 2002, Writing local search algorithms using EasyLocal++, In: V. Stefan, D. L. Woodruff, Optimization Software Class Libraries.

[7]. L. D. Gaspero, A. Schaerf, 2003, EasyLocal++: An object-oriented framework for flexible design of local search algorithms, Software - Practice and Experience, pp. 733765.

[8]. A. Liefooghe, L. Jourdan, E.-G. Talbi, 2011, A software framework based on a conceptual unified model for evolutionary multiobjective optimization: ParadisEOMOEO, European Journal of Operational Research, pp. 104-112.

[9]. A. S. Mendes, P. M. França, P. A. Moscato, 2001, NP-Opt: an optimization framework for NP problems, International Conference of the Production and Operations Management Society, pp. 82-89.

[10]. I. H. Osman, G. Laporte, 1996, Metaheuristics: A bibliography, Operations Research, pp. 513-623.

[11]. T. Nguyen, S. Yang, J. Branke, 2012, Evolutionary dynamic optimization: A survey of the state of the art, Swarm and Evolutionary Computation, pp. 1-24.

[12]. I. Boussaïd, J. Lepagnot, P. Siarry, 2013, A survey on optimization metaheuristics, Information Sciences, pp. 82-117.

[13]. Y. Jin, 2011, Surrogate-assisted evolutionary computation: Recent advances and future challenges, Swarm and Evolutionary Computation, pp. 61-70.

[14]. K. de Jong, 2006, Evolutionary Computation. A Unified Approach, MIT Press.

[15]. C. Blum, J. Puchinger, G. Raidl, A. Roli, 2011, Hybrid metaheuristics in combinatorial optimization: A survey, Applied Soft Computing, pp. 4135-4151.

[16]. M. Ball, 2011, Heuristics based on mathematical programming, Surveys in Operations Research and Management Science, pp. 21-38. 
[17]. CPLEX User's Manual, 2011, IBM ILOG CPLEX Optimization Studio, Copyright IBM Corporation.

[18]. A. S. Mendes, 2003, O Framework NP-Opt e suas Aplicações a Problemas de Otimização, Tese de doutorado Universidade Estadual de Campinas, Faculdade de Engenharia Elétrica e de Computação.

[19]. C. F. M. Toledo, M. S. Arantes, R. R. R. Oliveira, L. Oliveira, P. M. França, 2010, A Genetic Algorithm Approach to Solve the General Lot Sizing and Scheduling Problem, InfoComp, pp. 01-08.

[20]. C. F. M. Toledo, R. R. R. Oliveira, P. M. França, 2011, A hybrid heuristic approach to solve the multi level capacitated lot sizing problem, IEEE Congress on Evolutionary Computation, pp. 1194-1201.

[21]. C. F. M. Toledo, M. S. Arantes, P. M. França, 2011, Tabu Search to Solve the Synchronized and Integrated Two-Level Lot Sizing and Scheduling Problem, Genetic and Evolutionary Conference.

[22]. C. F. M. Toledo, M. S. Arantes, P. M. França, R. Morabito, 2011, A Memetic Framework for Solving the Lot Sizing and Scheduling Problem in Soft Drink Plants. In: R. Chiong, T. Weise, \& Z. Michalewicz (Eds.), Variants of Evolutionary Algorithms for Real-World Applications.

[23]. C. F. M. Toledo, M. H. Santos, R. R. R. Oliveira, M. S. Arantes, P. M. França, 2010, Algoritmos baseados em seleção clonal aplicados ao problema geral de dimensionamento de lotes e programação da produção, Simpósio Brasileiro de Pesquisa Operacional.

[24]. C. F. M. Toledo, T. Fialho, M. S. Arantes, R. R. R. Oliveira, P. M. França, 2010, Otimização por Enxame de Partículas Aplicada ao Problema Geral de Dimensionamento de Lotes e Programação da Produção, Encontro Nacional de Engenharia de Produção.

[25]. C. F. M. Toledo, R. R. R. Oliveira, M. S. Arantes, M. R. Pereira, P. M. França, 2011. Uma heurística determinística para a resolução do problema geral de dimensionamento de lotes e programação da produção, Simpósio Brasileiro de Pesquisa Operacional.

[26]. C. F. M. Toledo, J. M. Lima, M. S. Arantes, 2012, A Multi-Population Genetic Algorithm Approach for PID Controller Auto-Tuning, Emerging Technologies \& Factory Automation.

[27]. C. F. M. Toledo, M. S. Arantes, R. R. R. Oliveira, A. C. B. Delbem, 2013, A Hybrid Compact Genetic Algorithm Applied to the Multi-Level Capacitated Lot Sizing Problem, Symposium on Applied soft Computing.

[28]. C. F. M. Toledo, M. Y. Hossomi, M. S. Arantes, P. M. França, 2013, Genetic algorithm, MIP and improvement heuristic applied to the MLCLP with backlogging, IEEE Congress on Evolutionary Computation.

[29]. C. F. M. Toledo, M. S. Arantes, R. R. R. Oliveira, A. C. B. Delbem, 2013, A hybrid cGA applied to the MLCLSP with overtime, Applied Computing Review, pp. 7-16.

[30]. C. F. M. Toledo, M. S. Arantes, R. R. R. Oliveira, B. Almada-Lobo, 2013, Glass container production scheduling through hybrid multi-population based evolutionary algorithm, Applied Soft Computing, pp. 1352-1364.

[31]. D. Goldberg, 1989, Genetic Algorithms in Search, Optimization and Machine Learning. 
[32]. S. Kirkpatrick, C. D. Gelatt, M. P. Vecchi, 1983, Optimization by Simulated Annealing, Science Magazine, pp. 3097-3119.

[33]. K. Deb, A. Pratap, S. Agarwal, T. Meyarivan, 2002, A Fast and Elitist Multiobjective Genetic Algorithm : NSGA-II, IEEE Transactions on Evolutionary Computation.

[34]. D. Bertsimas, J. Tsitsiklis, 1997, Introduction to Linear Optimization.

[35]. A. Levitin, 2011, Introduction to the Design and Analysis of Algorithms, AddisonWesley.

[36]. D. L. Applegate, R. E. Bixby, V. Chvatal, W. J. Cook, 2006, The Traveling Salesman Problem: A Computational Study, Princeton University Press.

[37]. D. H. Ackley, 1987, A connectionist machine for genetic hillclimbing, Boston: Kluwer Academic Publishers.

[38]. M. Ali, C. Khompatraporn, Z. Zabinsky, 2005, A Numerical Evaluation of Several Stochastic Algorithms on Selected Continuous Global Optimization Test Problems, Jornal of Global Optimization, pp. 635-672.

[39]. J. J. Durillo, A. J. Nebro, 2011, jMetal: A Java framework for multi-objective optimization, Advances in Engineering Software, 760-771.

[40]. jMetal, http://jmetal.sourceforge.net/, 02/12/2013.

[41]. E. López-Camacho, M. J. Godoy, A. J. Nebro, J. R. Aldana-Montes, 2013, jMetalCpp: optimizing molecular docking problems with a C++ metaheuristic framework, Bioinformatics.

[42]. ParadisEO, http://paradiseo.gforge.inria.fr/, 02/12/2013.

[43]. E.-G. Talbi, S. Cahon, N. Melab, 2007, Designing cellular networks using a parallel hybrid metaheuristic on the computational grid, Computer Communications, pp. 698713.

[44]. N. Melab, S. Cahon, E.-G. Talbi, 2006, Grid computing for parallel bioinspired algorithms, Journal of Parallel and Distributed Computing, pp. 1052-1061.

[45]. S. Cahon, N. Melab, E.-G. Talbi, 2004, Building with ParadisEO reusable parallel and distributed evolutionary algorithms, Parallel Computing, pp. 677-697.

[46]. J. Humeau, A. Liefooghe, E.-G. Talbi, S. Verel, 2013, ParadisEO-MO: from fitness landscape analysis to efficient local search algorithms, Journal of Heuristics, pp. 881915.

[47]. oMetah, http://developer.berlios.de/projects/ometah/, 02/12/2013.

[48]. Open Beagle, https://code.google.com/p/beagle/, 02/12/2013.

[49]. C. Gagné, M. Parizeau, 2006, Genericity in Evolutionary Computation Software Tools: Principles and Case Study, International Journal on Artificial Intelligence Tools, pp. 173-194.

[50]. EasyLocal++, Doc., http://www.diegm.uniud.it/satt/projects/EasyLocal/doc/index.html, 02/12/2013.

[51]. EasyLocal++, Rep., https://bitbucket.org/satt/easylocal2/overview, 02/12/2013.

[52]. METSlib, https://projects.coin-or.org/metslib, 02/12/2013.

[53]. FOM, http://www.isa.us.es/fom/modules/portalWFInterface/init.php, 13/01/2014. 
[54]. J. A. Parejo, J. Racero, F. Guerrero, T. Kwok, K. A. Smith, 2003, FOM: A Framework for Metaheuristic Optimization, Computational Science, pp. 886-895.

[55]. I. Zunino, N. Melab, E.-G. Talbi, 2007, A Grid-enabled Framework for Exact Optimization Algorithms, European Conference on Modelling and Simulation.

[56]. V. J. Garcia, A. S. Mendes, P. M. França, P. A. Moscato, 2001, Algoritmo Memético Paralelo Aplicado a Problemas de Sequenciamento em Máquina Simples, Simpósio Brasileiro de Pesquisa Operacional, pp. 971-981.

[57]. C. F. M. Toledo, J. E. Ferreira, P. M. Franca, 2008, Memetic Algorithm Approaches to Solve the Synchronized and Integrated Two-Level Lot Sizing and Scheduling Problem, Simpósio Brasileiro de Pesquisa Operacional.

[58]. C. F. M. Toledo, P. M. Franca, R. Morabito, A. Kimms, 2009, Multi-population genetic algorithm to solve the synchronized and integrated two-level lot sizing and scheduling problem, International Journal of Production Research, pp. 3097-3119.

[59]. J. Parejo, A. Ruiz-Cortés, S. Lozano, P. Fernandez, 2012, Metaheuristic optimization frameworks: a survey and benchmarking, Soft Computing, pp. 527-561.

[60]. S. W. Ambler, 2005, The Elements of UML 2.0 Style, Cambridge University Press.

[61]. J. F. Cui, H. S. Chae, 2011, Applying agglomerative hierarchical clustering algorithms to component identification for legacy systems, Information and Software Technology, pp. 601-614.

[62]. A. Alkhalid, M. Alshayeb, S. Mahmoud, 2010, Software refactoring at the function level using new Adaptive K-Nearest Neighbor algorithm, Advances in Engineering Software, pp. 1160-1178.

[63]. ProOF, http://lcrserver.icmc.usp.br/projects/release/wiki/Wiki, 7/12/2013.

[64]. G. Syswerda, 1991, Schedule optimiz ation using genetic, In: L. Davis, Handbook of Genetic Algorithms.

[65]. L. Davis, 1991, Handbook of Genetic Algorithms, Van Nostrand Reinhold.

[66]. I. Bohachevsky, M. Johnson, M. Stein, 1986, Generalized simulated annealing for function optimization, Technometrics, pp. 209-217.

[67]. H.-P. Schwefel, 1995, Evolution and Optimum Seeking, Wiley-Interscience.

[68]. B. Almada-Lobo, J. F. Oliveira, M. A. Carravilla, 2008, Production planning and scheduling in the glass container industry: A VNS approach, International Jornal of Production Economics, pp. 363-375.

[69]. B. Almada-Lobo, D. Klabjan, M. A. Carravilla, J. F. Oliveira, 2010, Multiple machine continuous setup lotsizing with sequence-dependent setups, Computational Optimization and Applications, pp. 529-552.

[70]. K. Åström, T. Hägglund, 2006, Advanced PID Control.

[71]. T. Weise, 2011, Illustration of Statistical Test Results for Experiment Evaluation, Germany: self-published.

[72]. P. Deitel, H. Deitel, 2010, Java - Como Programar, Prentice Hall. 